\title{
Thiopeptides Induce Proteasome-Independent Activation of Cellular Mitophagy
}

Kelly E. Bird ${ }^{1}$, Christian Xander ${ }^{2}$, Sebastian Murcia ${ }^{2}$, Alan A. Schmalstig², Xianxi Wang 3 , Michael Emanuele ${ }^{3}$, Miriam Braunstein ${ }^{2}$, Albert A. Bowers ${ }^{1,3,4}$

${ }^{1}$ Division of Chemical Biology and Medicinal Chemistry, Eshelman School of Pharmacy, University of North Carolina, Chapel Hill, NC 27599, USA

${ }^{2}$ Department of Microbiology and Immunology, University of North Carolina, Chapel Hill, NC 27599, USA

${ }^{3}$ Department of Chemistry, University of North Carolina, Chapel Hill, NC 27599, USA

${ }^{4}$ Lineberger Comprehensive Cancer Center, The University of North Carolina at Chapel Hill, Chapel Hill, NC 27599, USA 


\section{Table of Contents}

1. General Materials and Methods............................................................................................. 2

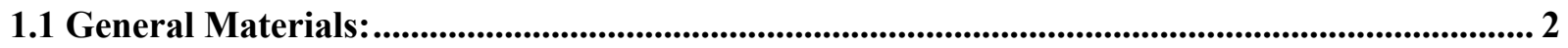

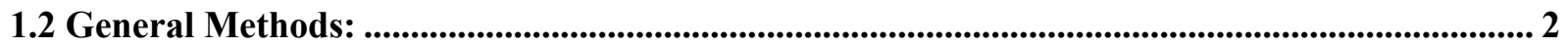

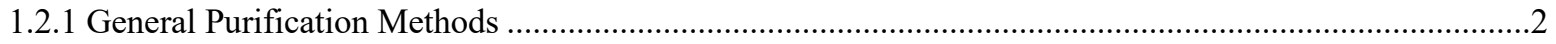

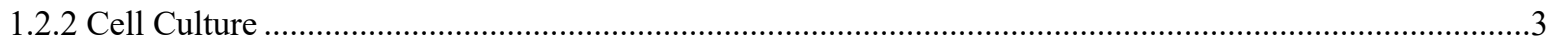

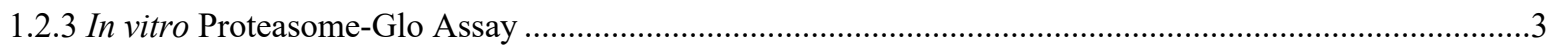

1.2.4 Ub-R-GFP Transiently Transfected Proteasome Sensor........................................................................

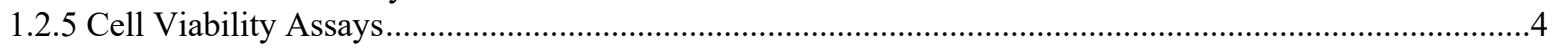

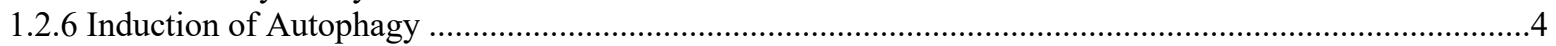

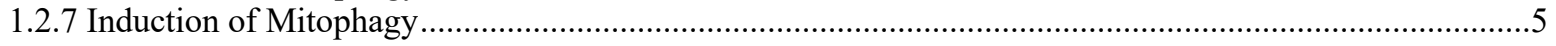

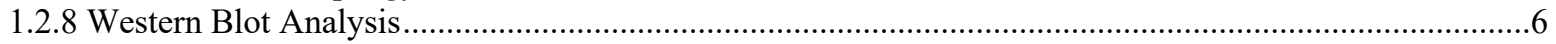

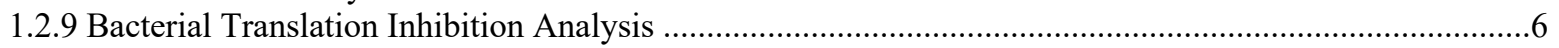

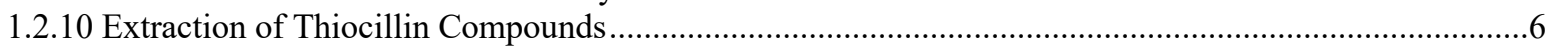

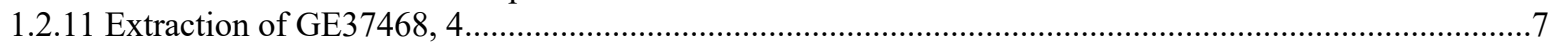

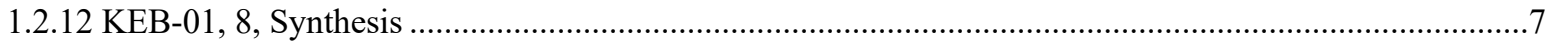

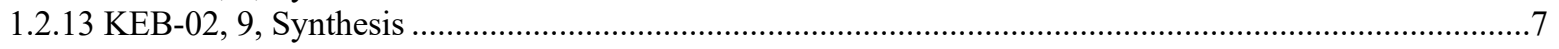

1.2.15 In vitro Mtb MICs - Resazurin Microtiter Assay ....................................................................................

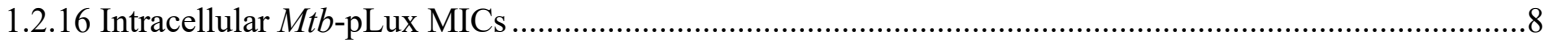

1.2.17 Visualization of Autophagy in Mtb-GFP-Infected Cells....................................................................

2. Supplemental Tables and Figures........................................................................................ 9

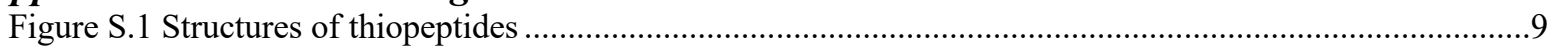

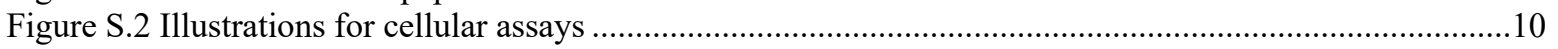

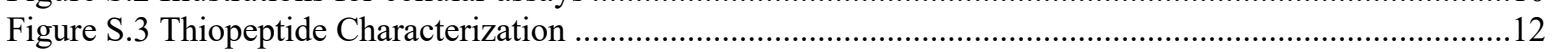

Figure S.4 Transient Transfection of Ub-R-GFP in RAW 264.7 cells .........................................................37

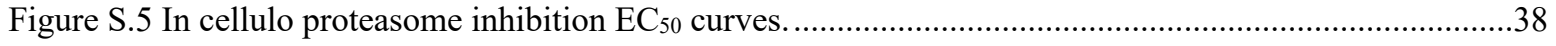

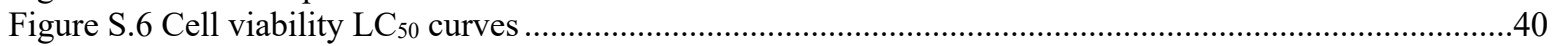

Figure S.7 In cellulo induction of autophagy representative photos.............................................................41

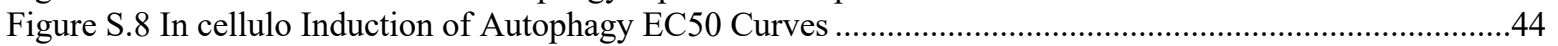

Figure S.9 Proteasome inhibition and autophagy induction proteomic marker validation ................................46

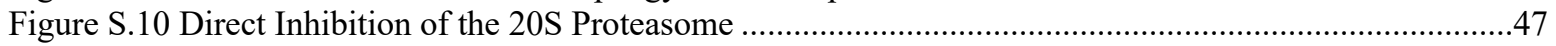

Figure S.11 Bacterial translation inhibition $\mathrm{IC}_{50}$ curves .............................................................................

Figure S.12 In vitro Mtb growth inhibition representative $\mathrm{IC}_{90}$ curves..........................................................52

Figure S.13 Intracellular Mtb growth inhibition .....................................................................................53

Figure S.14 Wortmannin autophagy inhibition and cytotoxicity ……............................................................54

Figure S.15 Assessment of the effects of wortmannin treatment on intracellular $\mathrm{Mtb}$......................................55

Figure S.16 Visualization of autophagy in $\mathrm{Mtb}$ infected cells ......................................................................56

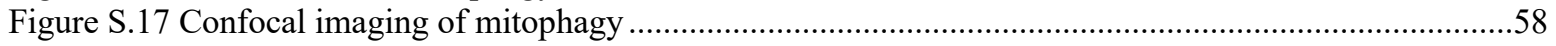

References ................................................................................................................................6. 61 


\section{General Materials and Methods}

\subsection{General Materials:}

Solvents, cell culture media, biochemicals, transfection reagents, and plates were purchased from Sigma Aldrich, Fisher Scientific, ACROS and Invitrogen. Thiostrepton was purchased from Sigma Aldrich. Nosiheptide was purchased from BOC Sciences. RAW 264.7 cells (ATCC TIB-71) were purchased from ATCC. RAW-DiFluo ${ }^{\mathrm{TM}} \mathrm{mLC} 3$ cells (rawdf-mlc3) and THP-1 DiFluo ${ }^{\mathrm{TM}} \mathrm{mLC}$ cells (thpdf-hlc3) were purchased from InvivoGen. Ub-R-GFP (\#11939) and pmRFP-LC3 (\#21075) plasmids were purchased from Addgene. JetPrime ${ }^{\circledR}$ reagents were purchased from Polyplus Transfection. For immunoblot experiments antibodies were purchased from Cell Signaling Technologies (CST) ${ }^{\circledR}$, Santa Cruz ${ }^{\circledR}$, and abcam ${ }^{\circledR}$ : EIF-2 $\alpha$ (CST-9722, 1:1000), phospho-EIF-2 $\alpha^{\text {Ser51 }}$ (CST-9721, 1:1000), FoxM1 (SC-376471, 1:1000), LC3B (CST-2775, 1:500), parkin (CST-4211, 1:1000), PINK1 (CST-6946, 1:1000), Ran (SC-271376, 1:1000), $\beta$ tubulin (ab6046, 1:1000), and ubiquitin (CST-3933, 1:1000). Assay kits used to monitor cell viability (CellTiter Glo ${ }^{\circledR} 2.0$ ), direct proteasome inhibition (Proteasome $\mathrm{Glo}^{\mathrm{TM}}$ ), and bacterial translation inhibition (E. coli S30 Extract System) were purchased from Promega. Mitophagy Detection Kit (MD01-10) was purchased from Dojindo Molecular Technologies.

\subsection{General Methods:}

1.2.1 General Purification Methods: LC/MS measurements were recorded using an Agilent 6520 Accurate-Mass Q-TOF high-resolution ESI-MS run in positive-ion mode. Gas temperature was set to $350^{\circ} \mathrm{C}$ and fragmentor voltage at $250 \mathrm{~V}$. Compounds were separated on either a $100 \times 2.10$ mm Kinetex ${ }^{\circledR} 2.6 \mu \mathrm{C} 8100 \AA$ column or a 50 x $2.1 \mathrm{~mm}$ Kinetex ${ }^{\circledR} 2.6 \mu \mathrm{C} 18100 \AA$ column, both purchased from Phenomenex. Two methods were used:

Method A:

\begin{tabular}{|l|l|}
\hline Time & \% Solvent B \\
\hline $0-2 \min$ & $2 \%$ \\
\hline $2-5 \min$ & $2-45 \%$ \\
\hline $5-22 \mathrm{~min}$ & $45-60 \%$ \\
\hline $22-23 \mathrm{~min}$ & $60-95 \%$ \\
\hline $23-24 \mathrm{~min}$ & $95 \%$ \\
\hline $24-25 \mathrm{~min}$ & $95-2 \%$ \\
\hline
\end{tabular}

Method B:

\begin{tabular}{|l|l|}
\hline Time & \% Solvent B \\
\hline $0-2 \mathrm{~min}$ & $2 \%$ \\
\hline $2-13 \mathrm{~min}$ & $2-98 \%$ \\
\hline $13-15 \mathrm{~min}$ & $98 \%$ \\
\hline
\end{tabular}

Preparatory HPLC was performed using a Shimadzu Prominence HPLC with a multi-channel wavelength detector at $220 \mathrm{~nm}, 254 \mathrm{~nm}$, and $350 \mathrm{~nm}$ with a S2 LUNA $10 \mu \mathrm{C} 18(2) 100 \AA$, AXIA (Phenomenex) semi-preparatory column with a $15 \mathrm{~mL} / \mathrm{min}$ flow rate. Purifications were carried 
out with a two-solvent system (solvent $\mathrm{A}=0.1 \%$ trifluoroacetic acid in water; solvent $\mathrm{B}=0.1 \%$ trifluoroacetic acid in acetonitrile). Analytical HPLC was performed with a dual channel wavelength detector at 254 and $350 \mathrm{~nm}$ on a Kinetex $10 \mu \mathrm{C} 18100 \AA \AA$, (Phenomenex) column with a $1.25 \mathrm{~mL} / \mathrm{min}$ flow rate.

Preparatory HPLC Method:

\begin{tabular}{|l|l|}
\hline Time & \% Solvent B \\
\hline $0-2 \min$ & $5 \%$ \\
\hline $2-4 \min$ & $5-40 \%$ \\
\hline $4-23 \min$ & $40-60 \%$ \\
\hline $23-25 \min$ & $60-100 \%$ \\
\hline $25-28 \min$ & $100 \%$ \\
\hline $28-30 \min$ & $100-5 \%$ \\
\hline $30-32 \min$ & $5 \%$ \\
\hline
\end{tabular}

Analytical Method:

\begin{tabular}{|l|l|}
\hline Time & \% Solvent B \\
\hline $0-2 \min$ & $5 \%$ \\
\hline $2-5 \min$ & $5-30 \%$ \\
\hline $5-16 \min$ & $30-50 \%$ \\
\hline $16-17 \min$ & $50-100 \%$ \\
\hline $17-18 \min$ & $100 \%$ \\
\hline $18-19 \min$ & $100-5 \%$ \\
\hline $19-20 \min$ & $5 \%$ \\
\hline
\end{tabular}

1.2.2 Cell Culture: RAW 264.7 (ATCC® TIB-71 ${ }^{\mathrm{TM}}$ ) and RAW 264.7 Ub-R-GFP cells were maintained in DMEM-high glucose $(4500 \mathrm{mg} / \mathrm{L})$ containing $10 \% \mathrm{FBS}$. RAW-Difluo ${ }^{\mathrm{TM}}$ mLC3 cells were maintained in DMEM-high glucose $(4500 \mathrm{mg} / \mathrm{L})$ containing 10\% FBS and zeocin (100 $\mu \mathrm{g} / \mathrm{mL}$ ). All cell lines tested negative for mycoplasma. Both RAW 264.7 cell lines were grown at $37^{\circ} \mathrm{C}$ and $5 \% \mathrm{CO}_{2}$ atmosphere in $75 \mathrm{~cm}^{2}$ cell culture flasks (CELLSTAR) and split twice per week at $80 \%$ confluence by rinsing with PBS and mechanical dissociation. THP-1 (ATCC TIB-202 ${ }^{\mathrm{TM}}$ ) were maintained in Gibco ${ }^{\mathrm{TM}}$ RPMI 1640 containing glutamine $(2 \mathrm{mM})$, HEPES $(25 \mathrm{mM})$ and 10\% FBS. THP-1-Difluo ${ }^{\mathrm{TM}}$ mLC3 cells were maintained in Gibco $^{\mathrm{TM}}$ RPMI 1640 containing Lglutamine $(2 \mathrm{mM})$, HEPES $(25 \mathrm{mM})$ and 10\% FBS and zeocin $(100 \mu \mathrm{g} / \mathrm{mL})$.

1.2.3 In vitro Proteasome-Glo Assay: Direct inhibition of the 20S proteasome (Human 20S Proteasome, Boston Biochem, E-360) was observed via the Proteasome-Glo ${ }^{\mathrm{TM}}$ assay. Proteasome activities were quantified via luminescence from the substrates Suc-LLVY-aminoluciferin (chymotrypsin-like), Z-LRR-aminoluciferin (trypsin-like) and Z-nLPnLD-aminoluciferin (caspase-like). Proteasome ( $1 \mu \mathrm{g} / \mathrm{mL}, 10 \mathrm{mM}$ HEPES pH 7.6) was added to a white 384 well plate (Corning, 3767). Serial dilutions of inhibitor were added to the solution and incubated at $37^{\circ} \mathrm{C}$ for $1 \mathrm{hr}$. After one hr, substrate was added to the solution for $15 \mathrm{~min}$. Luminescence was visualized on the Perkin Elmer Envision 2103 Multilabel Plate Reader. GraphPad Prism 8 was used for the 
analysis of all data. Curves were fit to a non-linear regression of $\log$ (inhibitor) vs. response (three parameters) where the equation to calculate the IC50 is, Y=Bottom + (Top-Bottom) $/(1+(\mathrm{X} / \mathrm{IC} 50)$.

1.2.4 Ub-R-GFP Transiently Transfected Proteasome Sensor: Transfection of DNA: RAW 264.7 cells were plated in $15 \mathrm{~mL}$ DMEM with $10 \%$ FBS in a $75 \mathrm{~mL}$ tissue culture flask and incubated overnight at $37^{\circ} \mathrm{C}$ in a $5 \% \mathrm{CO}_{2}$ incubator. Once cells reached $90 \%$ confluency, $4.8 \mu \mathrm{L}$ of Ub-R-GFP fused plasmid (1100 ng/ $\mu \mathrm{L}$ ) was diluted into $40 \mu \mathrm{L}$ DMEM with $10 \%$ FBS. To the diluted DNA solution was added $12.0 \mu \mathrm{L}$ of Lipofectamine $3000 \AA$. The solution was mixed gently and incubated for $1 \mathrm{hr}$ at room temperature. Following incubation, the DNA-Lipofectamine ${ }^{\circledR}$ complexes were added directly to the flask of RAW cells. RAW cells were seeded in 96-well plates (Corning 3904) at $1 \times 10^{4}$ cells per well and incubated at $37^{\circ} \mathrm{C}$ in a $5 \% \mathrm{CO}_{2}$ incubator for $24 \mathrm{hr}$. Following incubation, the cells were treated with compounds, in triplicate, for $16 \mathrm{hr}$ and fixed to assess the proteasome inhibition. Nuclei were stained with Hoechst 33342. Three FOV capturing nuclei and puncta were visualized using the high-throughput fluorescence microscope, INCell Analyzer 2200. Each well was imaged with three channels DAPI, GFP, and brightfield.

Data Processing and $E C_{50}$ Calculation: Data collected from the INCell Analyzer were processed using a CellProfiler pipeline to assess the dose-dependent inhibition of the proteasome. Three fields of view were collected per concentration. Each field of view contained approximately 80 cells for a total of 240 cells per compound concentration. The experiment was completed for a total of three biological replicates. All of the images were transferred to a developed CellProfiler pipeline. Initially, background illumination within the image was corrected. Next, the threshold of the image was set to normalize signal across all treatments. Cellular fluorescence was quantified and was binned to their respective cells using Hoechst 33342 stained nuclei. The average fluorescence was then calculated for each field of view. Fluorescence was normalized to the negative control, DMSO, and positive control, MG-132, for $0 \%$ and $100 \%$ inhibition respectively. The percent proteasome inhibition was plotted against the respective compound concentration to generate EC50s in GraphPad Prism 8.2 using non-linear regression that plots $\log$ (inhibitor) vs. response (three parameters).

1.2.5 Cell Viability Assays: CellTiter-Glo ${ }^{\circledR} 2.0$ was used to monitor cell viability according to published Promega protocols. Inhibitor concentration ranged from 0.01-100 $\mu \mathrm{M}$. All inhibitors were dissolved in DMSO with the final concentration of $1 \%$ DMSO in every well. Cells were plated at 2,000 cell/well in a 96 well plate (Corning 3788) with $100 \mu \mathrm{L}$ media $+/$ - inhibitors and grown for $48 \mathrm{hr}$ at $37^{\circ} \mathrm{C}$ in a $5 \% \mathrm{CO} 2$ incubator. Following incubation, $100 \mu \mathrm{L}$ of CellTiter-Glo ${ }^{\circledR}$ 2.0 was added to each well. The plate was mixed for 2 minutes on an orbital shaker to induce cell lysis and subsequently incubated at room temperature for 15 minutes. Luminescence was read on the Molecular Devices Spectra Max Gemini EM plate reader. All data is reported as the mean \pm standard deviation of triplicate assays. All data was fit to the standard $\mathrm{IC}_{50}$ equation and plotted using GraphPad Prism 8.2.

1.2.6 Induction of Autophagy: RAW-DiFluo ${ }^{\mathrm{TM}} \mathrm{mLC} 3$ cells possess a fluorescent dual reporter, GFP-RFP-LC3 fusion protein that enables the assessment of autophagic flux. RAW-DiFluo ${ }^{\mathrm{TM}}$ mLC3 cells were plated in a black, clear bottom 96 well plate (Corning 3904) at $1 \times 10^{4}$ cells per well and incubated for $24 \mathrm{hr}$. Cells were treated with compounds, in triplicate, for $16 \mathrm{hr}$ and fixed to assess the induced autophagic flux. Nuclei were stained with Hoechst 33342. Nuclei and puncta 
were then visualized using the InCell Analzyer high-throughput fluorescence microscope. Three fields of view were captured within each well with four channels DAPI, GFP, TexasRed, and brightfield.

Data Processing and $E_{50}$ Calculation: Data collected from the INCell Analyzer were processed using a CellProfiler pipeline to assess the dose-dependent induction of autophagic flux. Three fields of view were collected per concentration. Each field of view contained approximately 80 cells for a total of 240 cells per compound concentration. Additionally, the experiment was completed for a total of three biological replicates. All of the images were then transferred to a CellProfiler pipeline. Initially, background illumination was eliminated. Next, the threshold of the image was set to normalize signal across all treatments. Puncta were identified based on pixel size and were binned to their respective cells using Hoechst 33342 stained nuclei. Once puncta per cell was generated from a CellProfiler pipeline, the data was normalized to the top concentration of rapamycin to calculate percent induction of autophagy. The percent induction of autophagy was plotted against the respective compound concentration to generate EC50s in GraphPad Prism 8.0 using non-linear regression that plots $\log$ (agonist) vs. response (three parameters).

Microscope Settings: Confocal imaging was performed on an inverted Olympus FV1000 confocal microscope with an IX81 base. A 60x oil immersion Plan S-Apo NA 1.35 objective lens was used for all imaging protocols. Twelve fields of view were captured using the FluoView acquisition software.

1.2.7 Induction of Mitophagy: Mitophagy was observed with the use of Mitophagy Detection Kit as previously reported (Item \# MD01, Dojindo Molecular Technologies, Inc.). ${ }^{1}$ RAW 264.7 cells were seeded on a 24 well (MatTek P24G-1.5-10-F) and cultured at $37^{\circ} \mathrm{C}$ overnight in a $5 \%-\mathrm{CO}_{2}$ incubator. Once at 70\% confluence, the cells were washed with HEPES buffer twice and then incubated with $500 \mu \mathrm{L}$ of $100 \mathrm{nmol} / 1$ Mtphagy Dye working solution at $37^{\circ} \mathrm{C}$ in a $5 \% \mathrm{CO}_{2}$ incubator. The cells were then washed with HEPES buffer twice, and the cells were treated with culture medium containing $10 \mu \mathrm{M}$ thiopeptide. After $16 \mathrm{hr}$, the media was aspirated and cells were washed with HEPES buffer twice. Once the media was removed $250 \mu \mathrm{L}$ of $1 \mu \mathrm{mol} / \mathrm{L}$ Lyso Dye working solution were added to the cells and incubated for $30 \mathrm{~min}$ in a $37^{\circ} \mathrm{C}$ in a $5 \% \mathrm{CO}_{2}$ incubator. Following incubation, the media was removed and the nuclei were stained with Hoechst 33342 for $15 \mathrm{~min}$ at room temperature. The cells were washed and incubated in HEPES buffer. The nuclei and co-localization of Mtphagy Dye and Lyso Dye were observed by confocal fluorescence microscopy.

Data Processing and Mitochondria Positive Puncta Calculation: Data collected on the Olympus FV1000 confocal microscope were processed using a CellProfiler pipeline to assess the dosedependent induction of mitophagic flux. Three fields of view were collected per concentration for three biological replicates. Each field of view contained approximately 30 cells. Within each field of view, 10 cells were randomly selected for a total of 30 cells that were used for quantification. All of the images were then transferred to a developed CellProfiler pipeline. In this pipeline, initially, background illumination was corrected. Next, the threshold of the image was set to remove any undesired signal. Both red and green puncta were identified based on pixel size and were binned to their respective cells using Hoechst stained nuclei. The colocalization of puncta 
was observed using overlays of the data. The number of red and green puncta per cell was used to calculate the number of mitochondria positive puncta per lysosome.

Statistical Analysis: GraphPad Prism version 8.2 was used for data analysis. Determination of the significance between compound and vehicle treatment were calculated by repeated measures, oneway ANOVA followed by Dunn-Šidák correction. Determination of the significance between different compound treatments were calculated by repeated measures, one-way ANOVA followed by Tukey's test for post-hoc analysis to determine significance between compound treatments.

Microscope Settings: Confocal imaging was performed on an inverted Olympus FV1000 confocal microscope with an IX81 base. A 60x oil immersion Plan S-Apo NA 1.35 objective lens was used for all imaging protocols. Twelve fields of view per compound treatment were captured using the FluoView acquisition software.

1.2.8 Western Blot Analysis: The murine macrophage cell line RAW 264.7 (ATCC TIB-71) was maintained at $37^{\circ} \mathrm{C}$ with $5 \% \mathrm{CO}_{2}$ in high glucose DMEM supplemented with $10 \%$ fetal bovine serum. Cells were lysed with RIPA buffer containing protease inhibitors, and lysates were centrifuged at $10,000 \times \mathrm{g}$ at $4^{\circ} \mathrm{C}$ for $15 \mathrm{~min}$. Tissues were first homogenized in RIPA buffer containing protease inhibitors, and lysates were centrifuged at $10,000 \times \mathrm{g}$ at $4^{\circ} \mathrm{C}$ for $15 \mathrm{~min}$. Lysates were subject to SDS-PAGE and the resolved polypeptides were transferred to PVDF membranes. Following transfer, the membranes were blocked with 5\% BSA in PBST (PBS containing $0.1 \%$ Tween-20) at room temperature for $1 \mathrm{hr}$, and incubated overnight with gentle rocking at $4^{\circ} \mathrm{C}$ with designated primary antibodies. Next, blots were washed with PBST and incubated at room temperature for $1 \mathrm{hr}$ with horseradish peroxidase (HRP)-conjugated secondary antibody, and the peroxidase activity was detected by enhanced chemiluminescence, using the ECL western blotting substrate.

1.2.9 Bacterial Translation Inhibition Analysis: Thiopeptide induced bacterial translation inhibition was assessed via the E. coli S30 Extract System for Circular DNA and the Luciferase Assay System from Promega. Kit \#L1020. The experiments were performed according to the manufacturer's protocol, except that the reaction was reduced to a $10 \mu \mathrm{L}$ volume containing $1 \mu \mathrm{L}$ of amino acid mixture, $4 \mu \mathrm{L}$ of S30 premix, $3 \mu \mathrm{L}$ of S30 extract, $1.25 \mu \mathrm{L}$ of nuclease-free water, $0.25 \mu \mathrm{L}$ of thiopeptide analogue, and $0.5 \mu \mathrm{L}$ of pBESTLuc template. The reaction mixtures were incubated at $37^{\circ} \mathrm{C}$ for $1 \mathrm{hr}$. Following incubation, $2.5 \mu \mathrm{L}$ of the mixture was added to $25 \mathrm{uL}$ of $1 \mathrm{X}$ luciferase substrate and immediately monitored for luminescence on the Perkin Elmer Envision 2103 Multilabel Plate Reader. Luminescence was normalized to DMSO treated (negative) and no luciferase (positive) controls and reported as relative luminescence.

1.2.10 Extraction of Thiocillin Compounds: Thiocillin III: B. cereus ATCC 14579 starter cultures $(5 \mathrm{~mL})$ were grown in LB for $20 \mathrm{hr}$ at $30^{\circ} \mathrm{C}$ and $200 \mathrm{rpm}$. LB cultures $(0.5 \mathrm{~L}$ in $2.8 \mathrm{~L}$ culture baffle flasks) were inoculated with $300 \mu \mathrm{L}$ of starter culture and grown for $68 \mathrm{hr}$ at $30^{\circ} \mathrm{C}$ and $200 \mathrm{rpm}$. $T 4 V$ : tclE mutant strain, T4V, was grown in media supplemented with $1 \mu \mathrm{g} / \mathrm{mL}$ erythromycin and $25 \mu \mathrm{g} / \mathrm{mL}$ lincomycin. ${ }^{2}$ Starter cultures $(5 \mathrm{~mL})$ were grown in LB supplemented with MLS for $20 \mathrm{hr}$ at $30^{\circ} \mathrm{C}$ and $200 \mathrm{rpm}$. LB cultures $(0.5 \mathrm{~L}$ in $2.8 \mathrm{~L}$ culture baffle flasks) were supplemented with MLS and inoculated with $300 \mu \mathrm{L}$ of starter culture and grown for $68 \mathrm{hr}$ at $30^{\circ} \mathrm{C}$ and $200 \mathrm{rpm}$. Cultures were harvested (4000 rpm, $30 \mathrm{~min}$ ) and the cell pellet and supernatant were 
saved. $50 \mathrm{~mL}$ methanol and $15 \mathrm{~g}$ sodium sulfate were added to the pellet. The mixture was vortexed vigorously and allowed to sit for 15 minutes. The mixture was then filtered through Whatman filter paper (no. 1) and the methanol was removed by vacuum. The resulting solid was solubilized in 10 $\mathrm{mL} 33 \%$ acetonitrile in water and was subjected to HPLC purification. The thiocillin variants eluted in a range from $45-55 \%$ acetonitrile. Characterization of each thiocillin variant was completed by NMR and LC/MS analysis.

1.2.11 Extraction of GE37468, 4: Streptomyces ATCC 55365 starter cultures $(50 \mathrm{~mL}, 250 \mathrm{~mL}$ baffle flasks) were grown in seed media ( $2 \%$ glucose sterile filtration, $0.5 \%$ yeast extract, $0.5 \%$ meat extract, $0.5 \%$ peptone, $0.3 \%$ hydrolyzed casein, $0.15 \% \mathrm{NaCl}$ ) for 3 days at $30^{\circ} \mathrm{C}$ and 250 rpm. Larger cultures $(0.5 \mathrm{~L}, 2.8 \mathrm{~L}$ baffle flasks) with $\mathrm{AF} / \mathrm{MS}$ media $(2 \%$ glucose, $0.2 \%$ yeast extract, $0.8 \%$ organic soybean flour, $0.1 \% \mathrm{NaCl}, 0.4 \% \mathrm{CaCO}_{3}$ ) were inoculated with $1 \mathrm{~mL}$ of the started culture and grown for $120 \mathrm{hr}$ at $29^{\circ} \mathrm{C}$ and $250 \mathrm{rpm}$. Cultures were harvested $(4000 \mathrm{rpm}, 30$ $\mathrm{min}$ ) and the pellet was saved. $20 \mathrm{~g}$ of $\mathrm{Na}_{2} \mathrm{SO}_{4}$ and $75 \mathrm{~mL}$ of acetone were added to the pellet and the mixture was vortexed vigorously and allowed to sit for $1 \mathrm{hr}$. The debris were filtered and concentrated by vacuum. The resulting solid was solubilized in $10 \mathrm{~mL} \mathrm{33 \%}$ acetonitrile in water and was subjected to HPLC purification, eluting in roughly $50 \%$ acetonitrile.

1.2.12 KEB-01, 8, Synthesis: Nosiheptide $(10.0 \mathrm{mg}, 8.2 \mu \mathrm{mol})$ was dissolved in $800 \mu \mathrm{L}$ of THF: DMSO (10:1) in a $20 \mathrm{~mL}$ scintillation vial. The vial was charged with a stir bar and $20 \%$ triethylamine $(200 \mu \mathrm{L})$ was added to the solution. The reaction proceeded at room temperature for $14 \mathrm{hr}$. After $14 \mathrm{hr}$, the material was subjected to HPLC purification and peaks containing the product were lyophilized down to an off-white solid (7.15 mg, $6.2 \mu \mathrm{mol}, 75 \%$ yield).

1.2.13 KEB-02, 9, Synthesis: KEB-01 (12.0 mg, $10.4 \mu \mathrm{mol})$ was dissolved in THF: MeOH (3:8) in a $20 \mathrm{~mL}$ scintillation vial. The vial was charged with a stir bar and cooled to $0^{\circ} \mathrm{C}$. $\mathrm{NaOH}(5$ eq., $1.0 \mathrm{M})$ was added in a slow dropwise manner. The reaction warmed to RT and the reaction proceeded for $3 \mathrm{hrs}$. The material was subjected to HPLC purification and peaks containing the product were lyophilized down to an off-white solid $(6.8 \mathrm{mg}, 7.1 \mu \mathrm{mol}, 68 \%$ yield $)$.

1.2.15 In vitro Mtb MICs - Resazurin Microtiter Assay: Test compounds TCIII (2), TSR (3), NOS (6), KEB-01 (8), KEB-02 (9), and T4V (10) were prepared in DMSO and kanamycin was prepared in deionized water as a positive control. Using non-treated polystyrene 96-well plates (Corning), drugs were serially two-fold diluted in triplicate in $7 \mathrm{H} 9$ broth (Difco) supplemented with albumin dextrose saline (ADS; $10 \mathrm{~g} / \mathrm{L}$ bovine serum albumin fraction $\mathrm{V}, 4 \mathrm{~g} / \mathrm{L}$ dextrose, 1.6 $\mathrm{g} / \mathrm{L} \mathrm{NaCl}$ ), $0.5 \%$ glycerol, and $0.1 \%$ Tyloxapol (7AGT). A frozen stock of Mycobacterium tuberculosis $\mathrm{H} 37 \mathrm{Rv}$ was thawed and 1 X $10^{5}$ cells/well were delivered. All wells contained a final concentration of $1 \%$ DMSO and $100 \mu \mathrm{L}$ total volume. Plates were incubated for $96 \mathrm{hrs}$ at $37^{\circ} \mathrm{C}$, $80 \mathrm{rpm}$ before adding $10 \mu \mathrm{L}$ resazurin solution $(125 \mu \mathrm{g} / \mathrm{mL}$ in phosphate buffered saline). Following the addition of resazurin, plates were incubated in the dark for an additional 96 hrs. Fluorescence was measured with an excitation at $544 \mathrm{~nm}$ and emission at $590 \mathrm{~nm}$ with Tecan Infinite 200 Pro plate reader (Zurich, Switzerland).

Statistical analysis: GraphPad Prism version 8.2 was used for data analysis. The log(agonist) vs. response, find ECanything equation was used to calculate IC90 and $\log$ (inhibitor) vs. response, variable slope (four parameters) equation was used to determine the best fit curve. 
1.2.16 Intracellular Mtb-pLux MICs: THP- cells (ATCC TIB-202) were seeded and differentiated into macrophage-like cells using 20ng/ml PMA, in RPMI (Gibco) supplemented with $10 \% \mathrm{FBS}$, for $48 \mathrm{hr}$ in white-walled 96-well plates (Corning). THP-1s were infected at an MOI 1 with Mtb H37Rv expressing the luxBCADE operon from Vibrio harveyi on a hygromycinmarked plasmid. ${ }^{3} \mathrm{Mtb}$ was grown to log phage and prepared by washing 2 times in 1x PBS with $0.05 \%$ Tween 80 then diluted in RPMI as previously described. ${ }^{4}$ After $4 \mathrm{hr}$, macrophages were washed three times with 1x PBS to remove remaining extracellular $M t b$. Compounds to be tested and Rifampin, as a positive control, were prepared in DMSO. Drugs were diluted to the highest working concentrations in media to a maximum DMSO concentration of $0.5 \%$. Each compound was serially diluted two-fold in triplicate for a total of 9 data points with the final concentration of DMSO for each well remaining at $0.5 \%$. At 7 days post-infection the luminescence signal was measured using a Tecan Infinite 200 Pro plate reader. GraphPad Prism was used for data analysis. Percent inhibition for each compound was normalized to Rifampin.

Statistical analysis: GraphPad Prism version 8.2 was used for data analysis. $\log$ (inhibitor) vs. response, variable slope (four parameters) equation was used to determine the best fit curve.

1.2.17 Visualization of Autophagy in Mtb-GFP-Infected Cells: THP-1 cells (ATCC TIB-202) were seeded and differentiated into macrophage-like cells using 20ng/ml PMA, in RPMI (Gibco) supplemented with $10 \%$ FBS for $24 \mathrm{hr}$ in clear, 8-well chambered coverslips. Washed cells $3 \mathrm{x}$ with RPMI to remove PMA and incubated at $37^{\circ} \mathrm{C} / 5 \% \mathrm{CO}_{2}$ for $24 \mathrm{hr}$. pmRFP-LC3 (Addgene \#21075) was transfected into differentiated THP-1s using jetPRIME® reagents. ${ }^{5}$ After $24 \mathrm{hr}$ of incubation with DNA-JetPrime reagents, cells were washed $3 \mathrm{x}$ and recovered for $24 \mathrm{hr}$ at $37^{\circ} \mathrm{C} / 5 \%$ $\mathrm{CO}_{2}$. The following day, THP-1s were infected with Mtb H37Rv expressing GFP on a kanamycinmarked plasmid, as previously described, at an MOI $1 \mathrm{for} 4 \mathrm{hr}$ and washed three times with $1 \mathrm{x}$ PBS to remove extracellular bacteria. ${ }^{6-8}$ RPMI supplemented with $10 \%$ FBS and compounds and brought to a final DMSO concentration of $1 \%$ were added to infected THP-1s for 16-20 hr. Cells were fixed and Mtb neutralized for $1 \mathrm{hr}$ using $4 \%$ PFA.

Microscope Settings: Confocal imaging was performed on an inverted Olympus FV1000 confocal microscope with an IX81 base. A 60x oil immersion Plan S-Apo NA 1.35 objective lens was used for all imaging protocols. Twelve fields of view per compound treatment were captured using the FluoView acquisition software.

Data Processing: Data collected on the Olympus FV1000 confocal microscope were processed using Fiji. 10 fields of view were collected for three biological replicates. Each field of view contained approximately 15 cells. Within each field of view, infected macrophages were analyzed for number of autophagosomes (red puncta) and the number of autophagosomes containing Mtb (red+green puncta, orange puncta).

Statistical Analysis: GraphPad Prism version 8.2 was used for data analysis. Determination of the significance between compound and vehicle treatment were calculated by repeated measures, oneway ANOVA followed by Dunn-Šidák correction. Determination of the significance between different compound treatments were calculated by repeated measures, one-way ANOVA followed by Tukey's test for post-hoc analysis to determine significance between compound treatments. 


\section{Supplemental Tables and Figures}

Figure S.1 Structures of thiopeptides, both natural and unnatural, used in the analysis of thiopeptide biological activity characterization. Each macrocycle is numbered based on the amino acid composition to facilitate simplicity in discussion. Homologous regions have been highlighted in blue. A conserved epitope among multiple families of thiopeptides is highlighted in green.

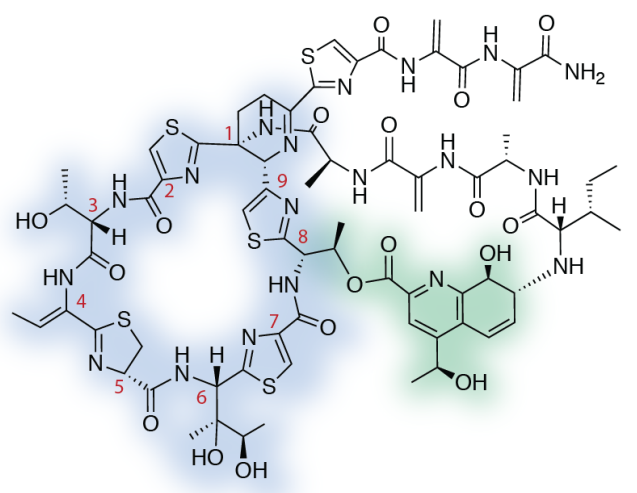

Thiostrepton (TSR)

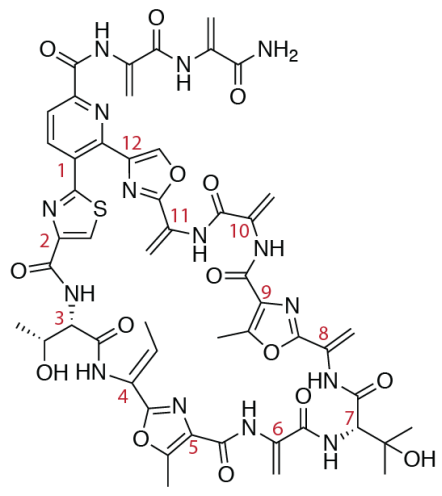

Berninamycin (BER)

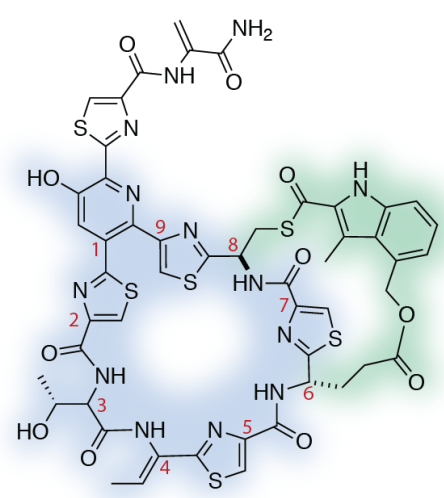

Nosiheptide (NOS)

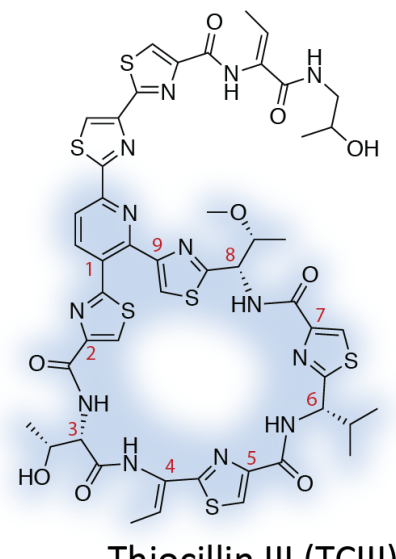

Thiocillin III (TCIII)

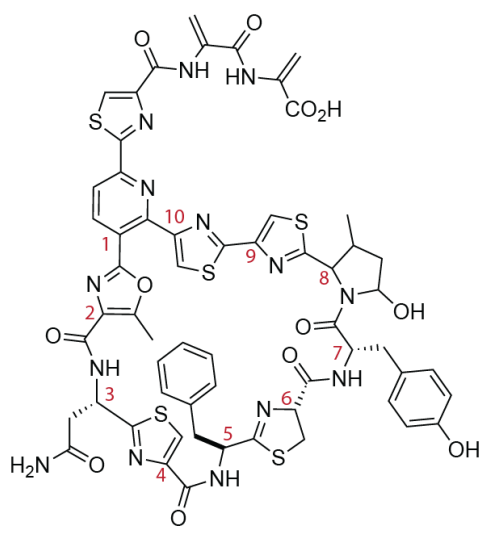

GE37468 (GE)

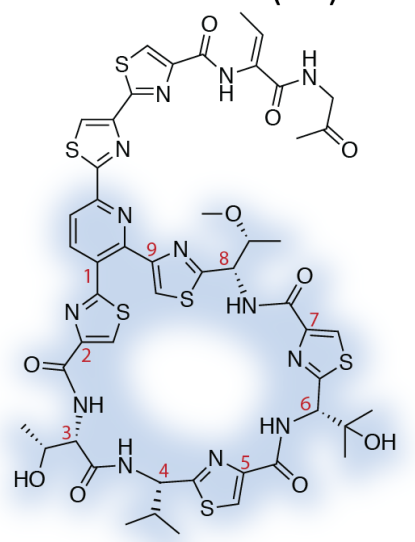

T4V

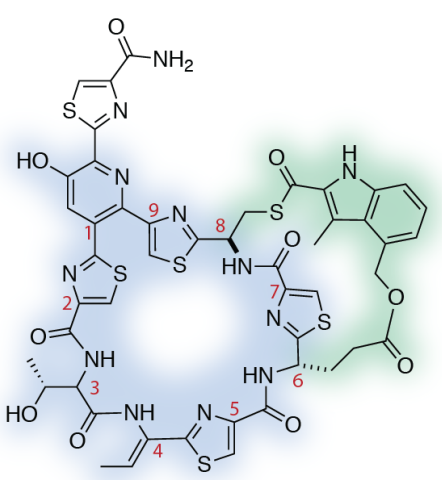

KEB-01

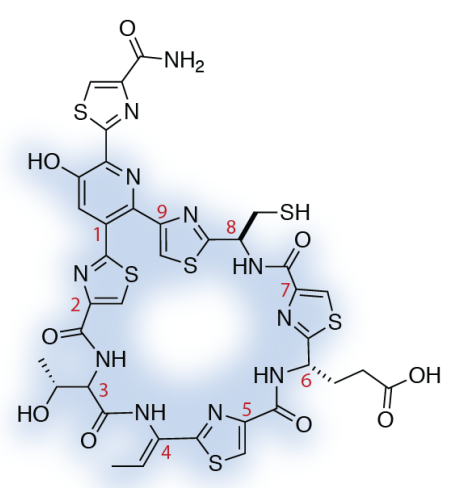

KEB-02 
Figure S.2 Illustrations for cellular assays

Figure S.2.1. In cellulo proteasome inhibition assay. Inhibition of the proteasome was monitored by the accumulation of Ub-R-GFP. Under normal physiological conditions the proteasome will recognize the ubiquitylated substrate and degrade the GFP signal. Upon inhibition of the proteasome, the degradation substrate will remain in the cytosol and emit fluorescence.

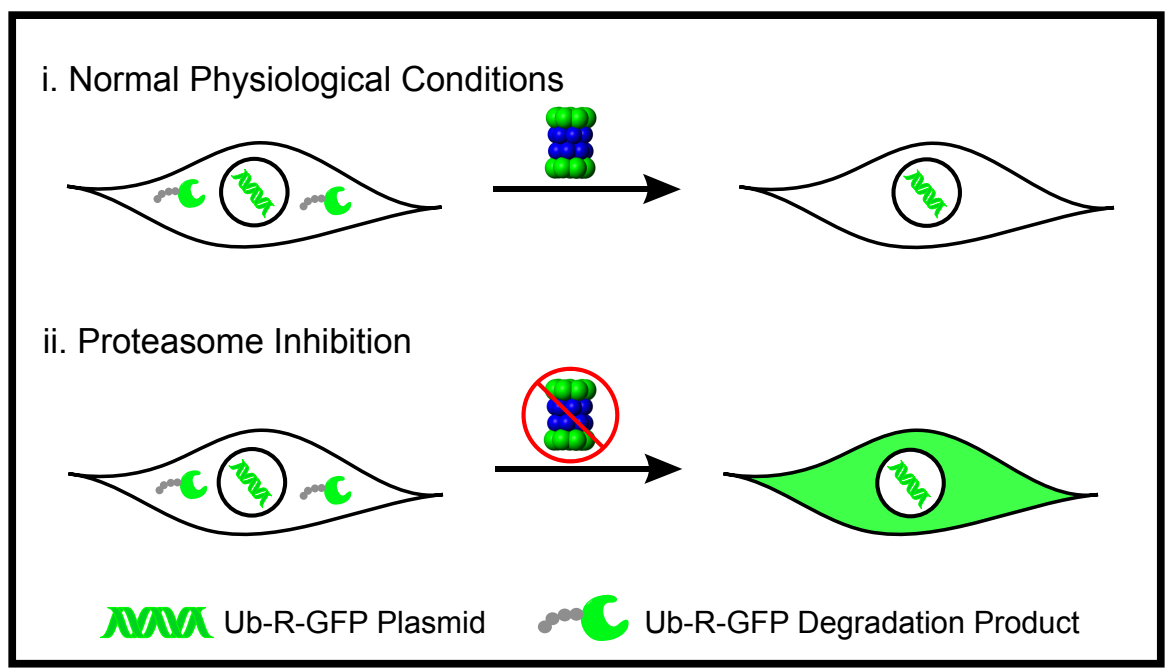

Figure S.2.2. In cellulo autophagy induction assay. Induction of autophagic flux was monitored by the presence of fluorescent (RFP-GFP) puncta. Once materials are encapsulated within the autophagosome RFP/GFP positive puncta will be present in the cell. After the autophagosome fuses with the lysosome, the acid-labile GFP will degrade and RFP puncta will remain.

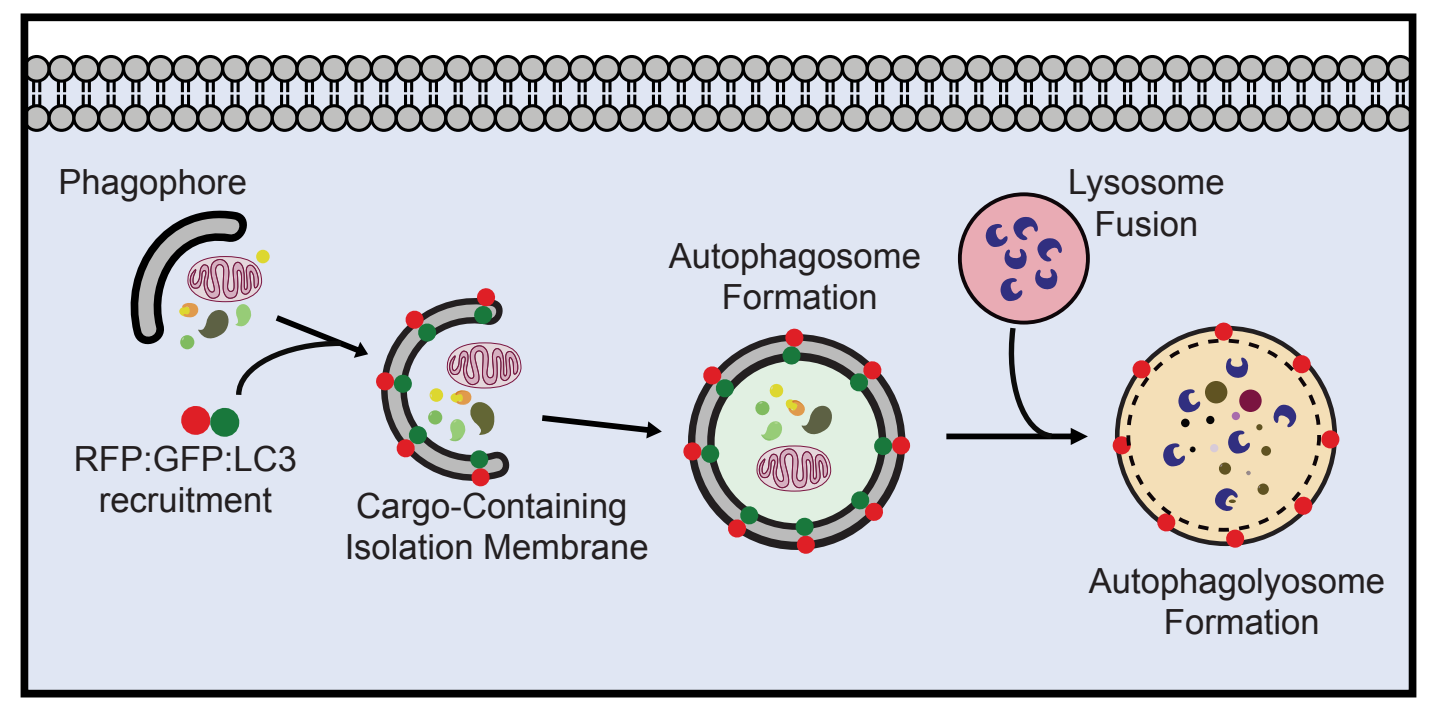


Figure S.2.3. In cellulo mitophagy induction assay. Induction of mitophagy was monitored by the acid-dependent fluorescence of a covalent mitochondrial-linked fluorophore.

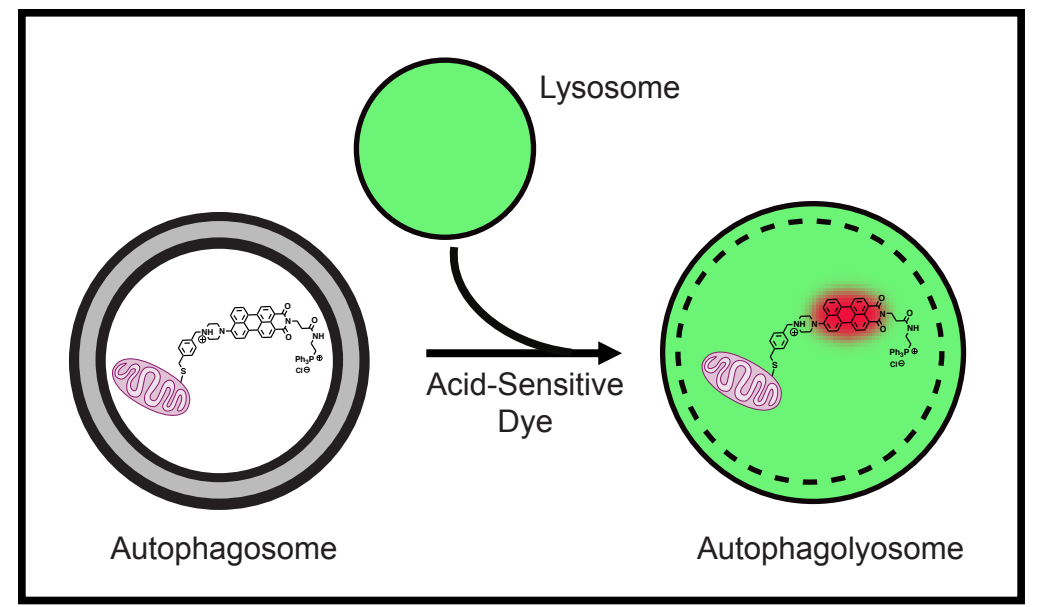




\section{Figure S.3 Thiopeptide Characterization}

S.3.1 Thiostrepton, 3, Characterization: ${ }^{1} \mathbf{H}$ NMR $\left(700 \mathrm{MHz}, \mathrm{DMSO}-d_{6}\right) \delta 9.96(\mathrm{~s}, 1 \mathrm{H}), 9.47$ $(\mathrm{s}, 1 \mathrm{H}), 9.25(\mathrm{~s}, 1 \mathrm{H}), 9.20(\mathrm{~s}, 2 \mathrm{H}), 8.53(\mathrm{~s}, 1 \mathrm{H}), 8.42(\mathrm{~s}, 1 \mathrm{H}), 8.39(\mathrm{~s}, 1 \mathrm{H}), 8.15(\mathrm{~s}, 2 \mathrm{H}), 8.12(\mathrm{~s}$, 2H), $7.94(\mathrm{~s}, 2 \mathrm{H}), 7.75(\mathrm{~s}, 3 \mathrm{H}), 7.50(\mathrm{~s}, 1 \mathrm{H}), 6.85(\mathrm{~d}, J=10.0 \mathrm{~Hz}, 1 \mathrm{H}), 6.43(\mathrm{~s}, 1 \mathrm{H}), 6.42-6.37$ $(\mathrm{m}, 1 \mathrm{H}), 6.29(\mathrm{dd}, J=10.1,3.3 \mathrm{~Hz}, 1 \mathrm{H}), 6.02(\mathrm{~s}, 1 \mathrm{H}), 5.76(\mathrm{~s}, 1 \mathrm{H}), 5.70(\mathrm{~s}, 1 \mathrm{H}), 5.68(\mathrm{~s}, 1 \mathrm{H}), 5.56$ $(\mathrm{s}, 3 \mathrm{H}), 5.38(\mathrm{~s}, 2 \mathrm{H}), 5.33(\mathrm{~s}, 2 \mathrm{H}), 5.31-5.25(\mathrm{~m}, 2 \mathrm{H}), 5.22-5.17(\mathrm{~m}, 1 \mathrm{H}), 5.05(\mathrm{t}, J=7.0 \mathrm{~Hz}$, $1 \mathrm{H}), 4.68(\mathrm{~s}, 1 \mathrm{H}), 4.62(\mathrm{~d}, J=11.5 \mathrm{~Hz}, 3 \mathrm{H}), 4.35(\mathrm{~s}, 1 \mathrm{H}), 4.28(\mathrm{~s}, 1 \mathrm{H}), 4.05(\mathrm{~d}, J=19.2 \mathrm{~Hz}, 1 \mathrm{H})$, $3.62(\mathrm{t}, J=9.3 \mathrm{~Hz}, 2 \mathrm{H}), 3.09(\mathrm{~s}, 1 \mathrm{H}), 2.52(\mathrm{~s}, 4 \mathrm{H}), 1.73(\mathrm{~d}, J=7.0 \mathrm{~Hz}, 4 \mathrm{H}), 1.41(\mathrm{~s}, 2 \mathrm{H}), 1.26(\mathrm{t}$, $J=6.4 \mathrm{~Hz}, 6 \mathrm{H}), 1.16(\mathrm{~s}, 4 \mathrm{H}), 1.06(\mathrm{~d}, J=5.9 \mathrm{~Hz}, 4 \mathrm{H}), 0.91(\mathrm{~d}, J=6.8 \mathrm{~Hz}, 6 \mathrm{H}), 0.81$ (t, $J=7.4$ $\mathrm{Hz}, 4 \mathrm{H}) .{ }^{13} \mathbf{C}$ NMR $(176 \mathrm{MHz}, \mathrm{DMSO}) \delta$ 217.04, 208.99, 202.35, 198.77, 184.72, 176.90, 175.17, $173.77,171.73,171.60,171.11,168.33,167.68,167.07,165.17,163.36,163.31,162.84,162.02$, $159.43,159.19,156.76,154.34,152.44,151.82,150.04,147.53,140.41,138.32,137.82,137.72$, $135.39,132.92,131.65,130.08,130.00,128.04,126.90,126.83,124.72,124.25,122.29,114.43$, $109.52,107.87,88.44,78.05,78.05,70.98,69.47,68.07,67.35,62.42,60.09,59.99,52.20,40.96$, 38.24, 30.48, 30.43, 28.13, 27.56, 27.24, 21.04, 20.93, 19.73, 19.70, 19.63, 18.84, 17.10, 14.57. LC/MS: Expected Mass: 1664.4996 m/z [M+H] ${ }^{+1}$, Observed Mass: $1664.5494 \mathrm{~m} / \mathrm{z}[\mathrm{M}+\mathrm{H}]^{+1}$

Analytical Trace: $\lambda-254 \mathrm{~nm}$

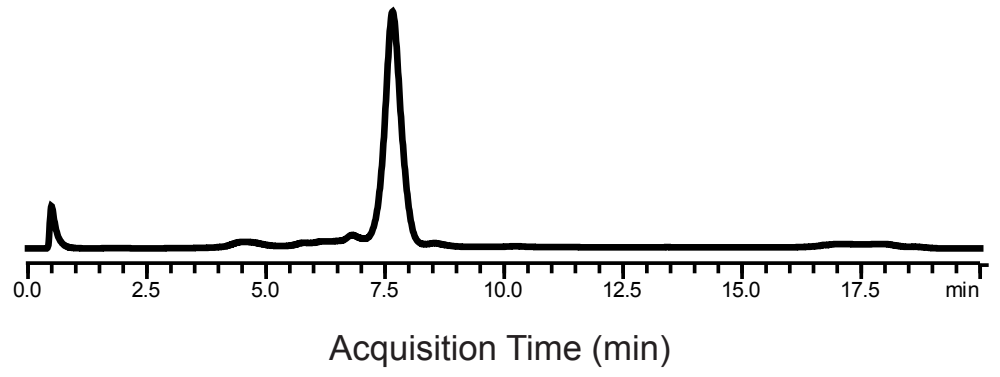


Thiostrepton, 3, ${ }^{1} \mathrm{H}$ NMR - $700 \mathrm{mHz}$, d6-DMSO

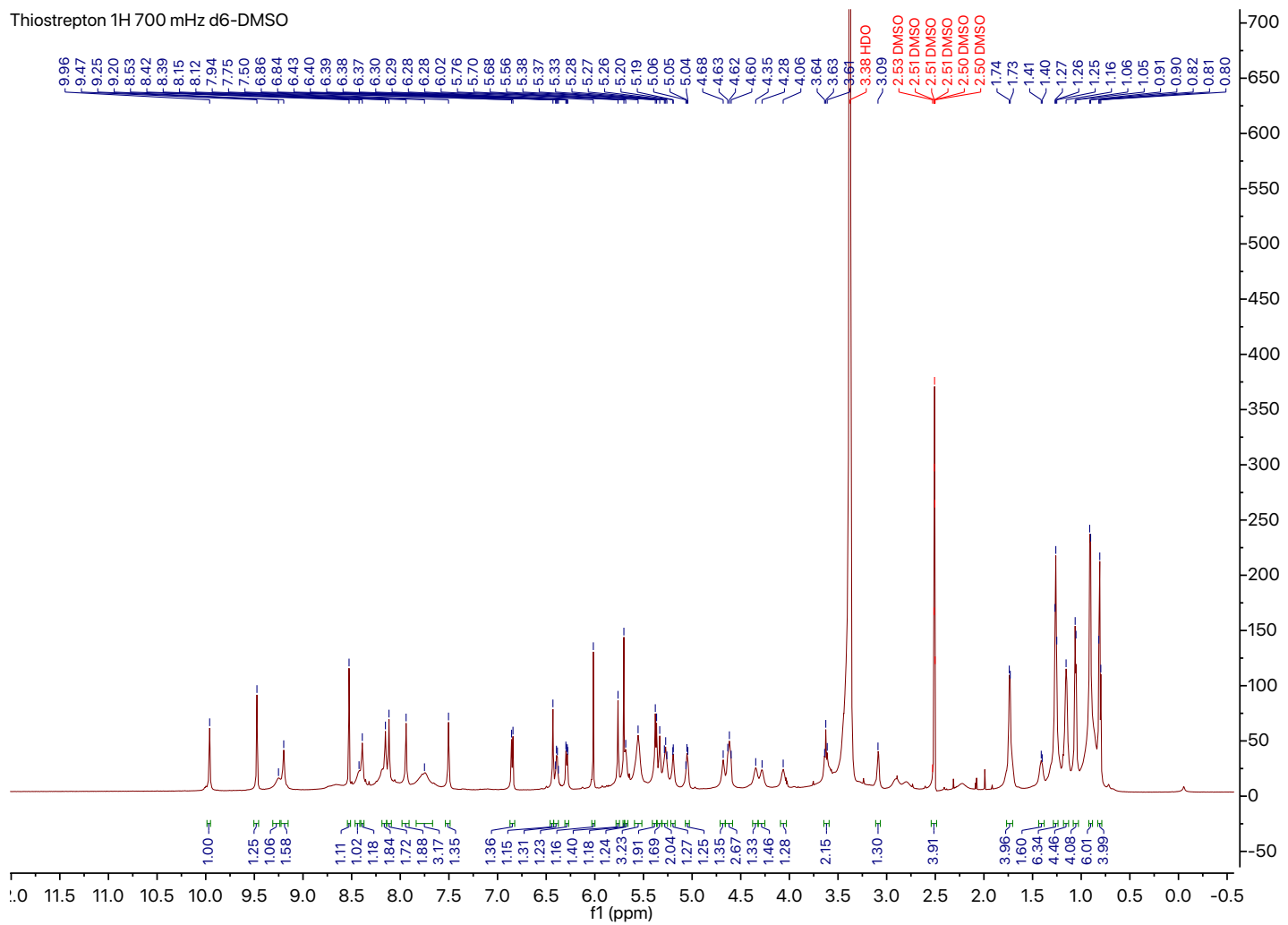

Thiostrepton, 3, ${ }^{13} \mathrm{C}$ NMR - $700 \mathrm{mHz}$, d6-DMSO

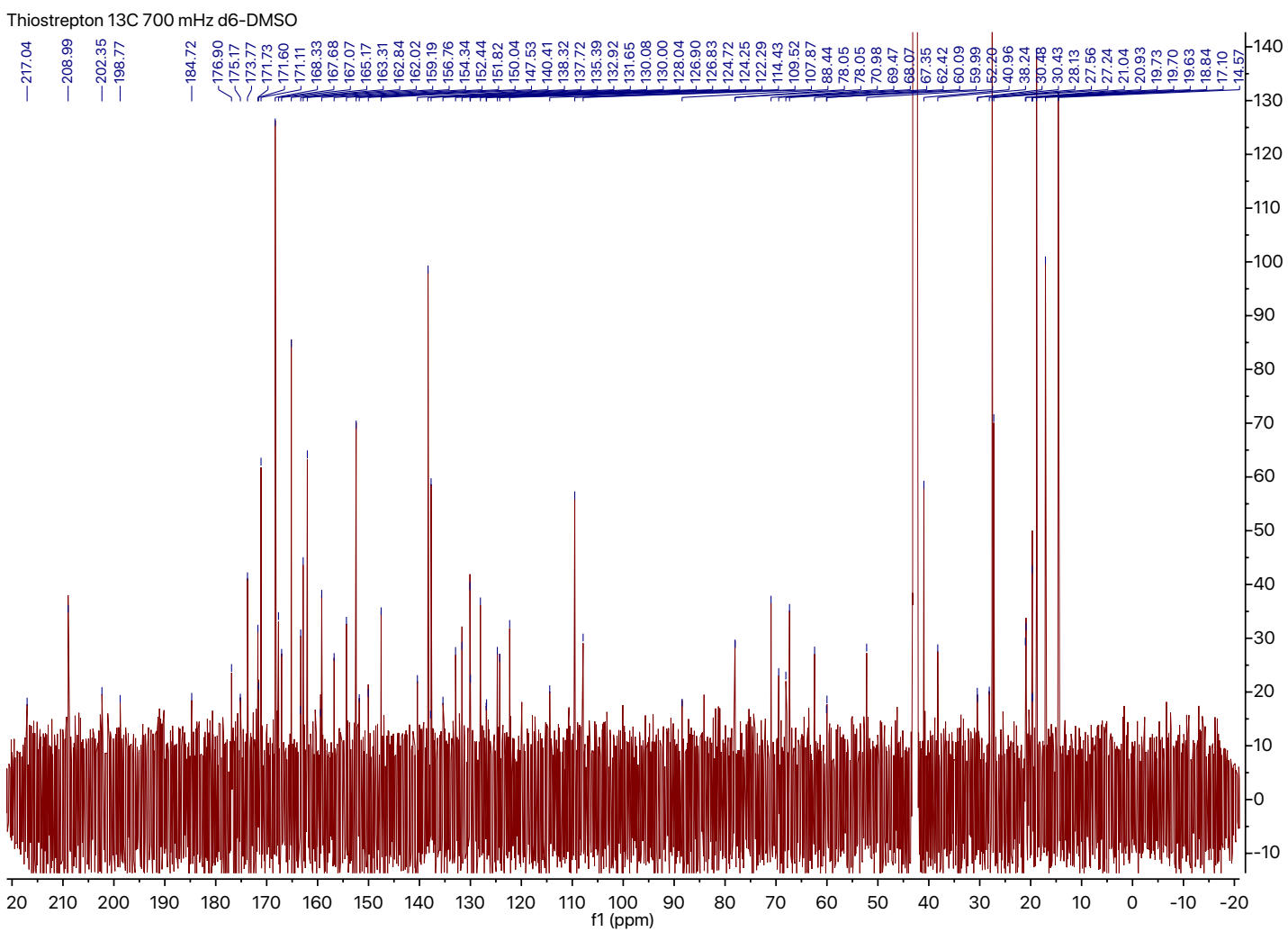


S.3.2 Berninamycin, 7, Characterization: ${ }^{1} \mathrm{H}$ NMR (700 MHz, DMSO- $\left.d_{6}\right) \delta 10.55(\mathrm{~s}, 1 \mathrm{H}), 9.80$ (s, 1H), $9.62(\mathrm{~s}, 1 \mathrm{H}), 9.57(\mathrm{~s}, 1 \mathrm{H}), 9.46(\mathrm{~s}, 1 \mathrm{H}), 9.39(\mathrm{~s}, 1 \mathrm{H}), 9.37(\mathrm{~s}, 1 \mathrm{H}), 8.70(\mathrm{~s}, 1 \mathrm{H}), 8.52(\mathrm{~d}, J$ $=8.0 \mathrm{~Hz}, 1 \mathrm{H}), 8.50(\mathrm{~s}, 1 \mathrm{H}), 8.25(\mathrm{~d}, J=8.0 \mathrm{~Hz}, 1 \mathrm{H}), 8.22(\mathrm{~d}, J=8.4 \mathrm{~Hz}, 1 \mathrm{H}), 8.01(\mathrm{~d}, J=8.7 \mathrm{~Hz}$, $1 \mathrm{H}), 7.95(\mathrm{~s}, 1 \mathrm{H}), 7.51(\mathrm{~s}, 1 \mathrm{H}), 6.50(\mathrm{~d}, J=7.0 \mathrm{~Hz}, 1 \mathrm{H}), 6.48(\mathrm{~s}, 1 \mathrm{H}), 6.44(\mathrm{~s}, 1 \mathrm{H}), 6.38(\mathrm{~s}, 1 \mathrm{H})$, $6.16(\mathrm{~s}, 1 \mathrm{H}), 6.05(\mathrm{~s}, 1 \mathrm{H}), 5.85(\mathrm{~s}, 1 \mathrm{H}), 5.78(\mathrm{~s}, 1 \mathrm{H}), 5.73(\mathrm{~d}, J=6.5 \mathrm{~Hz}, 1 \mathrm{H}), 5.70(\mathrm{~s}, 2 \mathrm{H}), 5.67$ $(\mathrm{s}, 1 \mathrm{H}), 5.20(\mathrm{~s}, 1 \mathrm{H}), 4.96(\mathrm{~s}, 1 \mathrm{H}), 4.66(\mathrm{~d}, J=8.4 \mathrm{~Hz}, 1 \mathrm{H}), 4.60(\mathrm{dd}, J=8.7,3.3 \mathrm{~Hz}, 1 \mathrm{H}), 4.31(\mathrm{~s}$, $1 \mathrm{H}), 2.62(\mathrm{~d}, J=19.5 \mathrm{~Hz}, 7 \mathrm{H}), 1.74(\mathrm{~d}, J=7.2 \mathrm{~Hz}, 3 \mathrm{H}), 1.23(\mathrm{~d}, J=12.0 \mathrm{~Hz}, 6 \mathrm{H}), 1.15$ (d, $J=6.2$ $\mathrm{Hz}, 3 \mathrm{H}) .{ }^{13} \mathrm{C}$ NMR $(176 \mathrm{MHz}$, DMSO) $\delta 172.53,171.88,168.30,166.93,166.28,165.87,165.19$, $164.73,163.06,162.77,162.66,161.28,159.80,158.30,157.72,156.78,152.55,152.38,150.00$, $144.11,143.66,142.33,138.24,137.84,137.00,136.61,133.37,132.49,132.30,131.93,131.66$, $129.99,126.14,114.56,109.40,109.22,109.06,106.07,104.37,74.18,70.53,64.88,60.90,60.73$, 30.48, 29.21, 23.67, 23.47, 16.90, 14.71, 14.62. LC/MS: Expected Mass: $1168.3302 \mathrm{~m} / \mathrm{z}$ $[\mathrm{M}+\mathrm{Na}]^{+1}$, Observed Mass: $1168.3349 \mathrm{~m} / \mathrm{z}[\mathrm{M}+\mathrm{Na}]^{+1}$

Analytical Trace: $\lambda-350 \mathrm{~nm}$

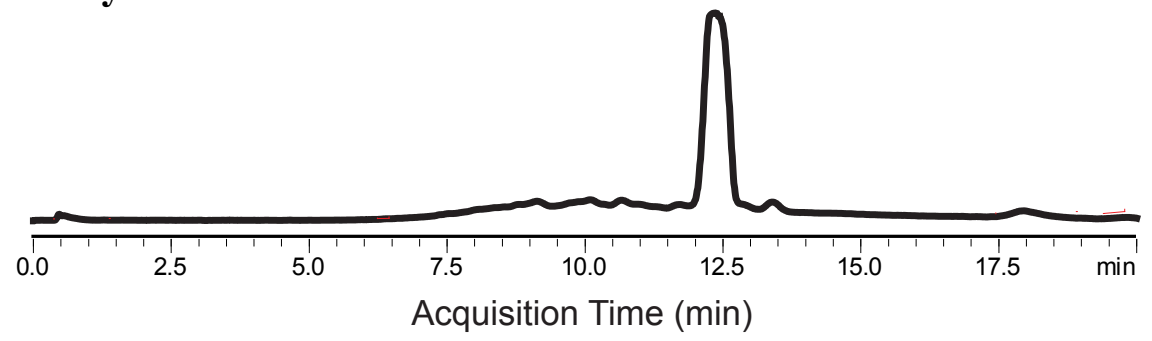


Berninamycin, 7, ${ }^{1} \mathrm{H}$ NMR - $700 \mathrm{mHz}$, d6-DMSO

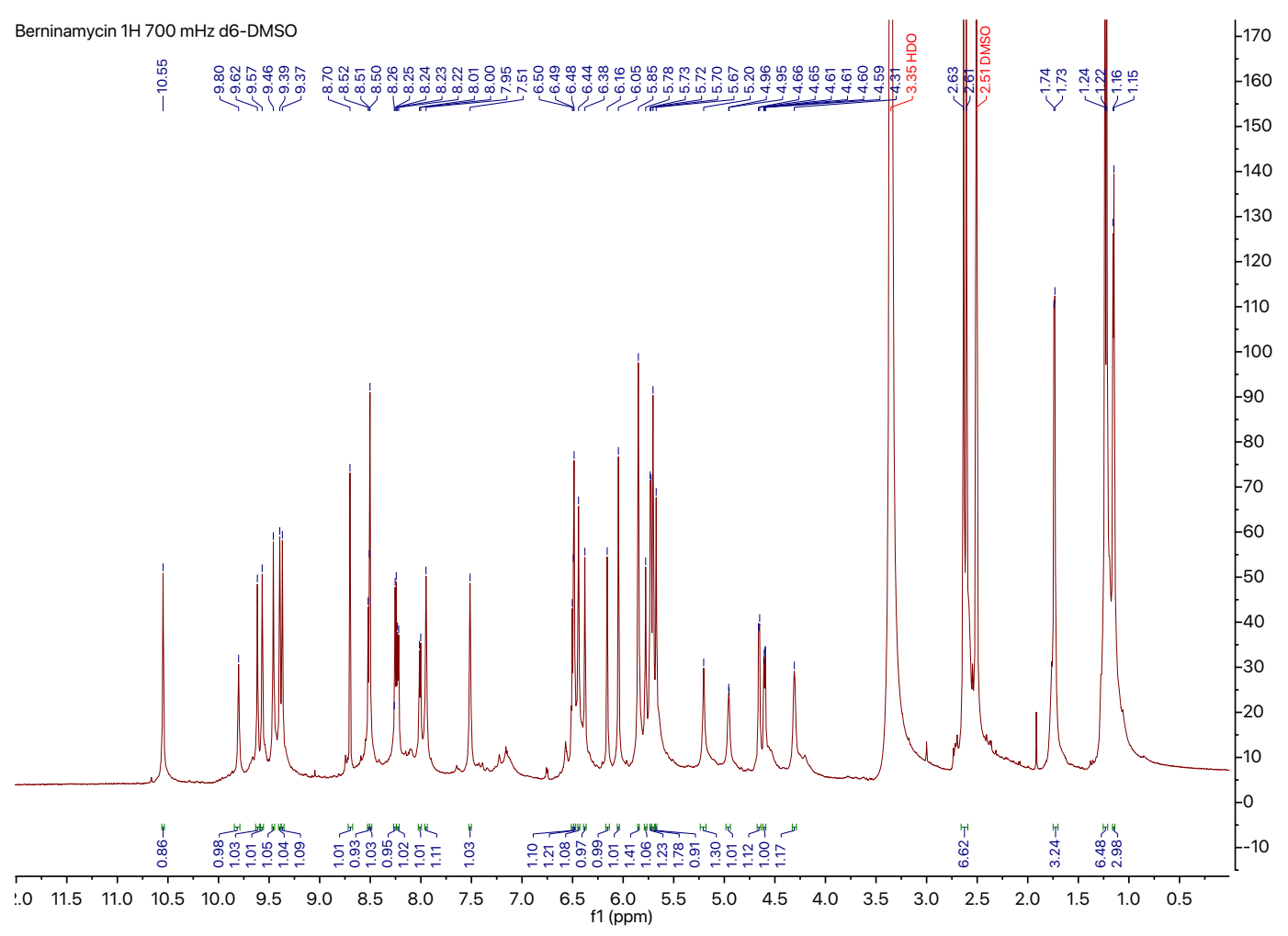

Berninamycin, 7, ${ }^{13} \mathrm{C}$ NMR - $700 \mathrm{mHz}$, d6-DMSO

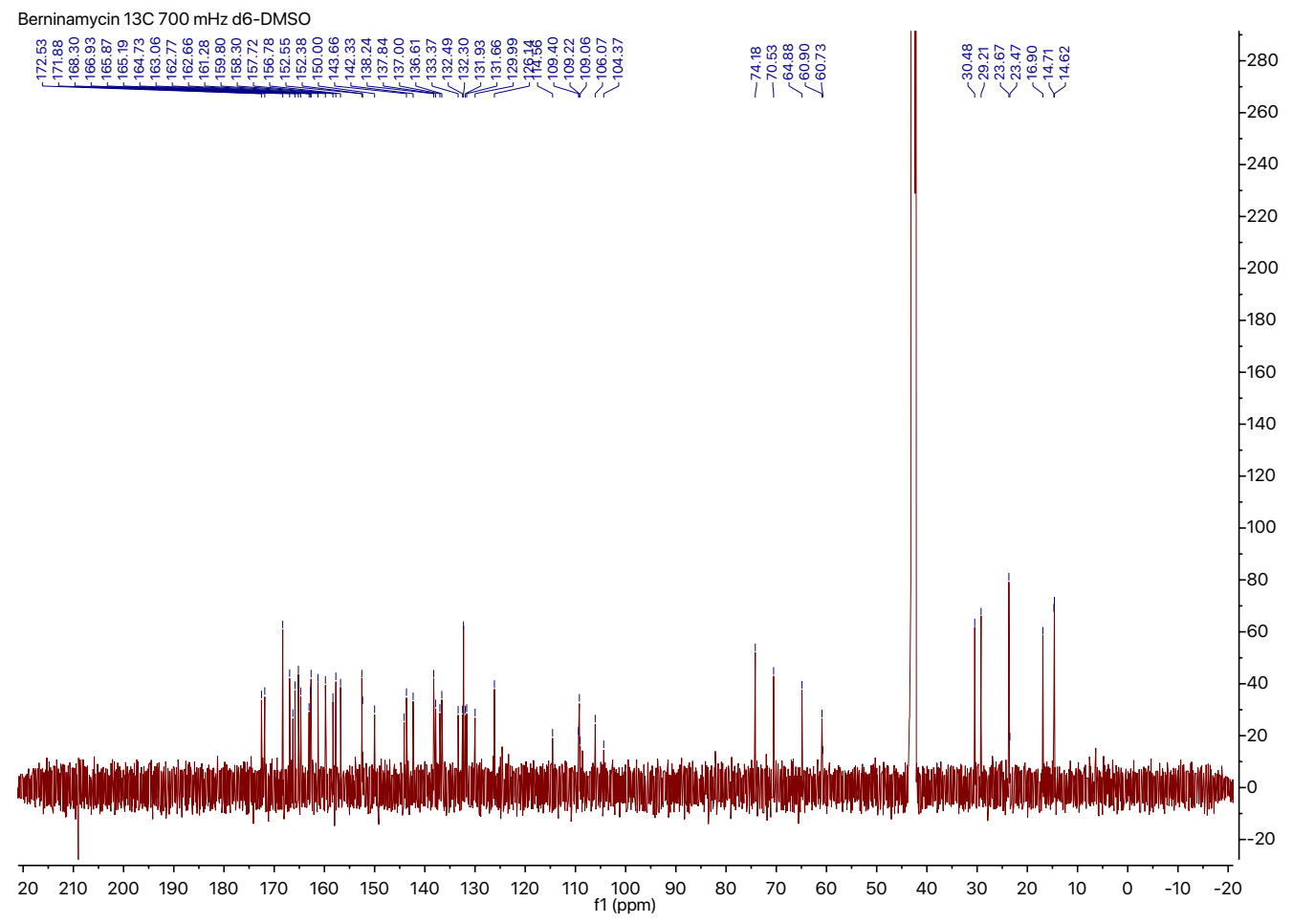


S.3.3 GE37468, 4, Characterization: ${ }^{1}$ H NMR (700 MHz, DMSO- $\left.d_{6}\right) \delta 13.35(\mathrm{~s}, 1 \mathrm{H}), 10.09(\mathrm{~d}$, $J=2.9 \mathrm{~Hz}, 1 \mathrm{H}), 9.58(\mathrm{~d}, J=2.9 \mathrm{~Hz}, 1 \mathrm{H}), 8.67$ (dd, $J=14.6,5.5 \mathrm{~Hz}, 2 \mathrm{H}), 8.60(\mathrm{~d}, J=7.0 \mathrm{~Hz}, 1 \mathrm{H})$, $8.56(\mathrm{dd}, J=8.0,2.9 \mathrm{~Hz}, 1 \mathrm{H}), 8.39(\mathrm{dd}, J=8.2,2.9 \mathrm{~Hz}, 1 \mathrm{H}), 8.19(\mathrm{~d}, J=2.9 \mathrm{~Hz}, 1 \mathrm{H}), 7.91(\mathrm{~d}, J=$ $2.9 \mathrm{~Hz}, 1 \mathrm{H}), 7.77(\mathrm{~d}, J=3.0 \mathrm{~Hz}, 1 \mathrm{H}), 7.29(\mathrm{t}, J=3.7 \mathrm{~Hz}, 4 \mathrm{H}), 7.20(\mathrm{~d}, J=9.5 \mathrm{~Hz}, 2 \mathrm{H}), 7.08-$ $7.05(\mathrm{~m}, 2 \mathrm{H}), 6.82(\mathrm{~s}, 2 \mathrm{H}), 6.59(\mathrm{~d}, J=5.5 \mathrm{~Hz}, 2 \mathrm{H}), 6.46(\mathrm{~s}, 2 \mathrm{H}), 6.05(\mathrm{~d}, J=2.9 \mathrm{~Hz}, 1 \mathrm{H}), 5.88(\mathrm{t}$, $J=3.2 \mathrm{~Hz}, 3 \mathrm{H}), 5.79(\mathrm{~d}, J=4.8 \mathrm{~Hz}, 1 \mathrm{H}), 5.28(\mathrm{dt}, J=9.3,4.4 \mathrm{~Hz}, 1 \mathrm{H}), 5.06(\mathrm{t}, J=9.5 \mathrm{~Hz}, 1 \mathrm{H})$, $4.94(\mathrm{q}, J=10.2,9.5 \mathrm{~Hz}, 2 \mathrm{H}), 4.86(\mathrm{q}, J=7.0 \mathrm{~Hz}, 2 \mathrm{H}), 4.63(\mathrm{dd}, J=9.6,2.9 \mathrm{~Hz}, 2 \mathrm{H}), 3.37(\mathrm{q}, J=$ $13.5,11.4 \mathrm{~Hz}, 4 \mathrm{H}), 3.32-3.29(\mathrm{~m}, 2 \mathrm{H}), 3.21-3.17(\mathrm{~m}, 2 \mathrm{H}), 2.96(\mathrm{~d}, J=11.4 \mathrm{~Hz}, 1 \mathrm{H}), 2.72(\mathrm{~d}, J$ $=2.9 \mathrm{~Hz}, 2 \mathrm{H}), 2.62(\mathrm{dd}, J=17.5,10.9 \mathrm{~Hz}, 3 \mathrm{H}), 2.11(\mathrm{q}, J=5.9 \mathrm{~Hz}, 1 \mathrm{H}), 2.02(\mathrm{~d}, J=15.3 \mathrm{~Hz}$, 1H), $1.96-1.89(\mathrm{~m}, 2 \mathrm{H}), 1.24(\mathrm{~s}, 2 \mathrm{H}), 1.15(\mathrm{dd}, J=6.8,2.8 \mathrm{~Hz}, 3 \mathrm{H}), 0.88-0.83(\mathrm{~m}, 1 \mathrm{H}) .{ }^{13} \mathbf{C}$ NMR (176 MHz, DMSO) $\delta 174.78,174.29,173.33,171.89,171.73,169.62,167.94,165.31$, 162.89 , 161.67, 161.45, 161.21, 159.31, 158.69, 158.50, 158.32, 158.13, 156.29, 156.00, 154.20, $153.61,152.43,150.78,149.61,147.67,140.49$, 137.62, 137.62, 134.82, 134.16, 130.99, 130.13, $129.80,129.37,128.75,127.82,127.13,124.27,123.49,122.66,119.04,117.87,117.06,116.19$, $115.35,114.51,112.87,106.14,82.22,77.74,66.98,54.70,52.71,48.75,43.13,40.91,40.35$, 40.23, 40.11, 39.99, 39.87, 39.75, 39.64, 38.72, 38.46, 37.26, 36.69, 16.32, 12.04. LC/MS Expected Mass: $1309.2565 \mathrm{~m} / \mathrm{z}[\mathrm{M}+\mathrm{H}]^{+1}$ Observed Mass: $1309.2314 \mathrm{~m} / \mathrm{z}[\mathrm{M}+\mathrm{H}]^{+1}$

Analytical Trace: $\lambda-350 \mathrm{~nm}$

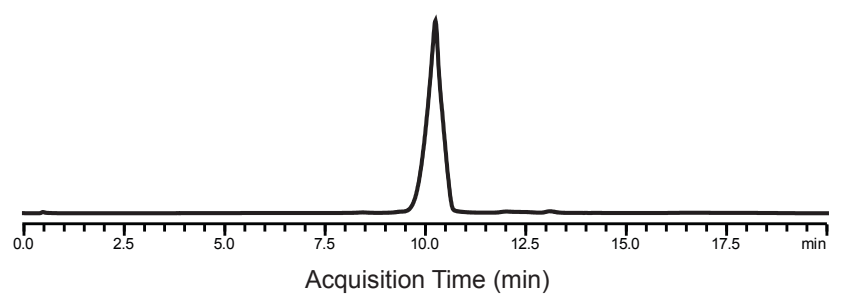


GE37468, 4, ${ }^{1} \mathrm{H}$ NMR - 700 mHz, d6-DMSO

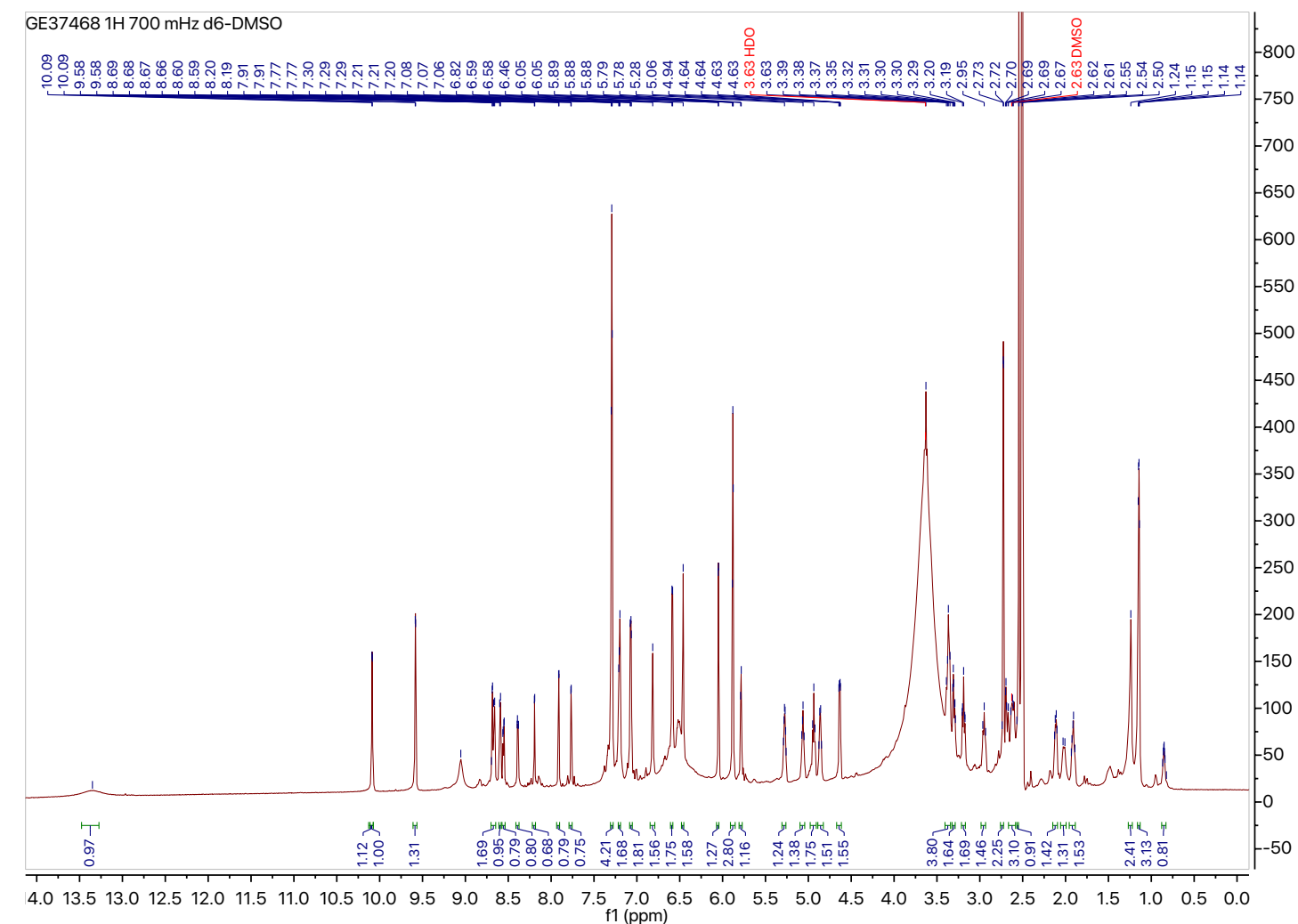

GE37468, 4, ${ }^{13} \mathrm{C}$ NMR - $700 \mathrm{mHz}$, d6-DMSO

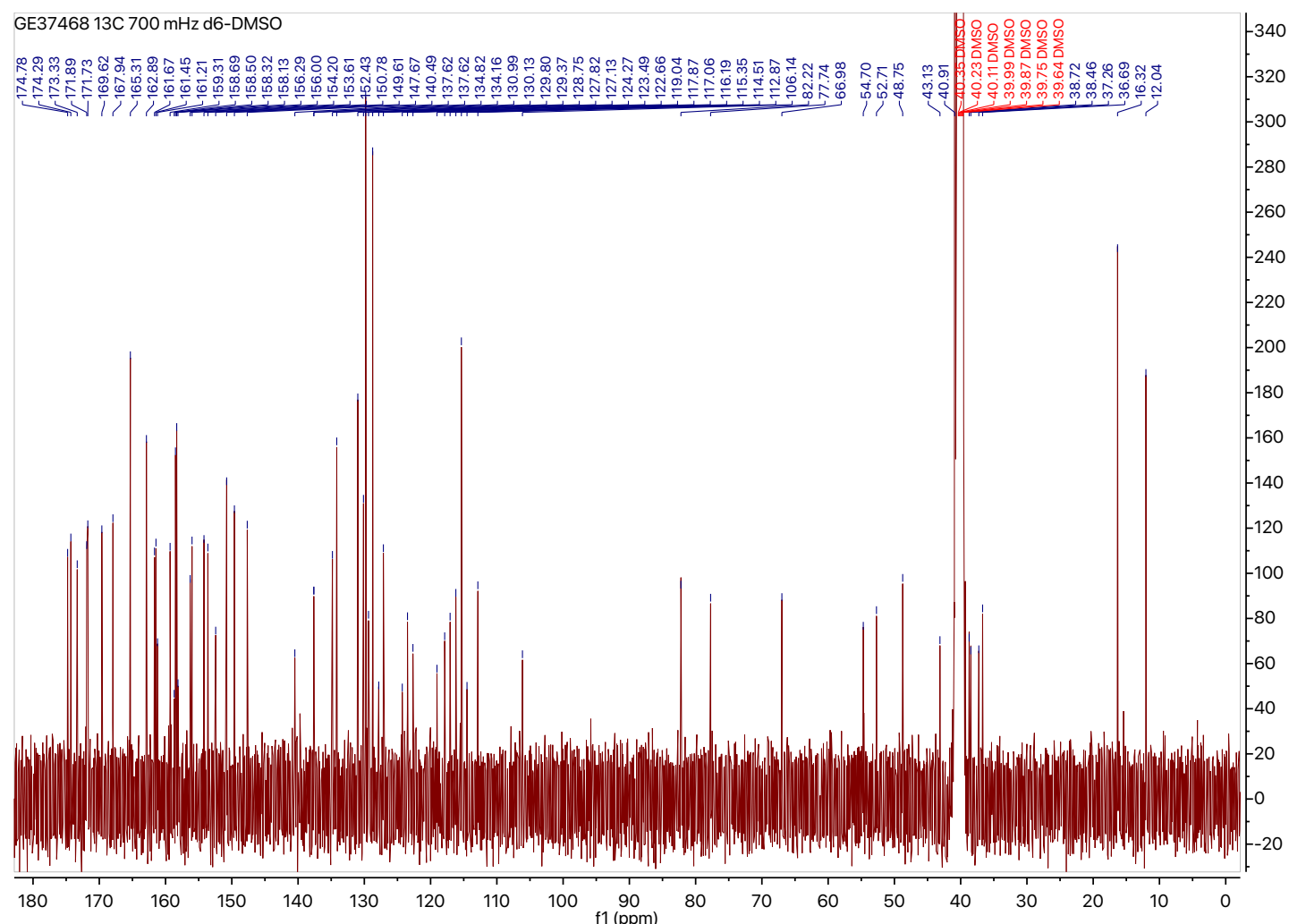


S.3.4 Thiocillin III, 2, Characterization: ${ }^{1} \mathrm{H}$ NMR $\left(600 \mathrm{MHz}, \mathrm{DMSO}-d_{6}\right) \delta 9.70(\mathrm{~s}, 1 \mathrm{H}), 9.63$ (s, $1 \mathrm{H}), 8.58(\mathrm{~d}, J=5.8 \mathrm{~Hz}, 1 \mathrm{H}), 8.49-8.44(\mathrm{~m}, 2 \mathrm{H}), 8.44-8.37$ (m, 3H), 8.34 (dq, $J=13.7,8.1$, $6.2 \mathrm{~Hz}, 2 \mathrm{H}), 8.26(\mathrm{~s}, 1 \mathrm{H}), 8.00(\mathrm{~s}, 1 \mathrm{H}), 7.57(\mathrm{~d}, J=8.0 \mathrm{~Hz}, 1 \mathrm{H}), 6.59(\mathrm{q}, J=7.0 \mathrm{~Hz}, 1 \mathrm{H}), 6.50(\mathrm{q}$, $J=6.9 \mathrm{~Hz}, 1 \mathrm{H}), 5.49(\mathrm{~d}, J=10.1 \mathrm{~Hz}, 1 \mathrm{H}), 5.09-5.01(\mathrm{~m}, 1 \mathrm{H}), 4.72(\mathrm{~d}, J=8.5 \mathrm{~Hz}, 1 \mathrm{H}), 4.53(\mathrm{~d}$, $J=7.3 \mathrm{~Hz}, 2 \mathrm{H}), 3.89$ (d, $J=5.7 \mathrm{~Hz}, 4 \mathrm{H}), 2.51$ (s, 3H), 2.09 (s, 3H), 1.73 (dd, $J=7.1,3.5 \mathrm{~Hz}, 5 \mathrm{H})$, $1.38(\mathrm{~d}, J=6.1 \mathrm{~Hz}, 2 \mathrm{H}), 1.29-1.19(\mathrm{~m}, 6 \mathrm{H}), 1.01(\mathrm{~d}, J=5.8 \mathrm{~Hz}, 3 \mathrm{H}){ }^{13} \mathbf{C}$ NMR $(151 \mathrm{MHz}$, DMSO) $\delta 205.84,170.89,169.73,169.05,168.80,168.36,167.27,164.96,164.89,164.80,163.60$, $161.85,160.96,160.42,160.24,159.75,159.17,158.93,158.70,158.47,153.53,153.00,151.53$, $150.78,150.31,150.27,150.15,149.87,149.24,148.97,148.75,141.39,130.68,129.78,129.48$, $128.85,126.29,126.11,125.97,125.21,122.18,121.21,119.11,117.35,115.41,113.46,71.86$, $71.68,68.87,67.50,57.62,57.17,57.12,50.00,40.79,40.29,40.15,40.01,39.88,39.74,39.60$, 39.46, 27.98, 27.93, 27.43, 26.34, 21.46, 21.42, 21.04, 20.78, 14.58, 14.19, 14.01. LC/MS: Expected Mass: $1158.2330 \mathrm{~m} / \mathrm{z}[\mathrm{M}+\mathrm{H}]^{+1}$, Observed Mass: $1158.2008 \mathrm{~m} / \mathrm{z}[\mathrm{M}+\mathrm{H}]^{+1}$

Analytical Trace: $\lambda-350 \mathrm{~nm}$

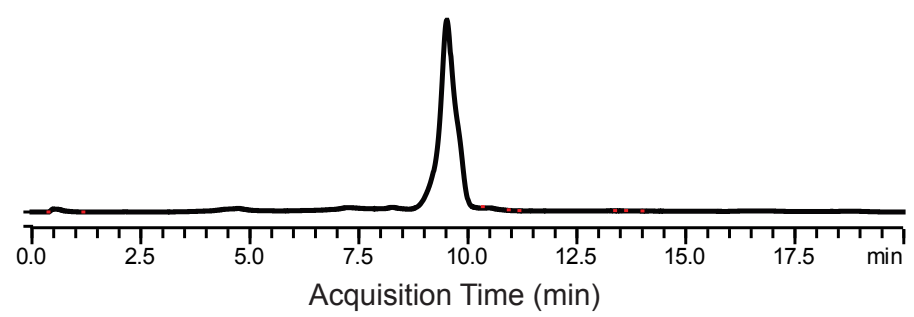


Thiocillin III, 2, ${ }^{1} \mathrm{H}$ NMR - 600 mHz, d6-DMSO

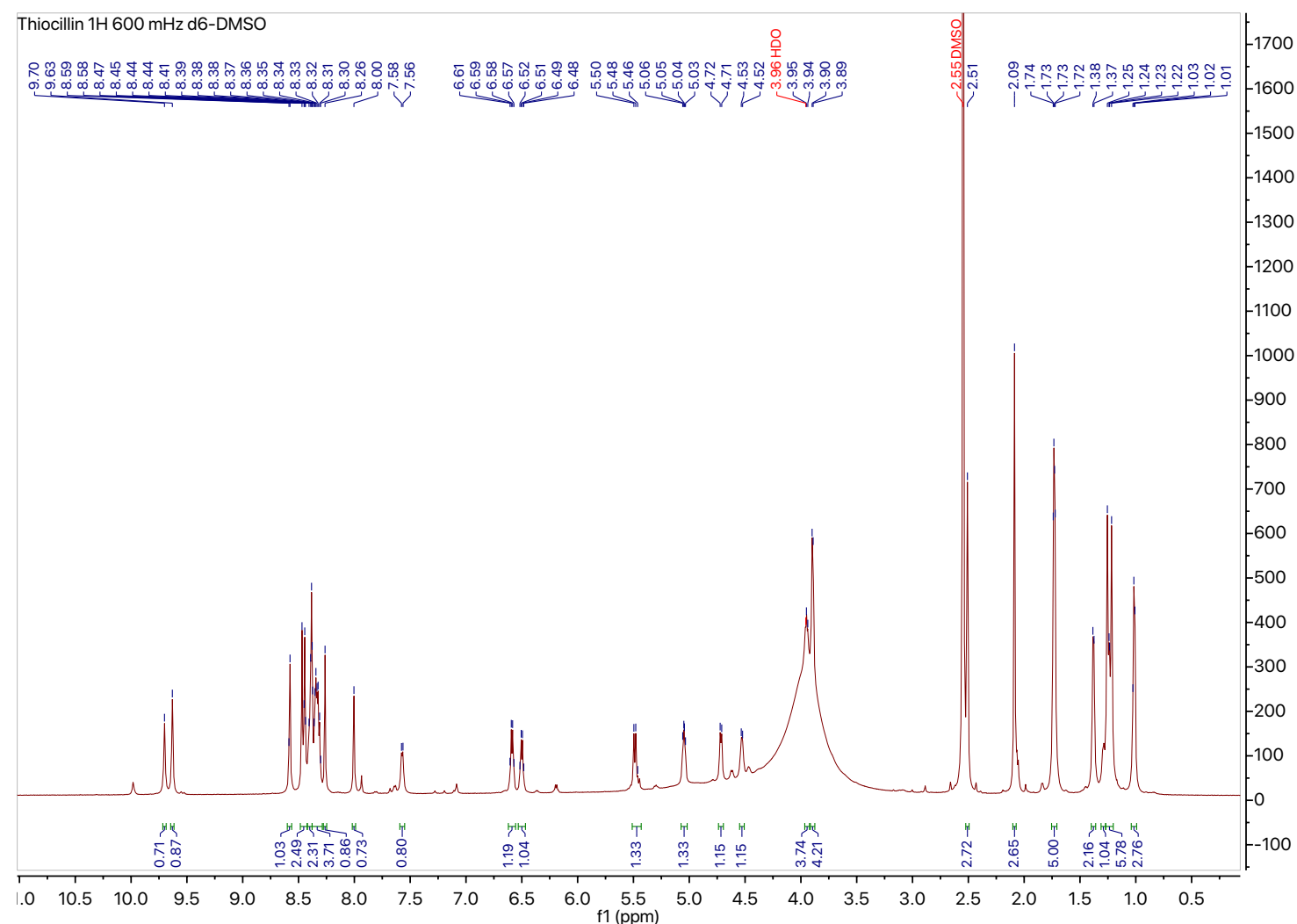

Thiocillin III, 2, ${ }^{13} \mathrm{C}$ NMR - $700 \mathrm{mHz}$, d6-DMSO

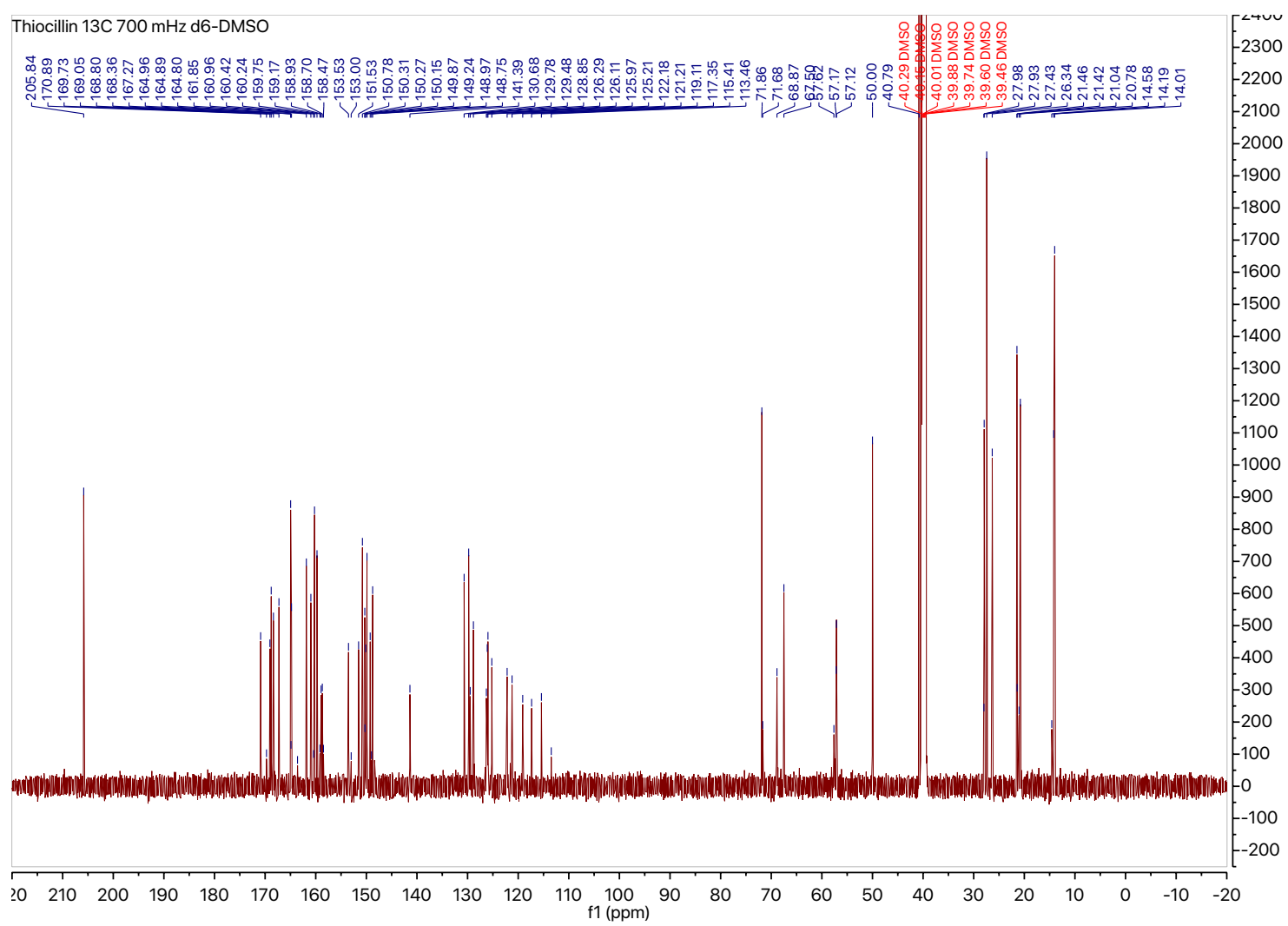


S.3.5 T4V, 10, Characterization: ${ }^{1} \mathrm{H}$ NMR $\left(600 \mathrm{MHz}, \mathrm{DMSO}-d_{6}\right) \delta 9.64(\mathrm{~s}, 1 \mathrm{H}), 8.59(\mathrm{~s}, 1 \mathrm{H})$, $8.48(\mathrm{~s}, 1 \mathrm{H}), 8.46(\mathrm{~s}, 1 \mathrm{H}), 8.42(\mathrm{~s}, 1 \mathrm{H}), 8.40(\mathrm{~s}, 1 \mathrm{H}), 8.39(\mathrm{~s}, 1 \mathrm{H}), 8.36(\mathrm{dd}, J=7.0,4.8 \mathrm{~Hz}, 2 \mathrm{H})$, $8.23(\mathrm{dd}, J=9.8,5.2 \mathrm{~Hz}, 2 \mathrm{H}), 7.98(\mathrm{~s}, 1 \mathrm{H}), 7.54(\mathrm{~d}, J=8.0 \mathrm{~Hz}, 2 \mathrm{H}), 6.58(\mathrm{q}, J=7.0 \mathrm{~Hz}, 2 \mathrm{H}), 5.49$ $(\mathrm{d}, J=9.9 \mathrm{~Hz}, 2 \mathrm{H}), 5.31(\mathrm{dd}, J=9.8,3.9 \mathrm{~Hz}, 2 \mathrm{H}), 5.26(\mathrm{dd}, J=9.2,4.2 \mathrm{~Hz}, 2 \mathrm{H}), 4.73-4.68(\mathrm{~m}$, 2H), $4.47(\mathrm{~s}, 1 \mathrm{H}), 3.88(\mathrm{~d}, J=5.8 \mathrm{~Hz}, 4 \mathrm{H}), 2.90(\mathrm{~s}, 3 \mathrm{H}), 2.28(\mathrm{~d}, J=8.6 \mathrm{~Hz}, 2 \mathrm{H}), 2.08(\mathrm{~s}, 3 \mathrm{H})$, $1.72(\mathrm{~d}, J=7.0 \mathrm{~Hz}, 3 \mathrm{H}), 1.47(\mathrm{~s}, 1 \mathrm{H}), 1.34(\mathrm{~d}, J=6.2 \mathrm{~Hz}, 3 \mathrm{H}), 1.27(\mathrm{~s}, 4 \mathrm{H}), 1.23(\mathrm{~s}, 6 \mathrm{H}), 1.03(\mathrm{~d}$, $J=6.2 \mathrm{~Hz}, 3 \mathrm{H}), 0.97(\mathrm{~d}, J=6.6 \mathrm{~Hz}, 3 \mathrm{H}), 0.85(\mathrm{~d}, J=6.7 \mathrm{~Hz}, 3 \mathrm{H}) .{ }^{13} \mathbf{C}$ NMR $(151 \mathrm{MHz}, \mathrm{DMSO})$ $\delta 205.87,172.41,170.75,169.78,168.83,168.76,164.94,164.69,161.81,160.97,160.18,160.08$, $159.74,154.21,152.05,150.80,150.58,150.05,149.90,149.01,147.82,141.14,130.71,129.74$, $129.15,128.68,126.68,126.55,126.34,126.01,122.22,120.69,119.45,76.11,71.53,70.22$, 68.05, 66.91, 57.73, 56.53, 56.09, 56.02, 55.68, 50.00, 33.39, 29.51, 27.87, 27.44, 26.54, 20.02, 19.62, 16.79, 16.06, 14.01. LC/MS: Expected Mass: $1188.2435 \mathrm{~m} / \mathrm{z}[\mathrm{M}+\mathrm{H}]^{+1}$, Observed Mass: $1188.2477 \mathrm{~m} / \mathrm{z}[\mathrm{M}+\mathrm{H}]^{+1}$

Analytical Trace: $\lambda-350 \mathrm{~nm}$

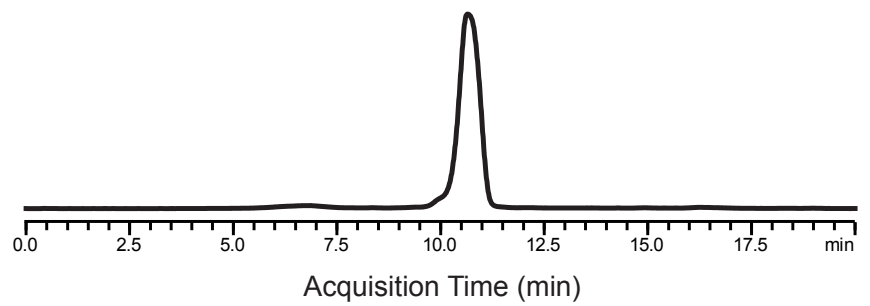


T4V, 10, ${ }^{1} \mathrm{H}$ NMR - $600 \mathrm{mHz}$, d6-DMSO

T4V 1H 600 mHz d6-DMSO

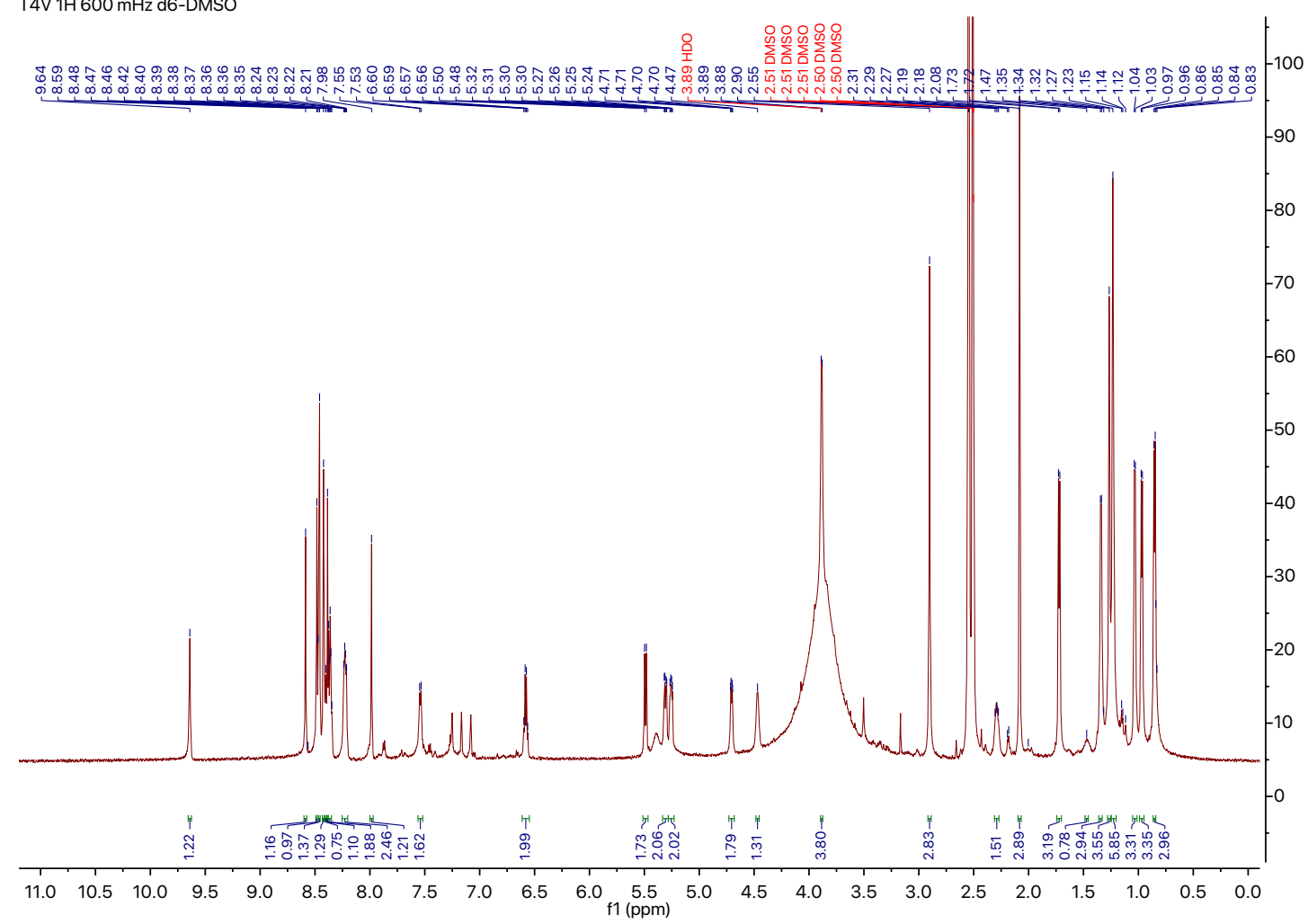

T4V, 10, ${ }^{13} \mathrm{C}$ NMR - $125 \mathrm{mHz}$, d6-DMSO

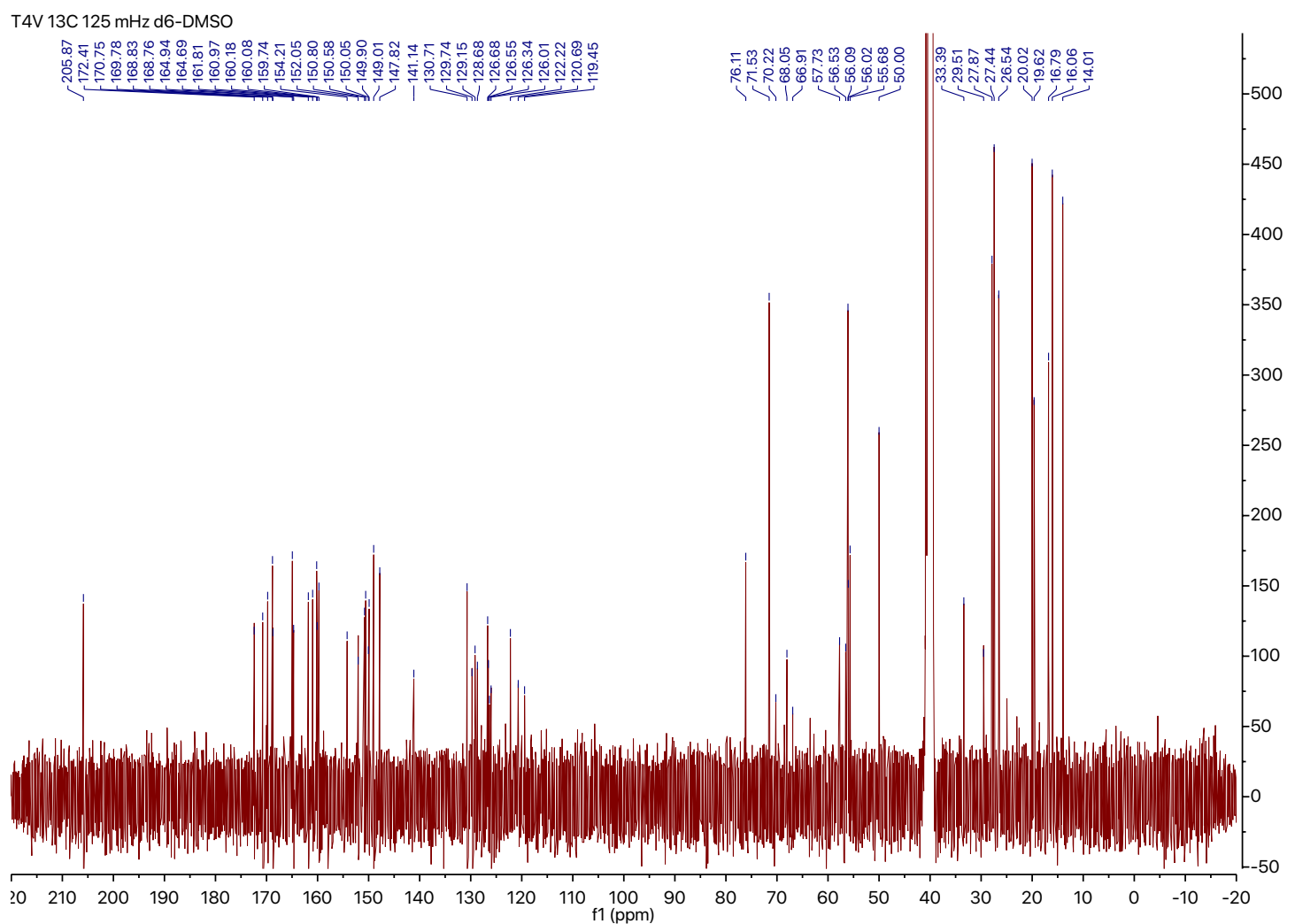




\section{S.3.6 Nosiheptide, 6, Characterization}

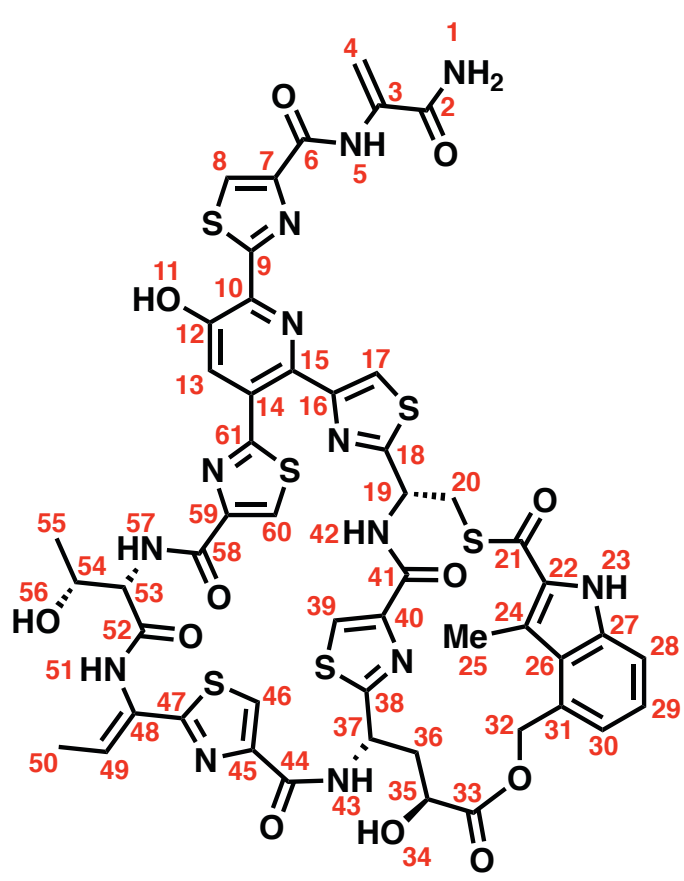

\begin{tabular}{|c|c|c|c|}
\hline${ }^{13} \mathrm{C}$ NMR (ppm) & Atom \# & ${ }^{13} \mathrm{C}$ NMR (ppm) & Atom \# \\
\hline 181.99 & 21 & 129.50 & 48 \\
\hline 173.03 & 33 & 128.90 & 49 \\
\hline 169.91 & 38 & 127.53 & 13 \\
\hline 168.95 & 18 & 127.45 & 8 \\
\hline 168.20 & 52 & 126.43 & 60 \\
\hline 166.97 & 9 & 125.61 & 39 \\
\hline 166.31 & 47 & 125.07 & 29 \\
\hline 165.07 & 2 & 124.94 & 26 \\
\hline 164.06 & 61 & 124.79 & 46 \\
\hline 159.67 & 41 & 123.45 & 30 \\
\hline 158.43 & 6 & 120.42 & 17 \\
\hline 157.94 & 58 & 118.60 & 24 \\
\hline 157.69 & 44 & 115.86 & 28 \\
\hline 152.88 & 16 & 103.82 & 4 \\
\hline 150.71 & 12 & 67.01 & 54 \\
\hline 149.91 & 59 & 66.12 & 35 \\
\hline 149.75 & 7 & 66.12 & 37 \\
\hline 148.89 & 40 & 56.78 & 53 \\
\hline 147.76 & 45 & 48.89 & 19 \\
\hline 142.55 & 15 & 45.09 & 32 \\
\hline 137.68 & 27 & 39.01 & 36 \\
\hline 135.37 & 10 & 29.74 & 20 \\
\hline 134.43 & 3 & 18.77 & 55 \\
\hline 130.74 & 22 & 13.70 & 50 \\
\hline 129.99 & 14 & 12.64 & 25 \\
\hline
\end{tabular}

\begin{tabular}{|c|c|c|c|c|c|}
\hline${ }^{1} \mathrm{H}$ NMR (ppm, mult, J-value, \#) & cosy & HSQC & HMBC & TOCSY & Atom \# \\
\hline $1.20(\mathrm{~d}, J=6.8 \mathrm{~Hz}, 3 \mathrm{H})$ & & 18.77 & $29.74,48.89$ & & 55 \\
\hline $1.70(\mathrm{~d}, J=6.9 \mathrm{~Hz}, 3 \mathrm{H})$ & 6.46 & 14.25 & $129.8,166.31$ & 6.44 & 50 \\
\hline 2.53 (broad, $1 \mathrm{H})$ & 4.07 & 39.01 & & $5.74,8.50,4.08$ & 36 \\
\hline $2.61(\mathrm{~s}, 3 \mathrm{H}$, broad $)$ & & 12.64 & 40.25 & & 25 \\
\hline $3.51(\mathrm{~m}, 1 \mathrm{H})$ & $3.81,5.84$ & 29.74 & 182.65 & $5.80,7.80$ & 20 \\
\hline $3.81(\mathrm{dd}, J=14.2,5.1 \mathrm{~Hz}, 1 \mathrm{H})$ & 3.51 & 29.74 & $169.4,181.99$ & $5.80,7.80$ & 20 \\
\hline $4.07(\mathrm{~d}, J=7.3 \mathrm{~Hz}, 1 \mathrm{H})$ & 2.51 & 66.98 & & $5.64,5.52$ & 35 \\
\hline $4.56(\mathrm{~s}, 1 \mathrm{H})$ & & 57.17 & & 7.53 & 53 \\
\hline $5.55(\mathrm{t}, J=10.6 \mathrm{~Hz}, 2 \mathrm{H}$, broad $)$ & $8.5,2.49,5.56$ & 45.62 & & $2.54,4.07,8.41$ & 32 \\
\hline $5.67(\mathrm{~d}, J=7.1 \mathrm{~Hz}, 1 \mathrm{H})$ & & & $37.75,66.97$ & $4.02,6.27$ & 37 \\
\hline $5.74(\mathrm{~s}, 1 \mathrm{H})$ & $10.1,6.34$ & 104.30 & $134.43,165.5$ & 6.35 & 4 \\
\hline $5.84(\mathrm{~d}, J=5.9 \mathrm{~Hz}, 1 \mathrm{H})$ & $7.83,3.87,3.54$ & 48.89 & & $3.53,3.86,7.83$ & 19 \\
\hline $6.34(\mathrm{~s}, 1 \mathrm{H})$ & 5.74 & 104.31 & $134.43,165.07$ & 5.74 & 4 \\
\hline $6.44(\mathrm{q}, J=6.9 \mathrm{~Hz}, 1 \mathrm{H})$ & 1.72 & 128.9 & $129.9,166.8$ & 1.70 & 49 \\
\hline $7.11(\mathrm{~d}, J=7.0 \mathrm{~Hz}, 1 \mathrm{H})$ & 7.32 & 123.94 & $66.12,115.85,125.07$ & 7.58 & 30 \\
\hline $7.26(\mathrm{t}, J=7.6 \mathrm{~Hz}, 1 \mathrm{H})$ & $7.53,7.15$ & 125.42 & $129.91,138.14,124.07$ & & 29 \\
\hline $7.53(\mathrm{~s}, 1 \mathrm{H}, \mathrm{OH})$ & & & & 4.56 & 56 \\
\hline $7.58(\mathrm{~s}, 1 \mathrm{H})$ & & 114.98 & 134.9 & 7.11 & 28 \\
\hline $7.67(\mathrm{~s}, 1 \mathrm{H}, \mathrm{NH})$ & & & & 8.03 & 23 \\
\hline $7.80(\mathrm{~d}, J=9.6 \mathrm{~Hz}, 1 \mathrm{H})$ & & & & $3.44,3.81,5.78$ & 42 \\
\hline $7.83(\mathrm{~s}, 1 \mathrm{H})$ & 5.84 & 128.01 & $135.9,142.9,151.3,164.5$ & & 13 \\
\hline $7.90(\mathrm{~s}, 1 \mathrm{H})$ & & 120.88 & $153.4,169.4$ & & 17 \\
\hline $8.05(\mathrm{~s}, 1 \mathrm{H}, \mathrm{OH})$ & & & & 5.67 & 34 \\
\hline $8.15(\mathrm{~s}, 1 \mathrm{H})$ & & 125.31 & $148.21,166.8$ & & 46 \\
\hline $8.28(\mathrm{~s}, 1 \mathrm{H})$ & & 126.10 & $149.97,170.60$ & $1.62,2.46,3.99,5.52$ & 39 \\
\hline $8.50(\mathrm{~s}, 1 \mathrm{H}, \mathrm{NH})$ & 5.58 & & & & 57 \\
\hline $8.58(\mathrm{~s}, 1 \mathrm{H})$ & & 127.93 & $150.18,167.4$ & & 8 \\
\hline $8.64(\mathrm{~s}, 1 \mathrm{H})$ & & 126.88 & & & 60 \\
\hline $9.39(\mathrm{~s}, 1 \mathrm{H}, \mathrm{NH})$ & & & & & 51 \\
\hline $10.07(\mathrm{~s}, 1 \mathrm{H}, \mathrm{NH})$ & 5.77 & & $104.31,158.9,165.5$ & & 5 \\
\hline 11.18 (broad, $1 \mathrm{H}, \mathrm{OH})$ & & & & & 11 \\
\hline
\end{tabular}


LC/MS Analysis: Expected Mass $1222.1562\left[\mathrm{M}-\mathrm{H}+\mathrm{H}_{2} \mathrm{O}\right]^{+1}$, Observed Mass: 1222.1509 [M$\left.\mathrm{H}+\mathrm{H}_{2} \mathrm{O}\right]^{+1}$

Analytical Trace: $\lambda-350 \mathrm{~nm}$

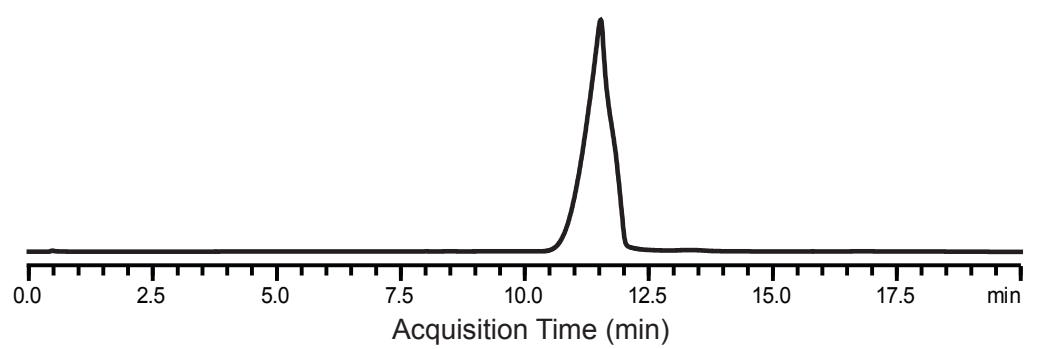


Nosiheptide, 6, ${ }^{1} \mathrm{H}$ NMR - $500 \mathrm{mHz}$, d6-DMSO

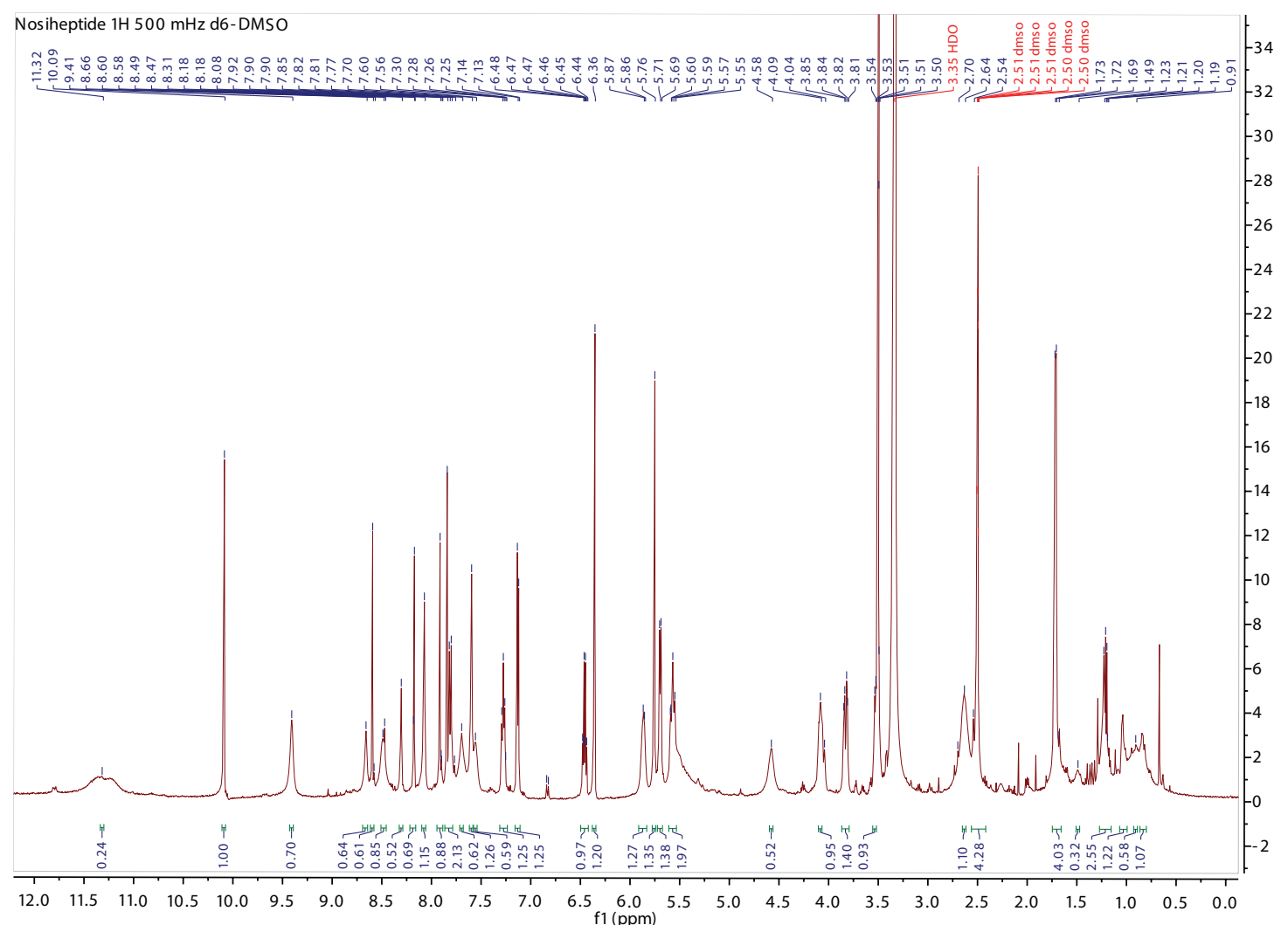

Nosiheptide, 6, ${ }^{13} \mathrm{C}$ NMR - $500 \mathrm{mHz}$, d6-DMSO

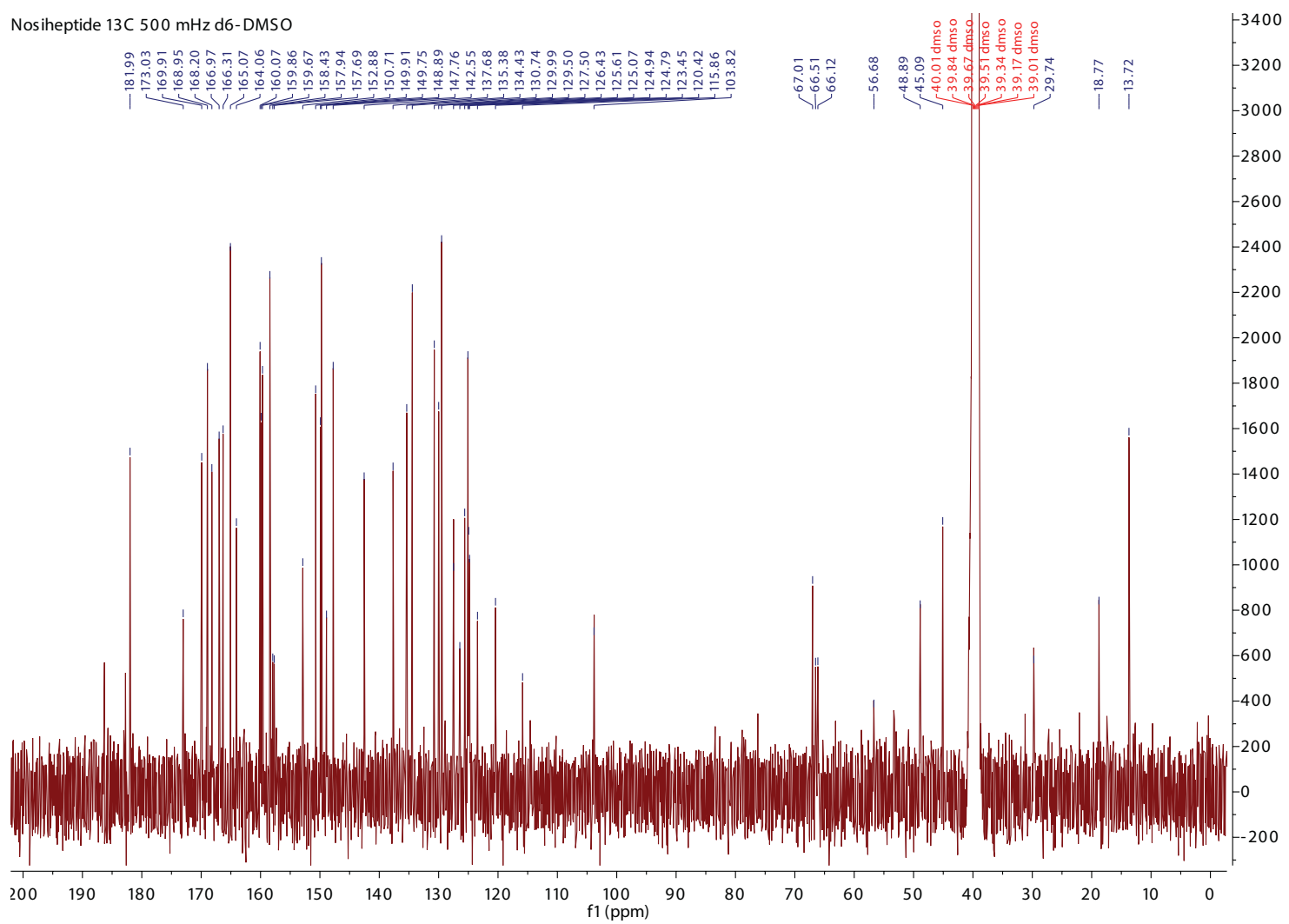


Nosiheptide, 6, COSY - $500 \mathrm{mHz}$, d6-DMSO

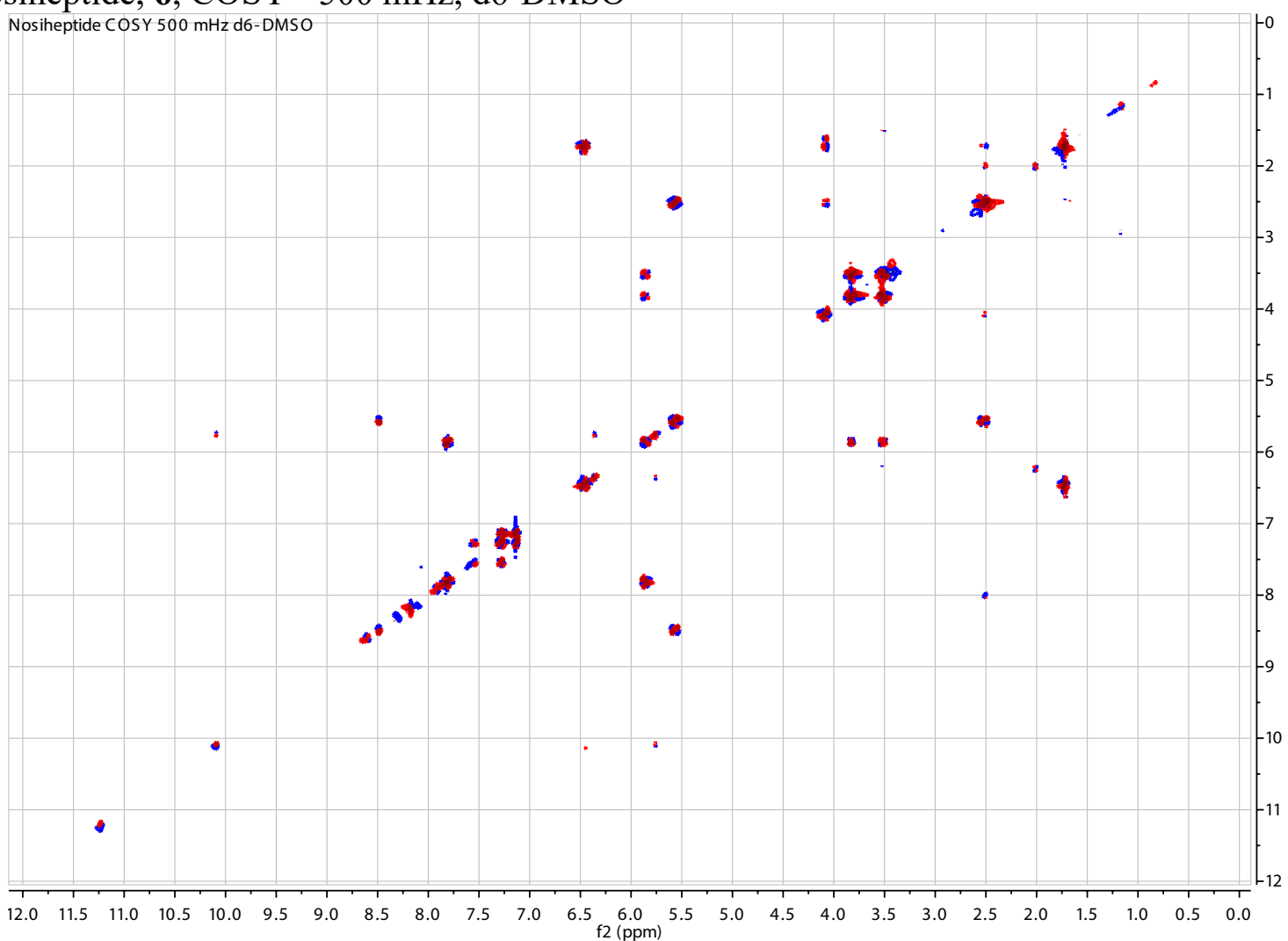

Nosiheptide, 6, HMBC - 500 mHz, d6-DMSO

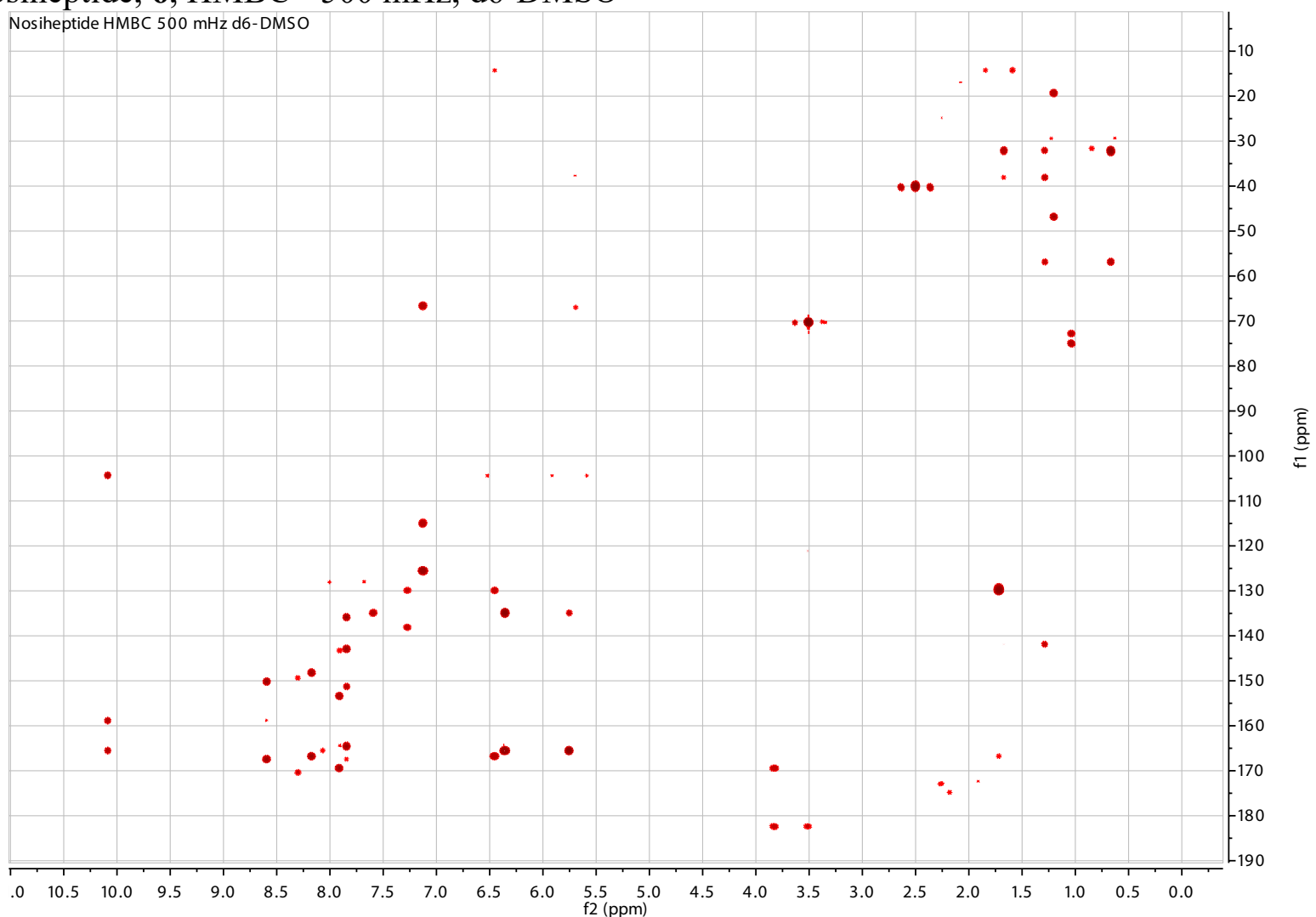


Nosiheptide, 6, HSQC - $500 \mathrm{mHz}$, d6-DMSO

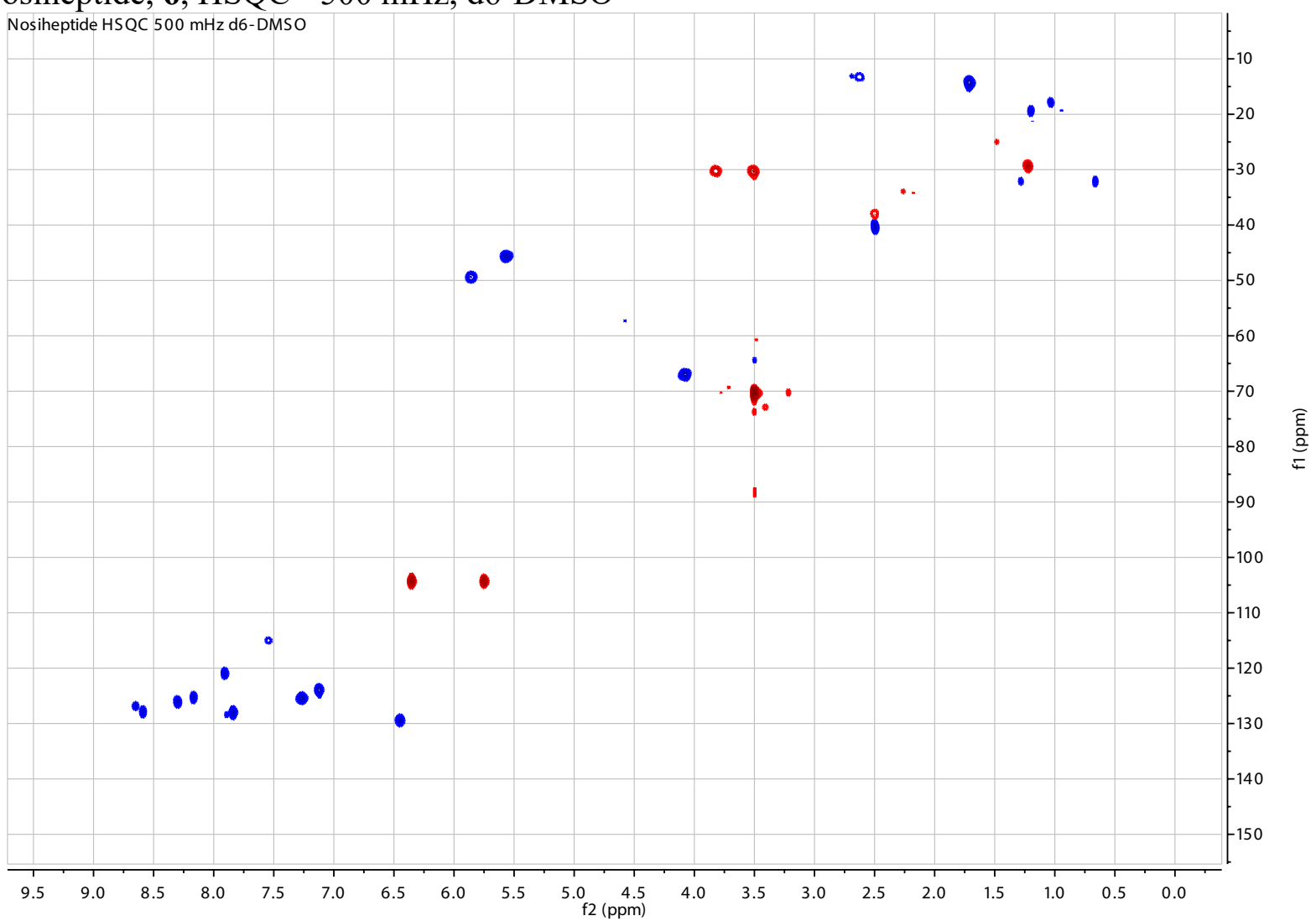

Nosiheptide, 6, TOCSY - $500 \mathrm{mHz}$, d6-DMSO

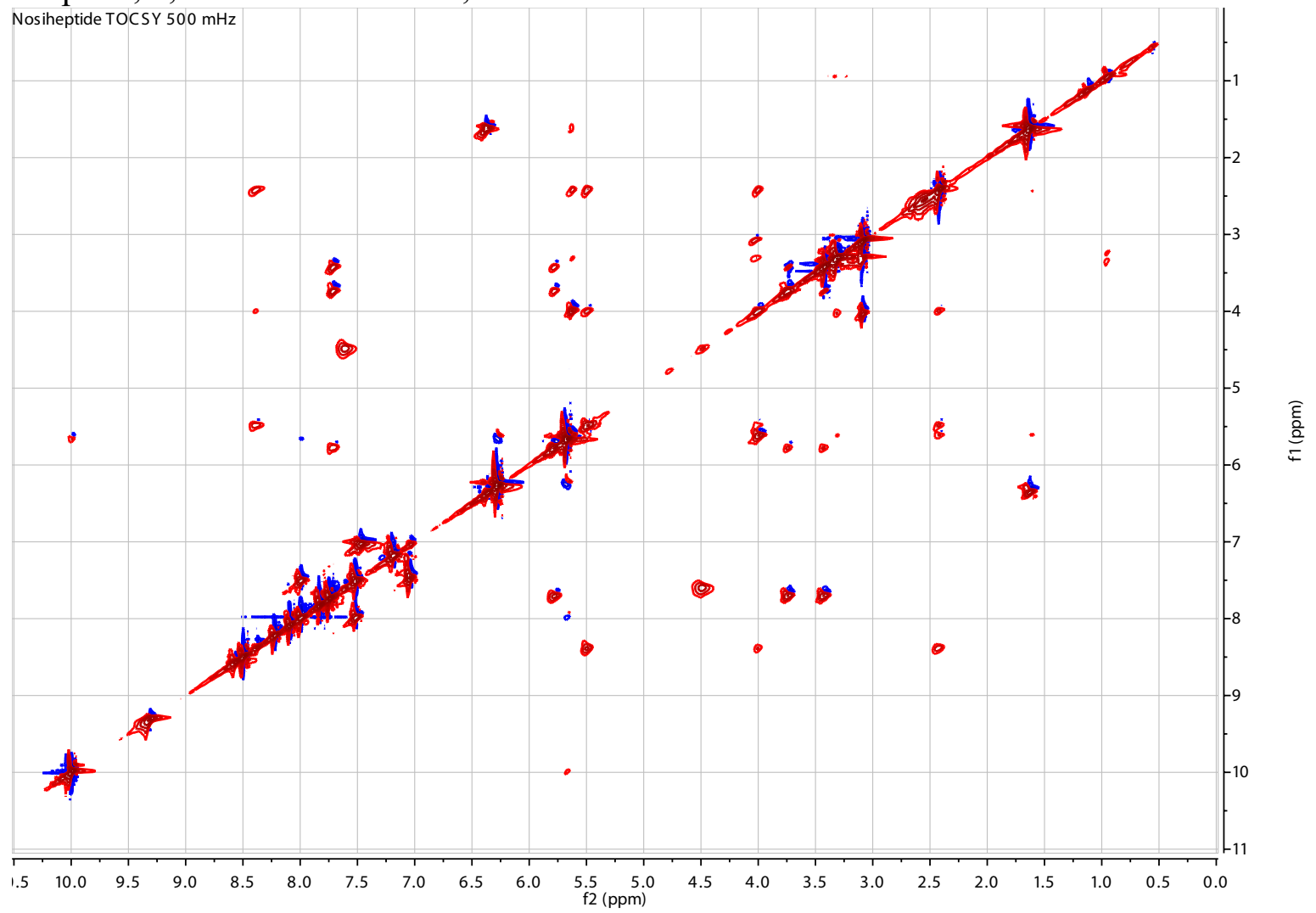




\section{S.3.7 KEB-01, 8, Characterization}

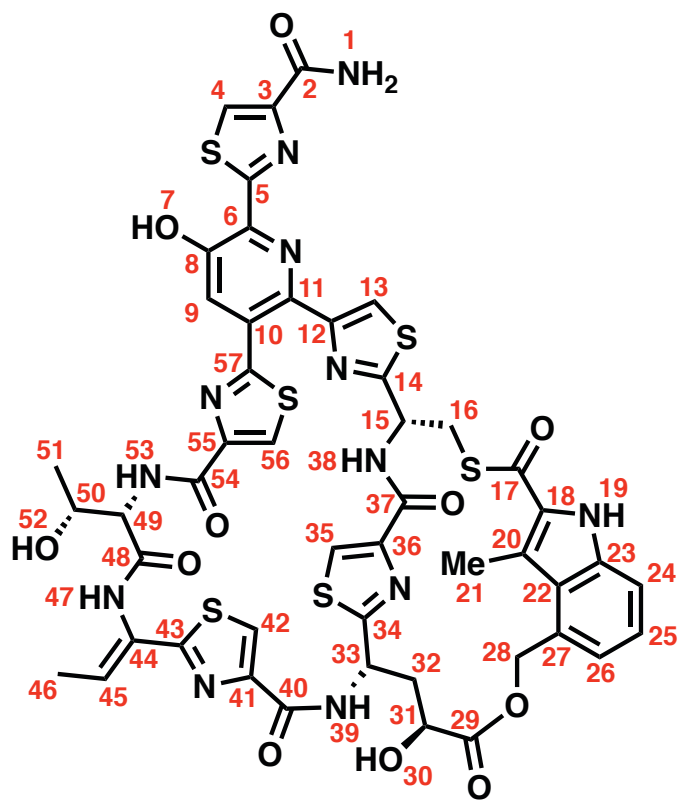

\begin{tabular}{|c|c|c|c|}
\hline${ }^{13} \mathrm{C}$ NMR (ppm) & Atom \# & ${ }^{13} \mathrm{C}$ NMR (ppm) & Atom \# \\
\hline 182.2 & 17 & 130.4 & 45 \\
\hline 173.2 & 29 & 129.7 & 44 \\
\hline 170.2 & 34 & 128.1 & 9 \\
\hline 169.3 & 14 & 127.0 & 4 \\
\hline 168.3 & 48 & 126.7 & 56 \\
\hline 168.1 & 5 & 125.9 & 35 \\
\hline 166.6 & 43 & 125.3 & 25 \\
\hline 164.2 & 11 & 124.9 & 42 \\
\hline 161.7 & 57 & 124.8 & 24 \\
\hline 160.2 & 2 & 123.7 & 26 \\
\hline 160.1 & 37 & 120.5 & 13 \\
\hline 159.8 & 40 & 67.1 & 31 \\
\hline 158.1 & 54 & 66.7 & 49 \\
\hline 157.9 & 36 & 66.3 & 33 \\
\hline 153.1 & 12 & 58.0 & 50 \\
\hline 151.2 & 8 & 49.2 & 15 \\
\hline 150.6 & 55 & 45.3 & 28 \\
\hline 150.1 & 3 & 41.5 & 21 \\
\hline 147.9 & 41 & 29.9 & 16 \\
\hline 143.0 & 10 & 18.9 & 32 \\
\hline 137.9 & 23 & 14.0 & 46 \\
\hline 134.8 & 6 & 11.2 & 51 \\
\hline 130.9 & 18 & & \\
\hline
\end{tabular}

\begin{tabular}{|c|c|c|c|c|c|}
\hline${ }^{1}$ H NMR (ppm, mult, J-value, \#) & cosy & HSQC & HMBC & TOCSY & Atom \# \\
\hline $1.14(\mathrm{t}, J=7.3 \mathrm{~Hz}, 2 \mathrm{H})$ & 2.96 & 11.2 & 41.5 & $8.43,2.91$ & 51 \\
\hline $1.70(\mathrm{~d}, J=6.9 \mathrm{~Hz}, 3 \mathrm{H})$ & 6.43 & 14.0 & 129.7 & 6.45 & 46 \\
\hline $2.54(\mathrm{~s}, 3 \mathrm{H})$ & & 41.5 & 150.1 & 8.43 & 21 \\
\hline $2.65(\mathrm{~m}, 2 \mathrm{H}, \mathrm{broad})$ & & & & & 32 \\
\hline $2.93(\mathrm{~m}, 1 \mathrm{H})$ & $1.17,8.44$ & & & $1.16,8.43$ & 50 \\
\hline $3.50(\mathrm{dd}, J=14.2,5.7 \mathrm{~Hz}, 1 \mathrm{H})$ & 3.83 & 29.9 & 182.2 & $5.87,7.77$ & 16 \\
\hline $3.81(\mathrm{dd}, J=13.9,5.0 \mathrm{~Hz}, 1 \mathrm{H})$ & $3.54,5.85$ & 29.9 & 182.2 & $5.87,7.77$ & 16 \\
\hline $4.06(\mathrm{~m}, 1 \mathrm{H})$ & & 67.1 & & $1.67,2.49,5.56,8.44$ & 31 \\
\hline $4.55(\mathrm{~s}, 1 \mathrm{H})$ & & 66.7 & & 7.67 & 49 \\
\hline $5.54(\mathrm{~d}, J=11.3 \mathrm{~Hz}, 1 \mathrm{H})$ & 2.55 & 45.3 & & & $28 \mathrm{a} / \mathrm{b}$ \\
\hline $5.55(\mathrm{~d}, J=11.3 \mathrm{~Hz}, 1 \mathrm{H})$ & 2.55 & 45.3 & & & $28 \mathrm{a} / \mathrm{b}$ \\
\hline $5.67(\mathrm{~d}, J=7.1 \mathrm{~Hz}, 1 \mathrm{H})$ & & 66.3 & & $1.67,2.51,4.09,8.44$ & 33 \\
\hline $5.85(\mathrm{~s}, 1 \mathrm{H})$ & $7.77,3.80$ & 49.2 & & $3.84,7.77$ & 15 \\
\hline $6.44(\mathrm{q}, J=6.8 \mathrm{~Hz}, 1 \mathrm{H})$ & 1.71 & 129.7 & $128.3,166.6$ & 1.71 & 45 \\
\hline $7.11(\mathrm{~d}, J=7.0 \mathrm{~Hz}, 1 \mathrm{H})$ & 7.29 & 123.7 & $66.10,114.6,125.3$ & 7.53 & 26 \\
\hline $7.26(\mathrm{t}, J=7.7 \mathrm{~Hz}, 1 \mathrm{H})$ & $7.13,7.56$ & 125.3 & $123.92,130.01,138.23$ & & 25 \\
\hline $7.53(\mathrm{~s}, 1 \mathrm{H})$ & 7.29 & & & 7.13 & 24 \\
\hline 7.63 (broad, $1 \mathrm{H}, \mathrm{NH}$ ) & & & & 8.02 & 19 \\
\hline $7.67(\mathrm{~s}, 1 \mathrm{H}, \mathrm{NH})$ & 8.57 & & 151.3 & & 53 \\
\hline $7.77(\mathrm{~d}, J=5.7 \mathrm{~Hz}, 1 \mathrm{H}, \mathrm{NH})$ & 5.85 & & & $3.82,5.88$ & 38 \\
\hline $7.88(\mathrm{~s}, 1 \mathrm{H})$ & & 120.5 & $153.6,169.5$ & & 13 \\
\hline $7.89(\mathrm{~s}, 1 \mathrm{H})$ & & 128.1 & $134.8,143.5,150.9,163.9$ & & 9 \\
\hline $8.16(\mathrm{~s}, 1 \mathrm{H})$ & & 125.0 & $148.4,166.9$ & & 42 \\
\hline $8.29(\mathrm{~s}, 1 \mathrm{H})$ & & 125.9 & $151.4,168.42$ & & 35 \\
\hline 8.42 (broad, $1 \mathrm{H}, \mathrm{NH})$ & & & & & 39 \\
\hline $8.45(\mathrm{~s}, 1 \mathrm{H})$ & & 127.0 & $150.9,168.4$ & & 4 \\
\hline $8.55(\mathrm{~s}, 1 \mathrm{H}, \mathrm{NH})$ & 7.69 & & & 7.74 & $1 \mathrm{~b}$ \\
\hline $8.65(\mathrm{~s}, 1 \mathrm{H})$ & & & & & 56 \\
\hline $9.38(\mathrm{~s}, 1 \mathrm{H}, \mathrm{NH})$ & & & & & 47 \\
\hline $10.80(\mathrm{~s}, 1 \mathrm{H}, \mathrm{OH})$ & & & $128.1,134.8,151.2$ & & 7 \\
\hline
\end{tabular}


LC/MS Analysis: Expected Mass: $1153.1347 \mathrm{~m} / \mathrm{z}\left[\mathrm{M}-\mathrm{H}+\mathrm{H}_{2} \mathrm{O}\right]^{+1}$, Observed Mass: 1153.1323 $\mathrm{m} / \mathrm{z}\left[\mathrm{M}-\mathrm{H}+\mathrm{H}_{2} \mathrm{O}\right]^{+1}$

Analytical Trace: $\lambda-350 \mathrm{~nm}$

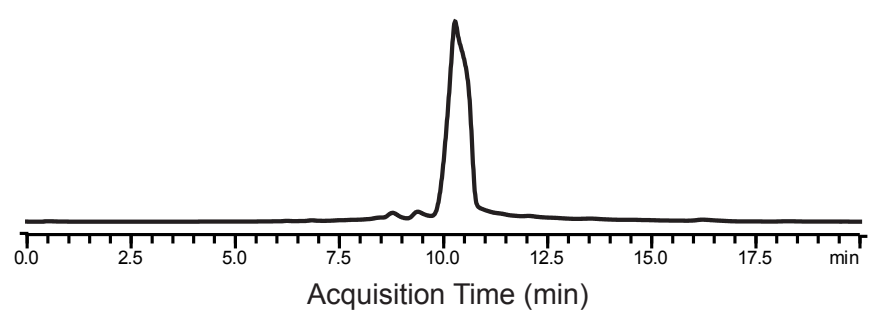




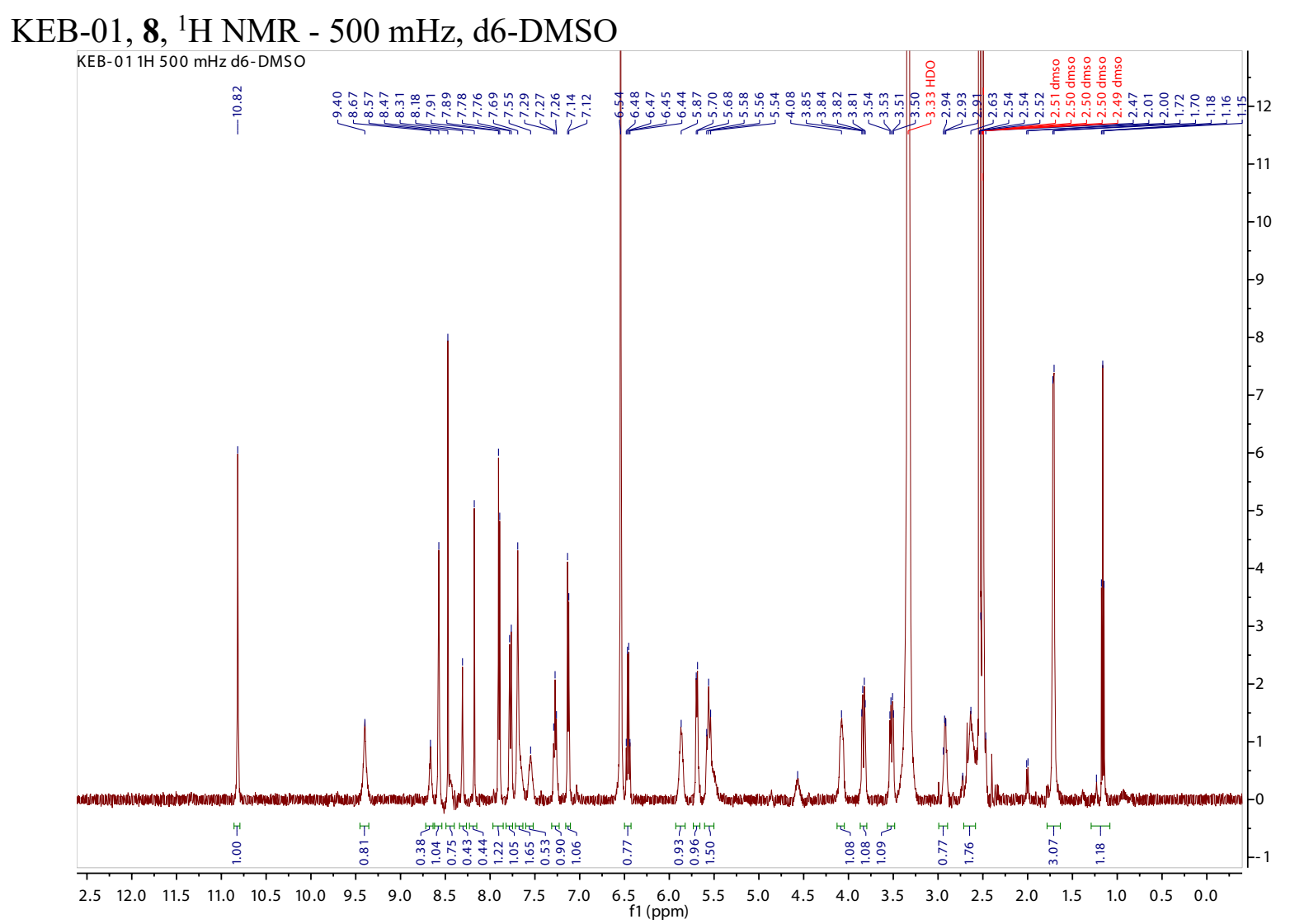

KEB-01, 8, ${ }^{13} \mathrm{C}$ NMR - 500 mHz, d6-DMSO

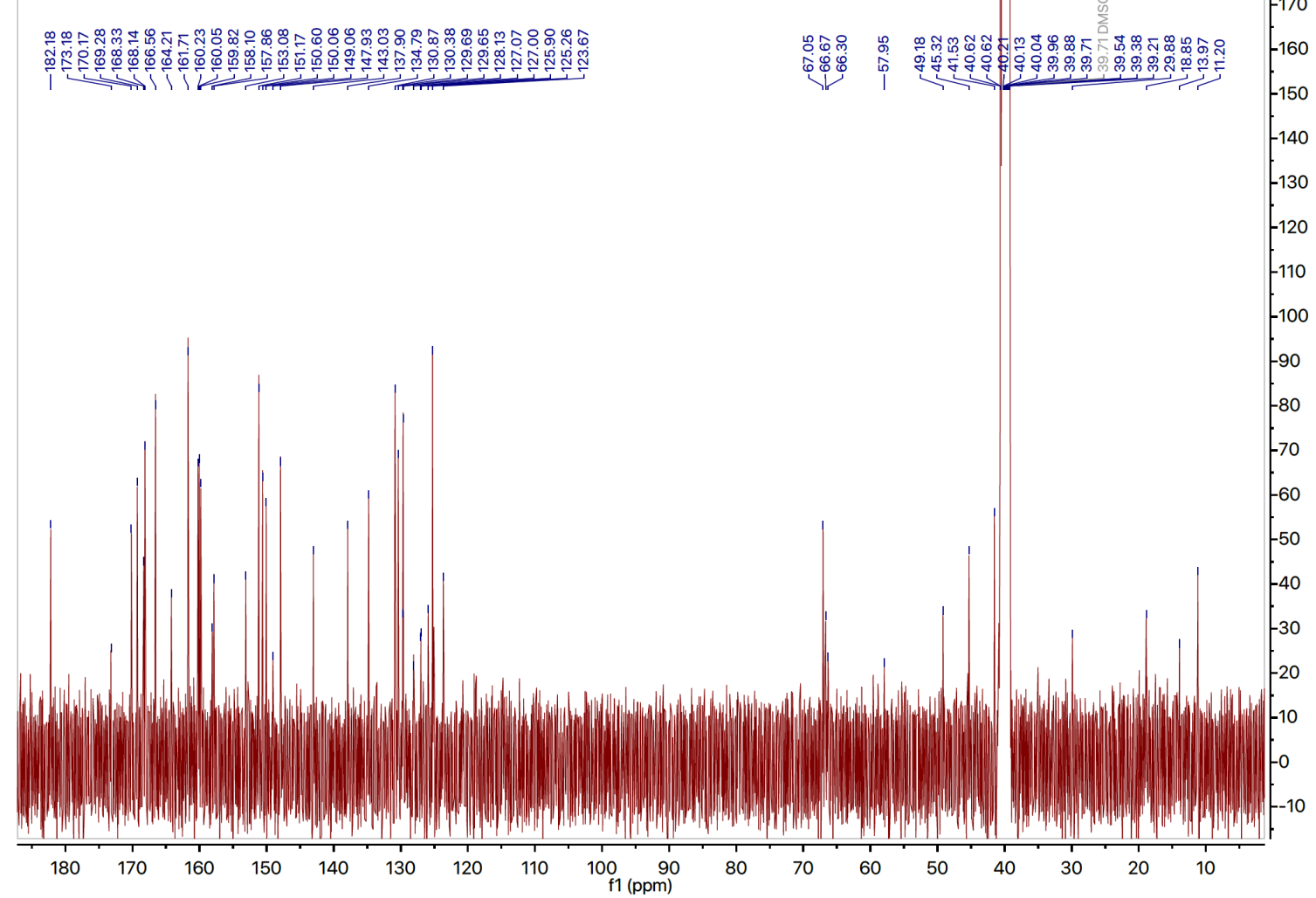


KEB-01, 8, COSY - $500 \mathrm{mHz}$, d6-DMSO

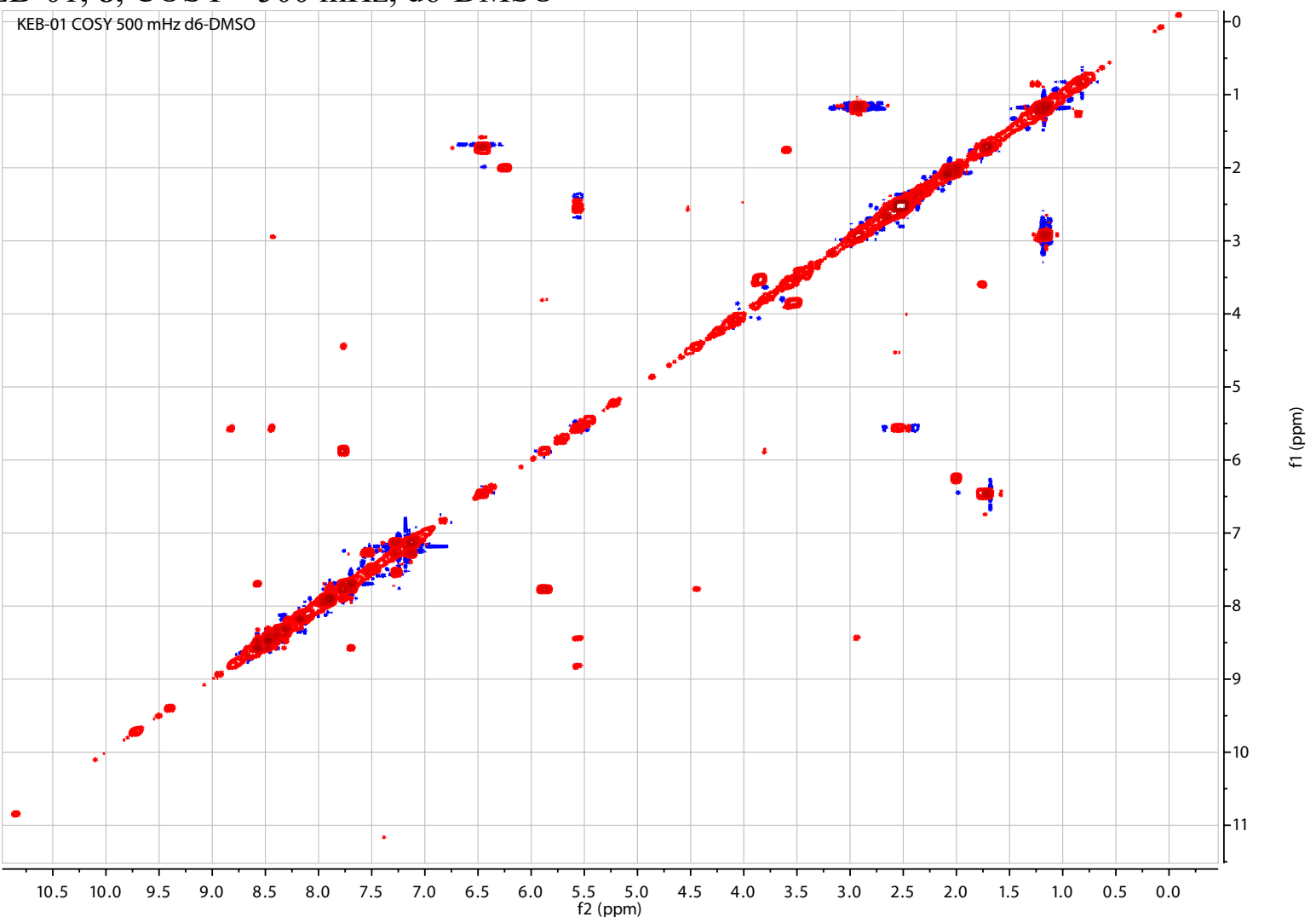

KEB-01, 6, HMBC - 500 mHz, d6-DMSO

KEB-01 HMBC $500 \mathrm{mHz}$ d6-DMSO

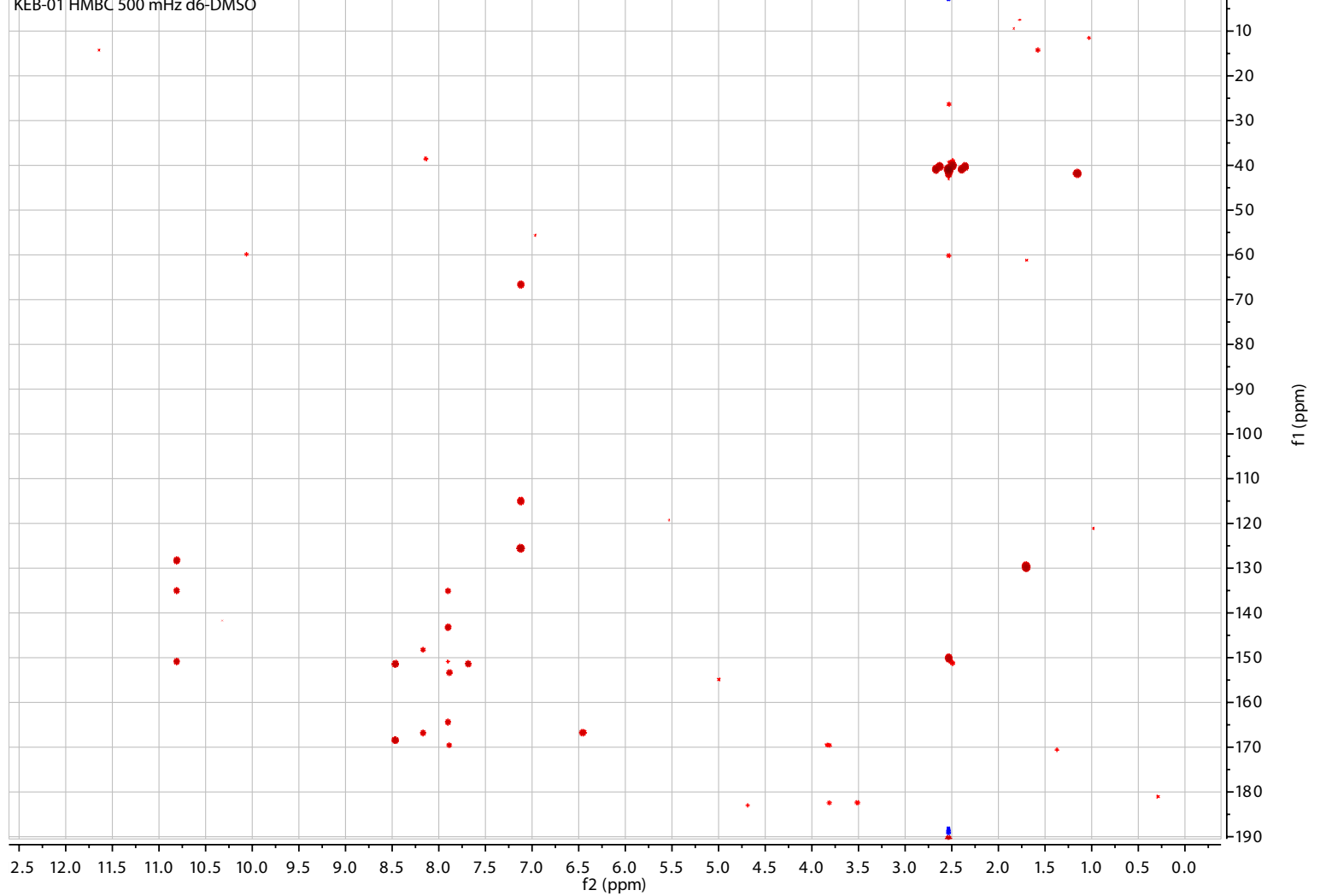


KEB-01, 8, HSQC - 500 mHz, d6-DMSO

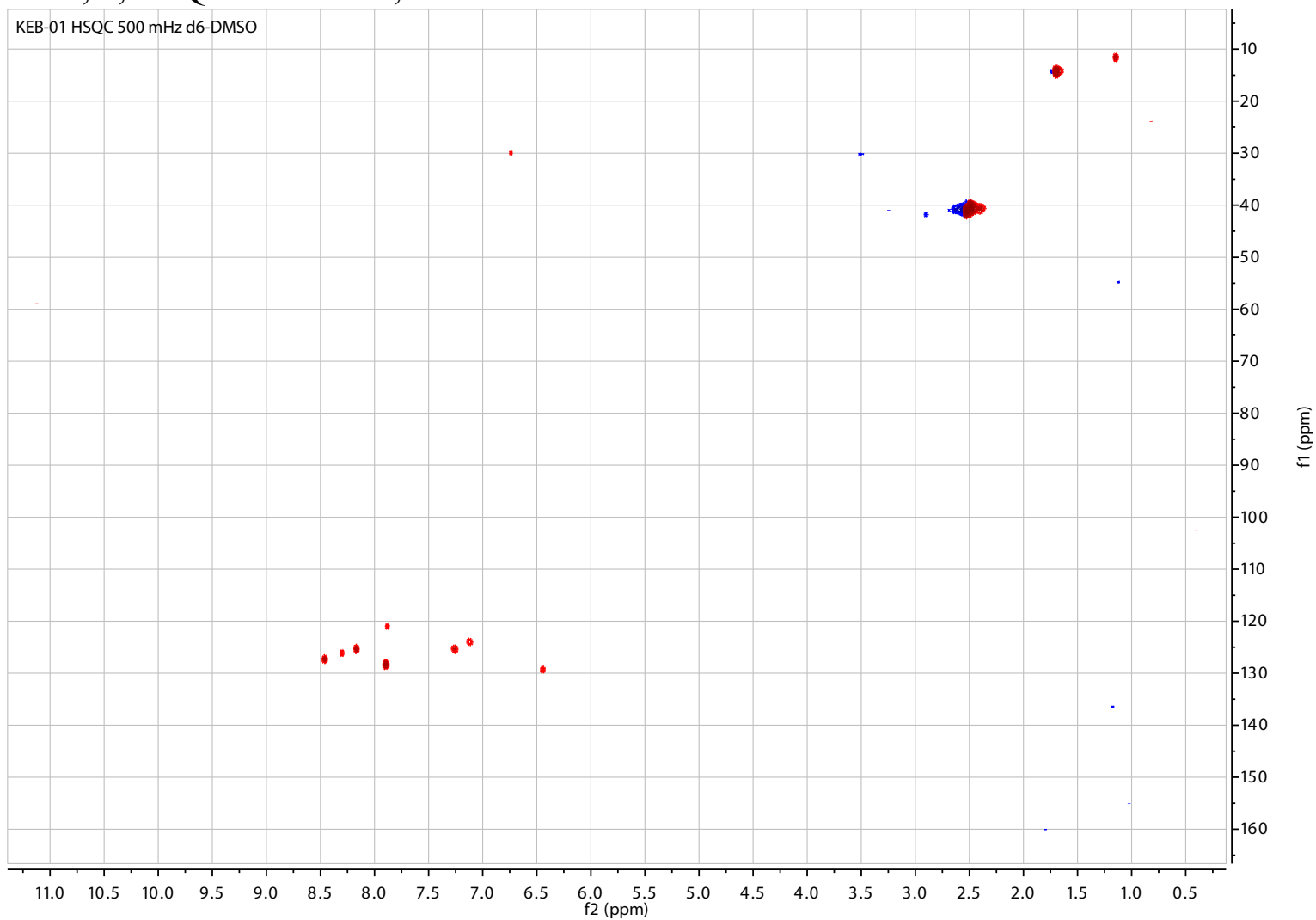

KEB-01, 8, TOCSY - 500 mHz, d6-DMSO

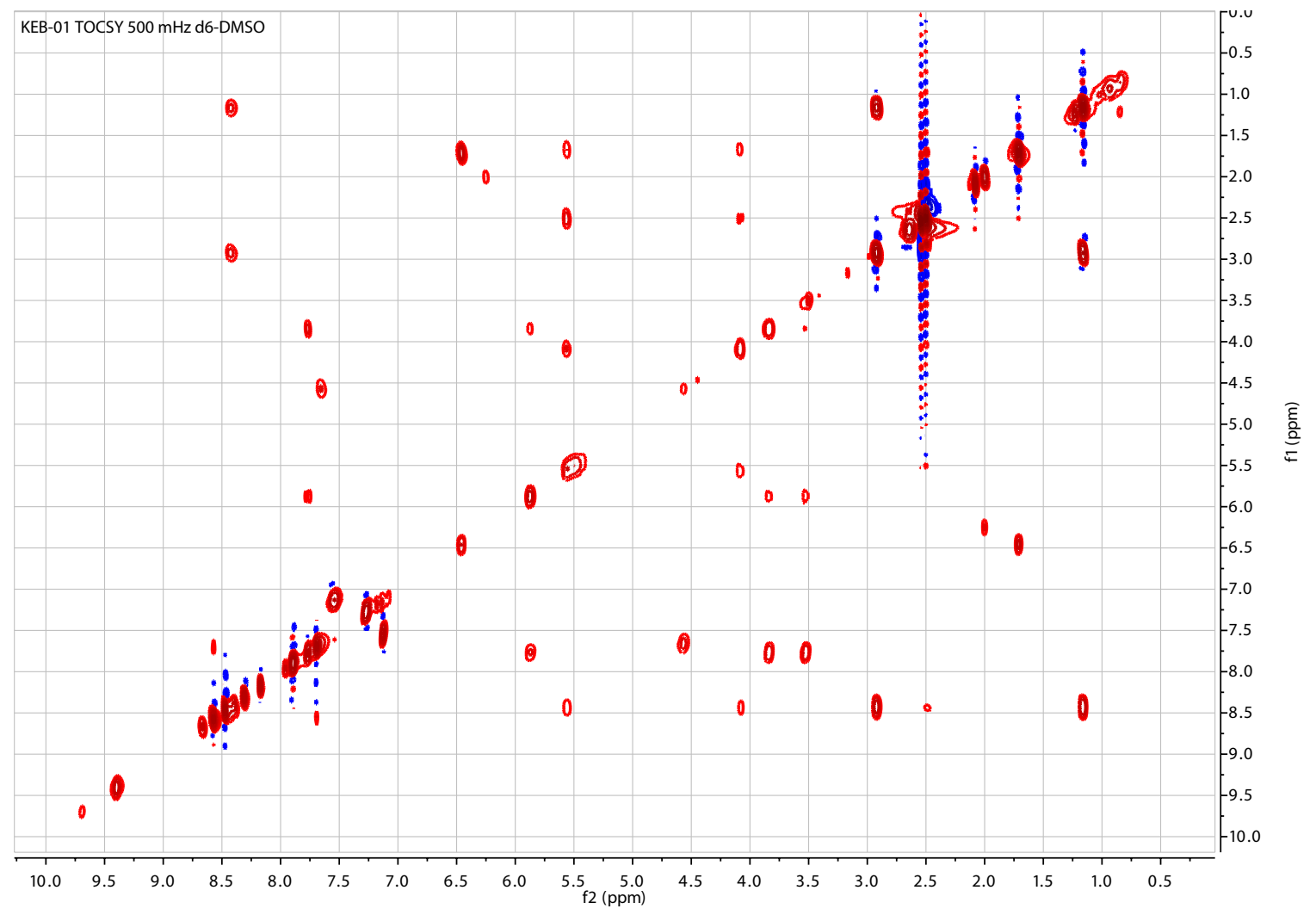




\section{S.3.8 KEB-02, 9, Characterization:}

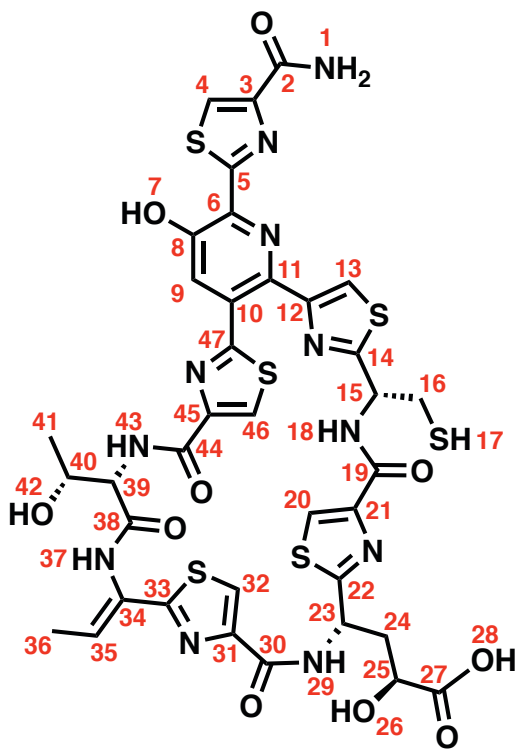

\begin{tabular}{|c|c|c|c|}
\hline${ }^{13} \mathrm{C}$ NMR (ppm) & Atom \# & ${ }^{13} \mathrm{C}$ NMR (ppm) & Atom \# \\
\hline 175.22 & 27 & 130.03 & 34 \\
\hline 169.71 & 22 & 129.52 & 6 \\
\hline 168.71 & 14 & 128.03 & 9 \\
\hline 167.75 & 38 & 127.84 & 35 \\
\hline 167.52 & 5 & 126.79 & 46 \\
\hline 165.61 & 33 & 125.92 & 4 \\
\hline 164.09 & 47 & 124.66 & 20 \\
\hline 161.4 & 19 & 123.63 & 32 \\
\hline 160.48 & 2 & 120.34 & 13 \\
\hline 160.11 & 44 & 68.79 & 40 \\
\hline 159.95 & 30 & 67.07 & 25 \\
\hline 151.92 & 12 & 57.27 & 39 \\
\hline 150.88 & 45 & 52.61 & 15 \\
\hline 149.95 & 8 & 47.83 & 23 \\
\hline 149.44 & 3 & 38.58 & 24 \\
\hline 149.05 & 21 & 26.43 & 16 \\
\hline 148.31 & 31 & 20.78 & 41 \\
\hline 141.87 & 11 & 13.34 & 36 \\
\hline 134.67 & 10 & & \\
\hline
\end{tabular}

\begin{tabular}{|c|c|c|c|c|c|}
\hline${ }^{1} \mathrm{H}$ NMR (ppm, mult, J-value, \#) & COSY & HSQC & HMBC & TOCSY & Atom \# \\
\hline $1.29(\mathrm{~d}, \mathrm{~J}=6.3 \mathrm{~Hz}, 3 \mathrm{H})$ & 4.47 & 21.46 & $57.89,69.39$ & $4.49,5.26$ & 41 \\
\hline $1.71(\mathrm{~d}, \mathrm{~J}=7.0 \mathrm{~Hz}, 3 \mathrm{H})$ & 6.46 & 14.00 & $128.43,130.63,166.19$ & 6.40 & 36 \\
\hline $2.05(\mathrm{t}, \mathrm{J}=11.7 \mathrm{~Hz}, 1 \mathrm{H})$ & 4.08 & 39.08 & & & 24 \\
\hline $2.22(\mathrm{t}, \mathrm{J}=8.5 \mathrm{~Hz}, 1 \mathrm{H})$ & 2.88 & & 27.07 & $2.86,5.32,8.49$ & 17 \\
\hline $2.72(\mathrm{~m}, 1 \mathrm{H})$ & & 39.09 & & & 24 \\
\hline $2.78(\mathrm{~m}, 1 \mathrm{H})$ & 2.22 & 27.12 & $53.20,169.29$ & & 16 \\
\hline $2.86(\mathrm{~m}, 1 \mathrm{H})$ & & 27.08 & $53.20,169.29$ & & 16 \\
\hline $4.02(\mathrm{~d}, \mathrm{~J}=8.1 \mathrm{~Hz}, 2 \mathrm{H})$ & $2.04,2.67,5.57,9.04$ & 67.27 & & $2.04,2.68,5.55,9.05$ & 25 \\
\hline $4.53(\mathrm{~s}, 1 \mathrm{H})$ & 1.33 & 69.41 & & 1.38 & 40 \\
\hline $4.79(\mathrm{~d}, \mathrm{~J}=10.5 \mathrm{~Hz}, 1 \mathrm{H})$ & 8.03 & 57.91 & & $1.36,8.02$ & 39 \\
\hline $5.29(\mathrm{q}, \mathrm{J}=7.3 \mathrm{~Hz}, 1 \mathrm{H})$ & $2.89,8.51$ & 53.23 & $27.04,169.27$ & $2.23,2.85,8.42$ & 15 \\
\hline $5.55(\mathrm{~s}, 1 \mathrm{H})$ & 9.04 & 47.06 & & $2.02,2.67,4.08,9.03$ & 23 \\
\hline $6.36(\mathrm{~m}, 1 \mathrm{H})$ & 1.76 & 128.45 & $130.63,166.24$ & 1.71 & 35 \\
\hline $7.69(\mathrm{~s}, 1 \mathrm{H})$ & & & 151.48 & 8.57 & 42 \\
\hline $7.85(\mathrm{~d}, \mathrm{~J}=3.7 \mathrm{~Hz}, 1 \mathrm{H})$ & & 128.72 & $135.28,142.45,150.32,164.67$ & & 9 \\
\hline $8.06(\mathrm{~s}, 1 \mathrm{H}, \mathrm{NH})$ & & & 160.77 & 4.76 & 43 \\
\hline $8.10(\mathrm{~s}, 1 \mathrm{H})$ & & 120.94 & $152.52,169.30$ & & 13 \\
\hline $8.12(\mathrm{~s}, 1 \mathrm{H})$ & & 124.37 & $148.88,166.22$ & & 32 \\
\hline $8.29(\mathrm{~s}, 1 \mathrm{H})$ & & 125.32 & $149.61,170.29$ & & 20 \\
\hline $8.42(\mathrm{~s}, 1 \mathrm{H})$ & & 126.56 & $150.00,164.69$ & & 4 \\
\hline $8.49(\mathrm{~s}, 1 \mathrm{H})$ & & 127.38 & $151.54,164.11,168.33$ & & 46 \\
\hline $8.57(2 \mathrm{H}$, broad, $\mathrm{NH})$ & & & 168.44 & 7.69 & 37 \\
\hline 9.04 (dd. $1 \mathrm{H})$ & & & 160.51 & & 1 \\
\hline $9.62(\mathrm{~d}, \mathrm{~J}=13.5 \mathrm{~Hz}, 1 \mathrm{H})$ & & & 169.98 & & 29 \\
\hline $10.89(\mathrm{~s}, 1 \mathrm{H})$ & & & 170.37 & & 7 \\
\hline
\end{tabular}


LC/MS Analysis: Expected Mass: $984.0820 \mathrm{~m} / \mathrm{z}\left[\mathrm{M}-\mathrm{H}+\mathrm{H}_{2} \mathrm{O}\right]^{+1}$, Observed Mass: $984.0798 \mathrm{~m} / \mathrm{z}$ $\left[\mathrm{M}-\mathrm{H}+\mathrm{H}_{2} \mathrm{O}\right]^{+1}$

Analytical Trace: $\lambda-350 \mathrm{~nm}$

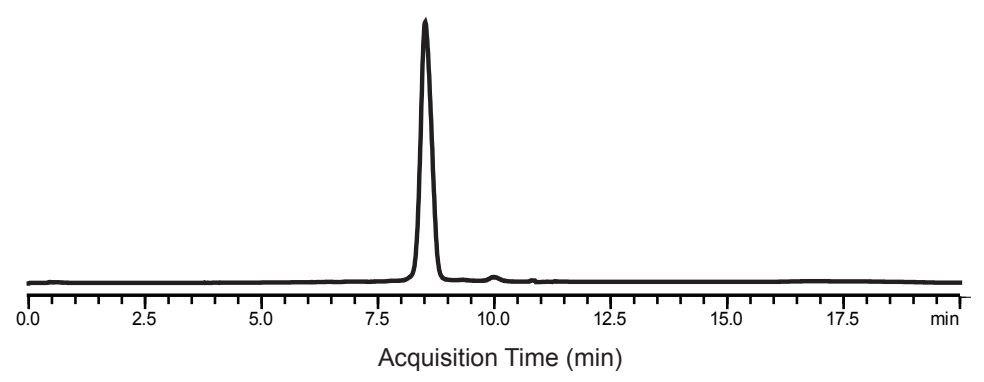


KEB-02, 9, ${ }^{1} \mathrm{H}$ NMR - $500 \mathrm{mHz}$, d6-DMSO

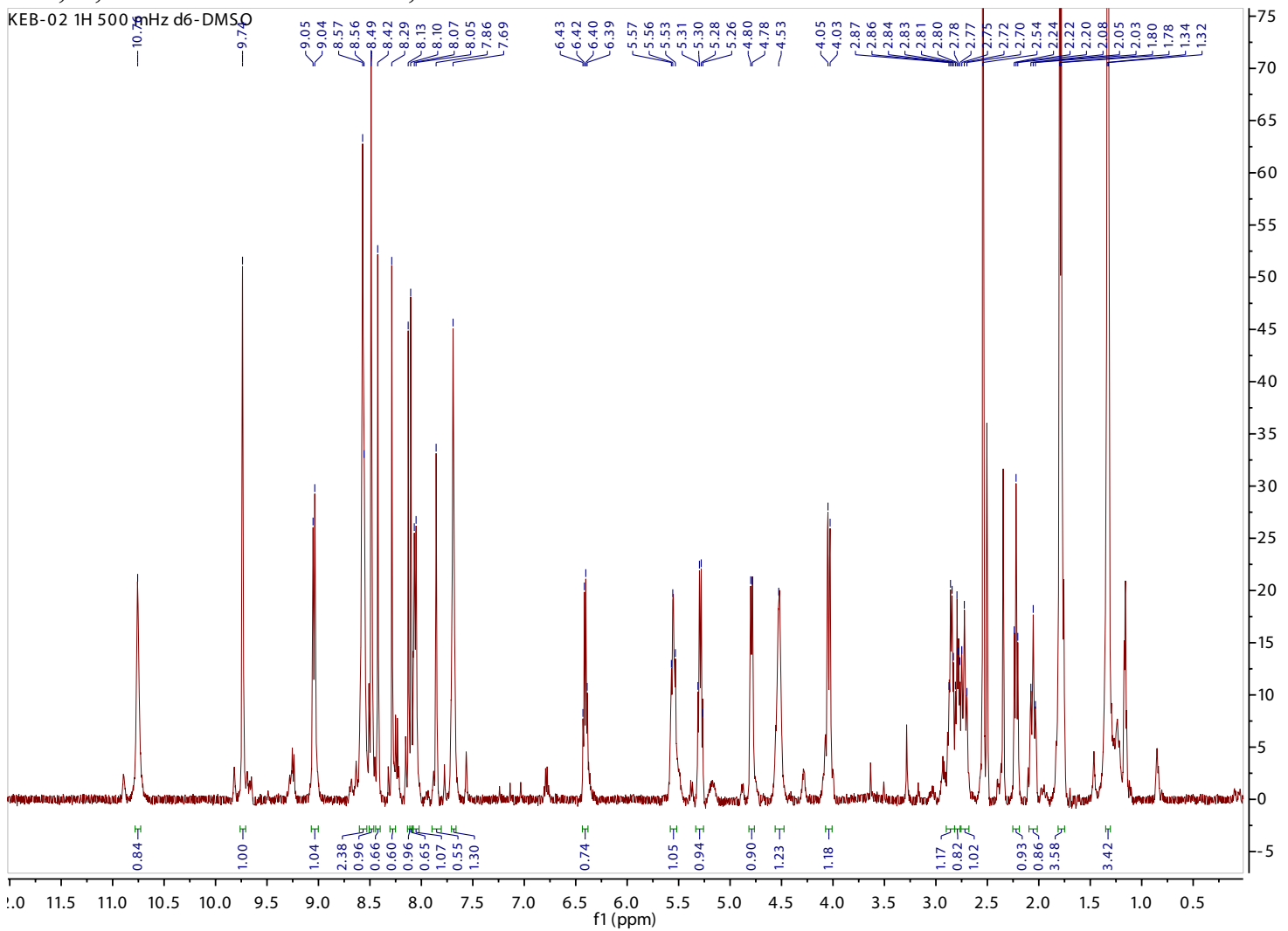

KEB-02, 9, ${ }^{13} \mathrm{C}$ NMR - $500 \mathrm{mHz}$, d6-DMSO

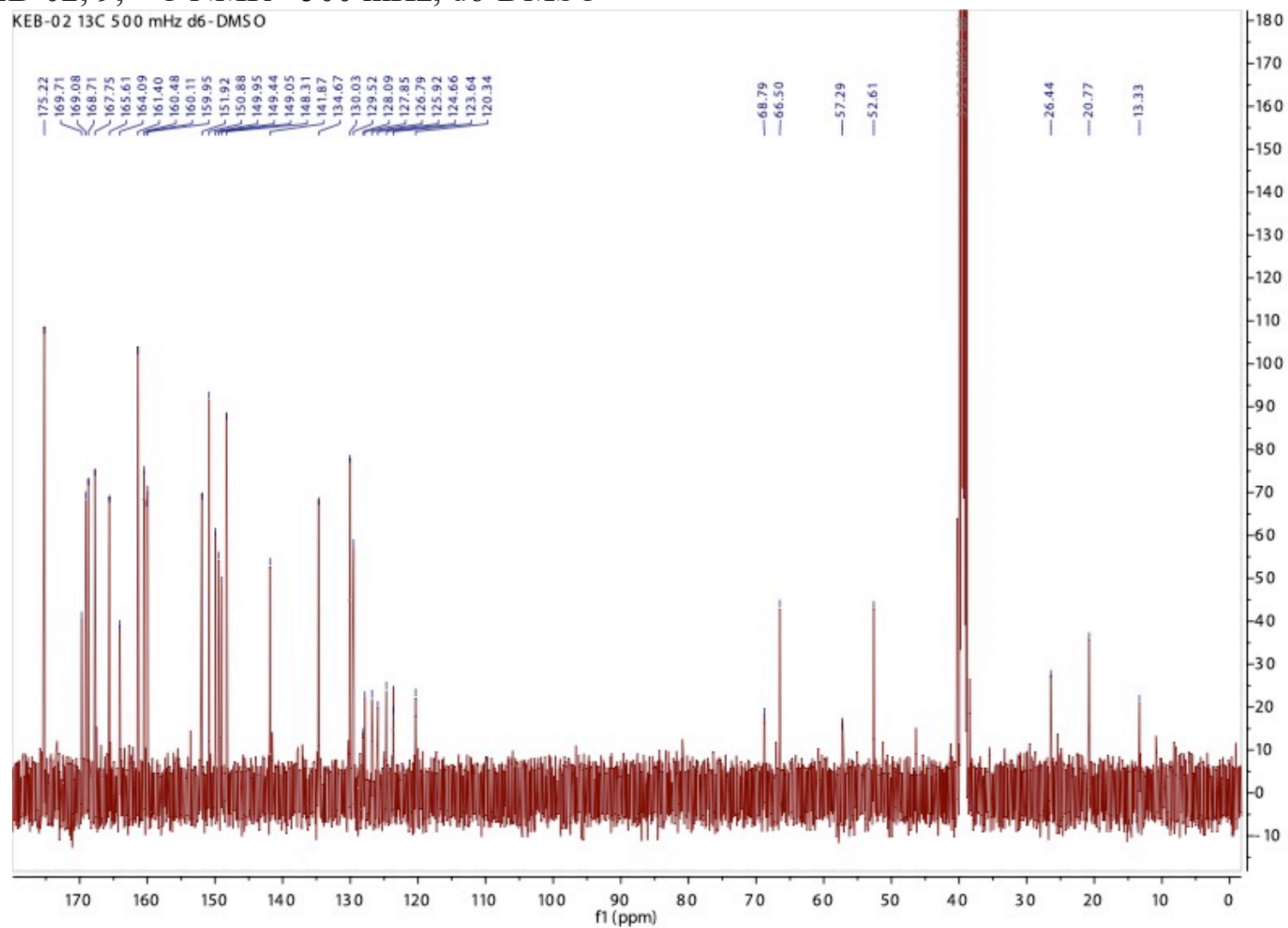


KEB-02, 9, COSY - 500 mHz, d6-DMSO

KEB-02 COSY $500 \mathrm{mHz}$ d6-DMSO

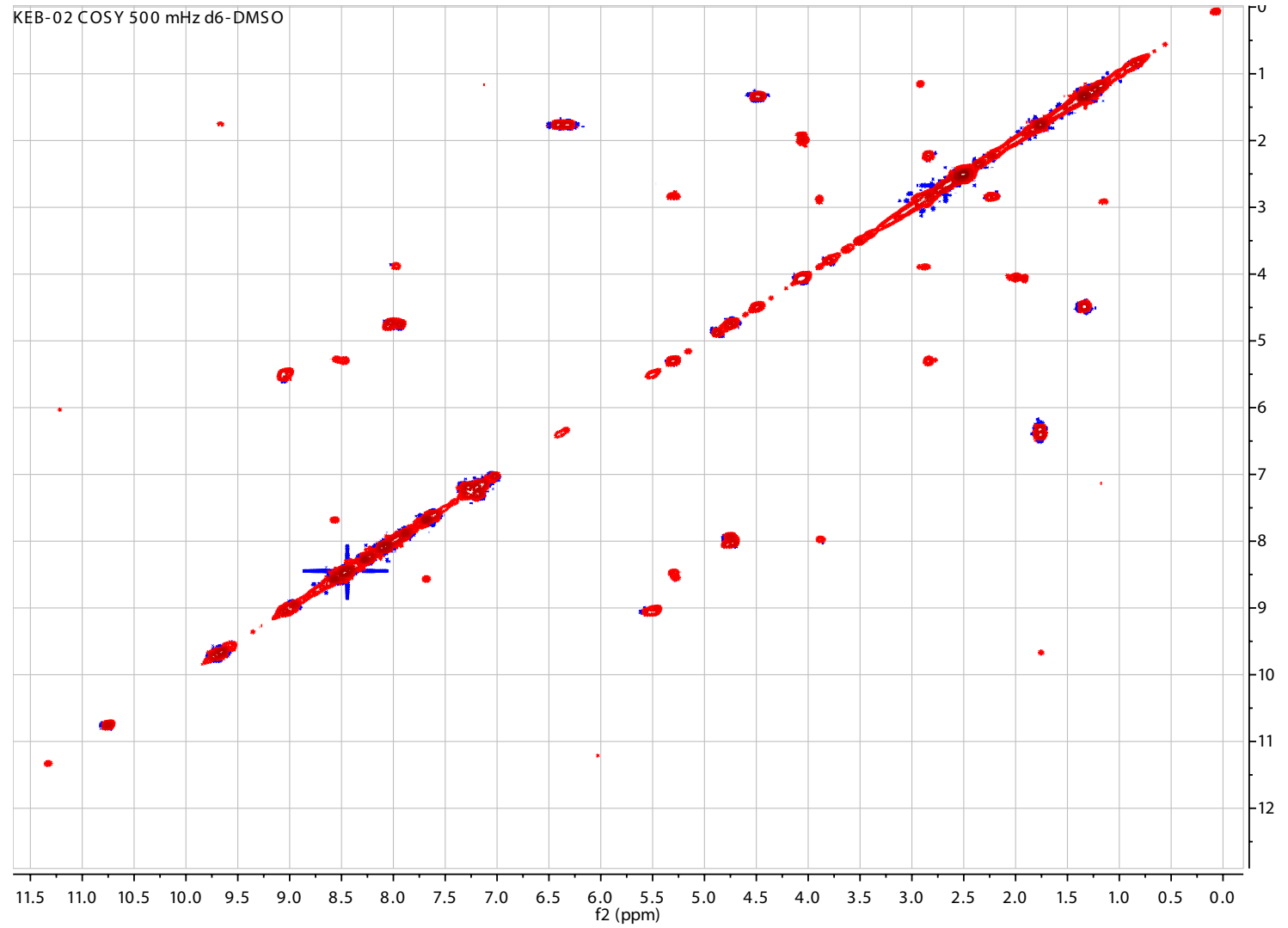

$\frac{\bar{\varepsilon}}{\underline{0}}$

KEB-02, 9, HMBC - 500 mHz, d6-DMSO

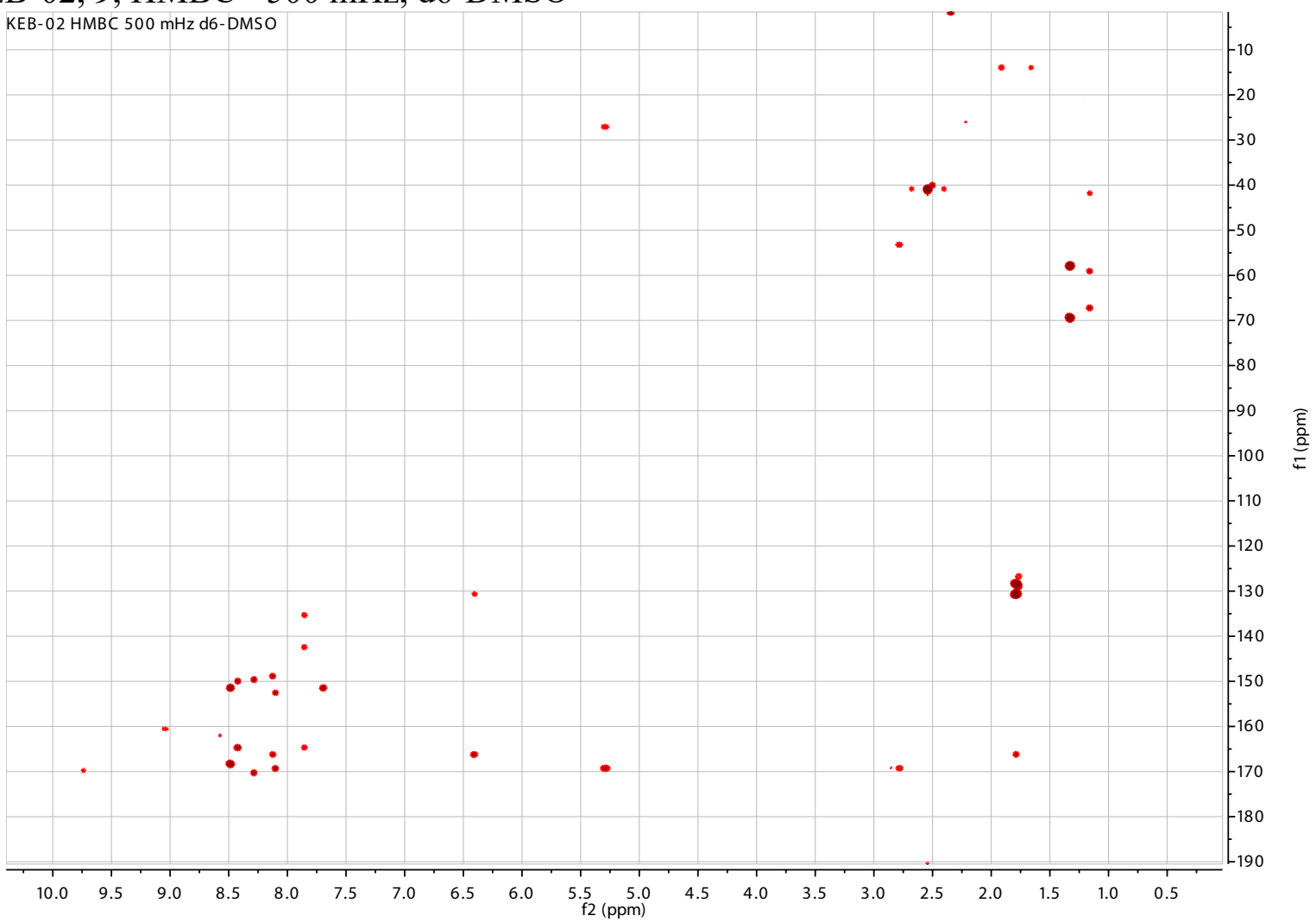


KEB-02, 9, HSQC - 500 mHz, d6-DMSO

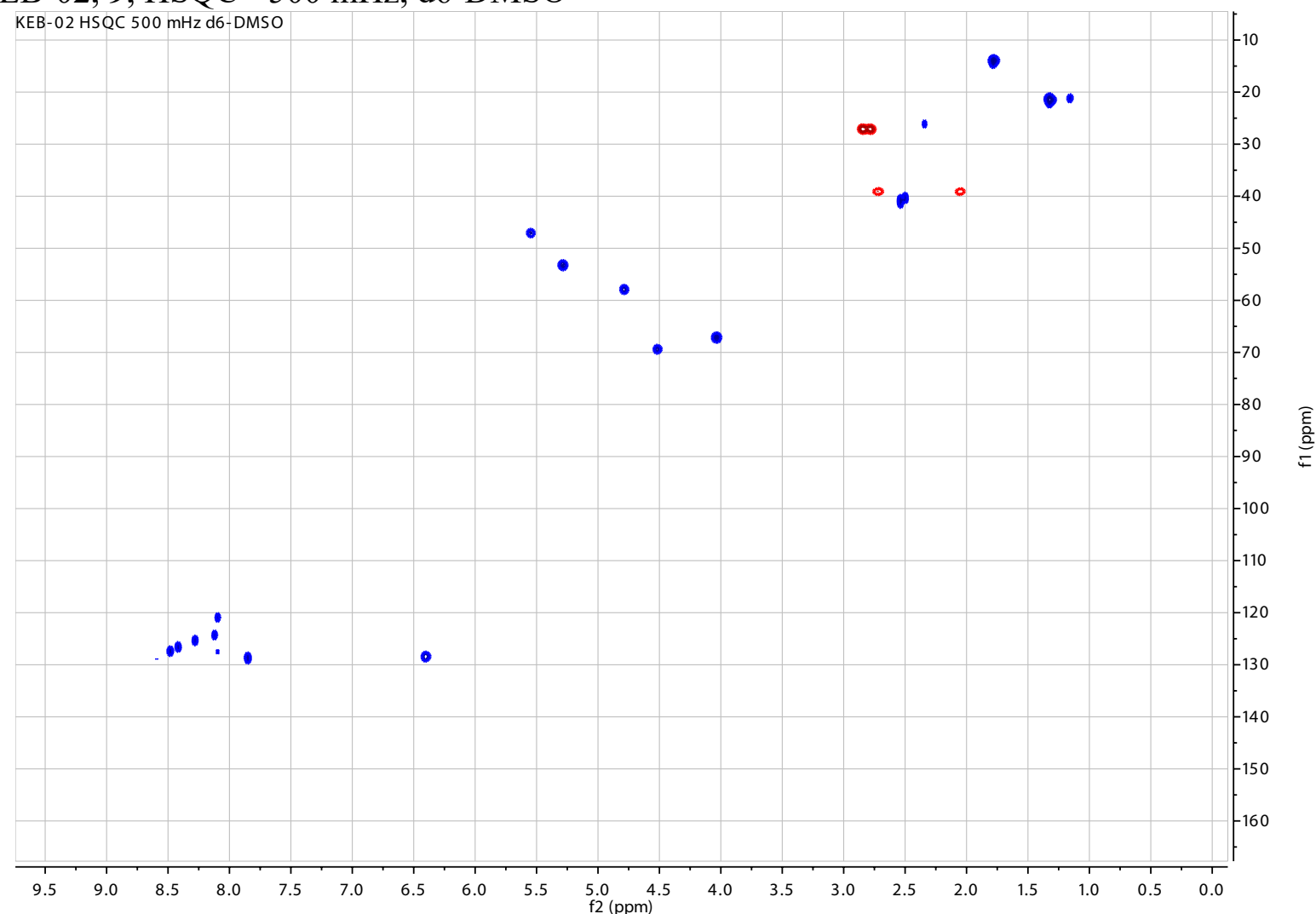

KEB-02, 9, TOCSY - $500 \mathrm{mHz}$, d6-DMSO

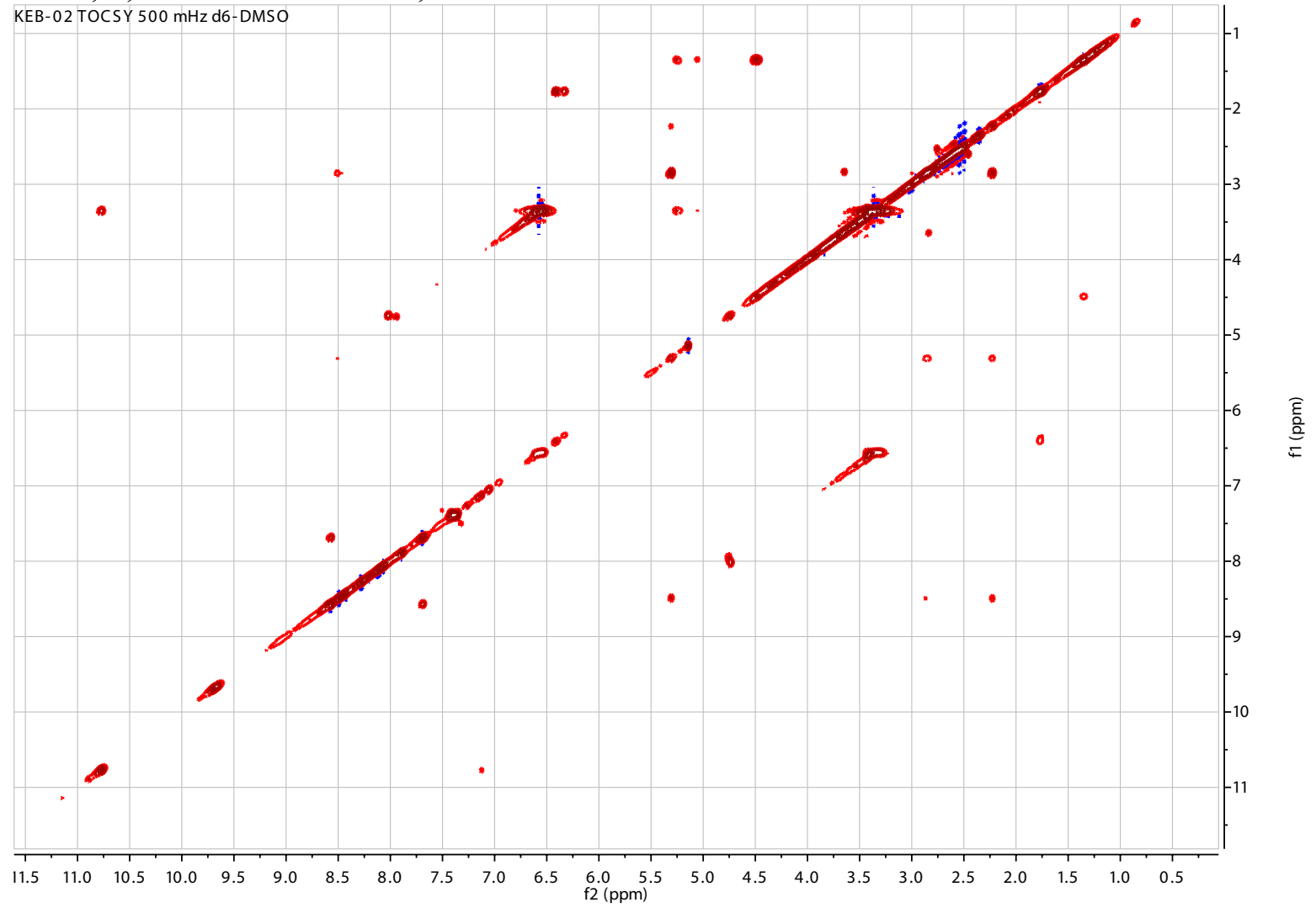


Figure S.4 Transient Transfection of Ub-R-GFP in RAW 264.7 cells. Representative image of thiostrepton (TSR, 3) induced proteasome inhibition in RAW 264.7 cells transiently transfected with Ub-R-GFP. Cells were treated with thiostrepton $(5 \mu \mathrm{M})$ for $16 \mathrm{hr}$ and imaged on the INCell Analyzer 2200.

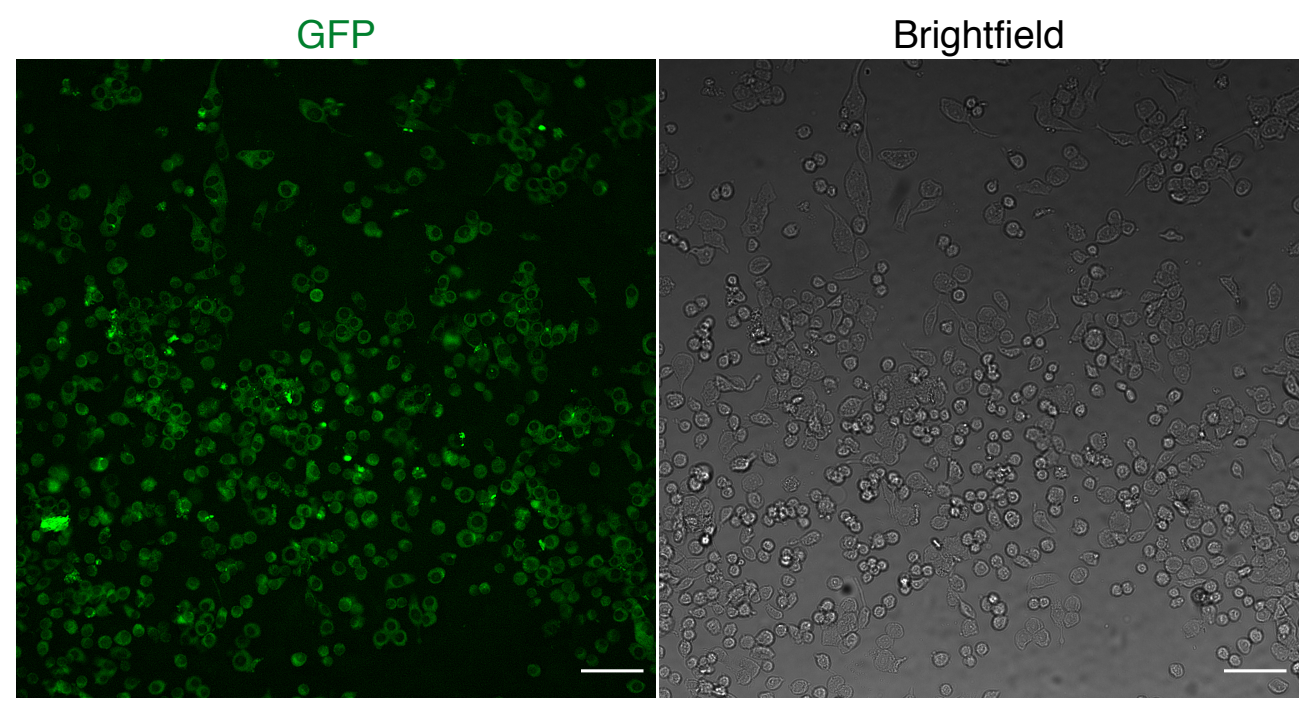


Figure S.5 In cellulo proteasome inhibition $\mathrm{EC}_{50}$ curves. Proteasome inhibition was quantified by total fluorescence corresponding to the total degradation substrate Ub-R-GFP present in the cell. Fluorescence per cell was measured in a dose-dependent manner and normalized to DMSO (negative) and MG-132 (positive) controls. Cells were treated for $16 \mathrm{hr}$, fixed, stained and visualized on the INCell Analyzer 2200.
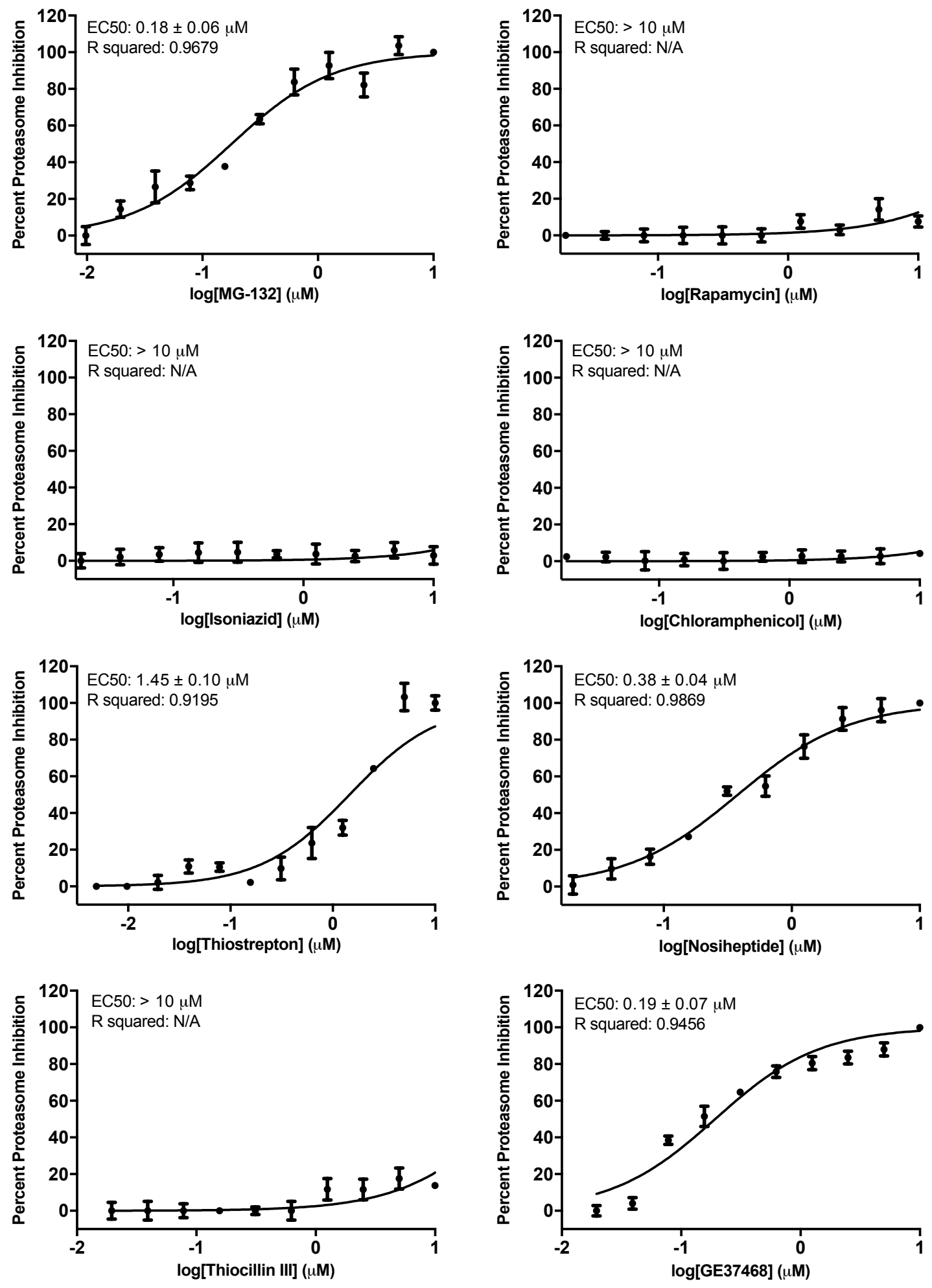

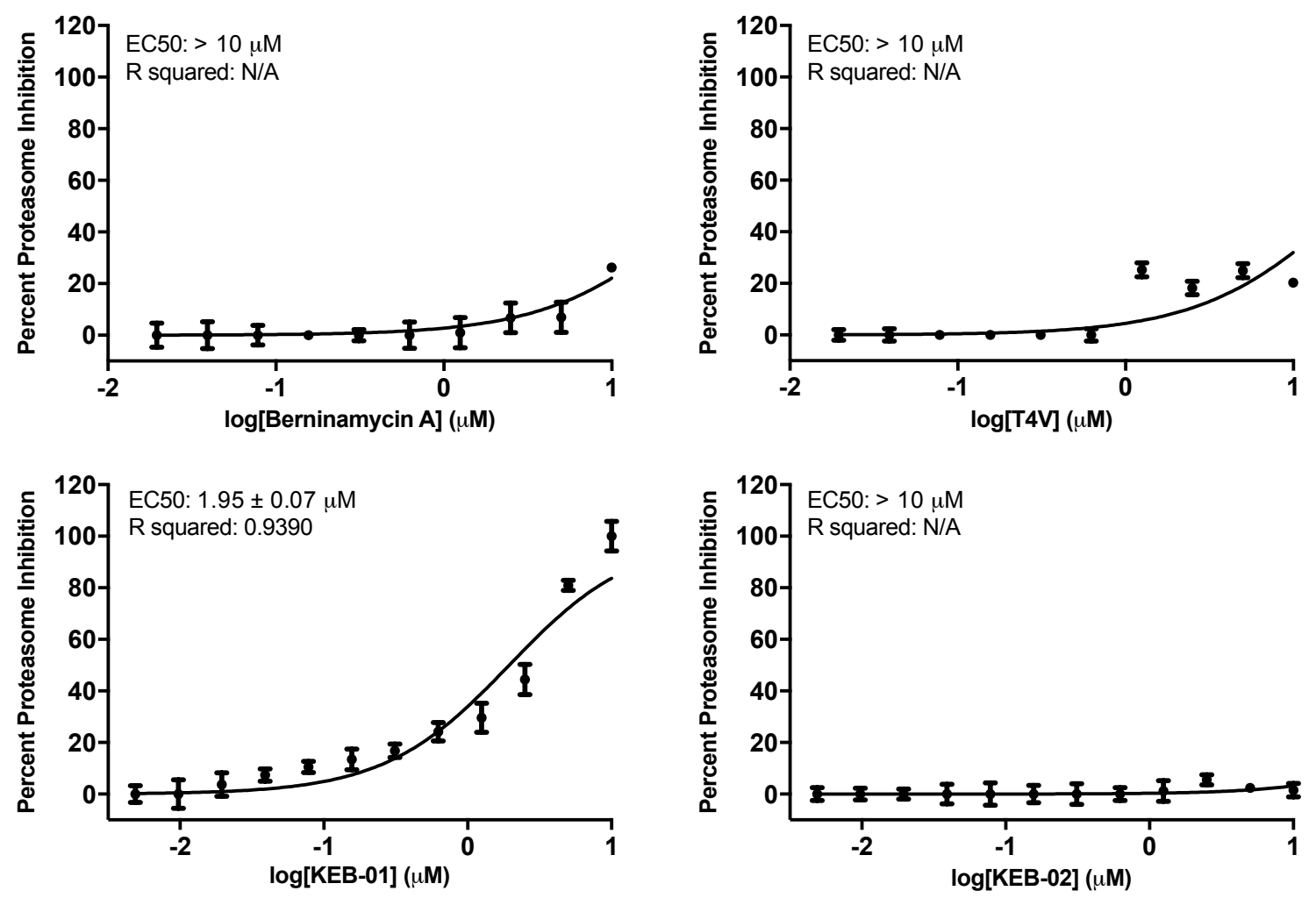
Figure S.6 Cell viability $\mathrm{LC}_{50}$ curves. Cells were treated with the compounds listed below and assessed for viability using Promega ${ }^{\circledR}$ Cell Titer Glo ${ }^{\circledR}$ 2.0. Decreased luminogenic output was directly correlated to a decrease in cell viability. Luminescence was normalized to DMSO (negative control) and MG-132 (positive cytotoxic control) treated cells to generate the following viability curves. Concentrations varied from $10 \mu \mathrm{M}$ to $40 \mathrm{nM}$.

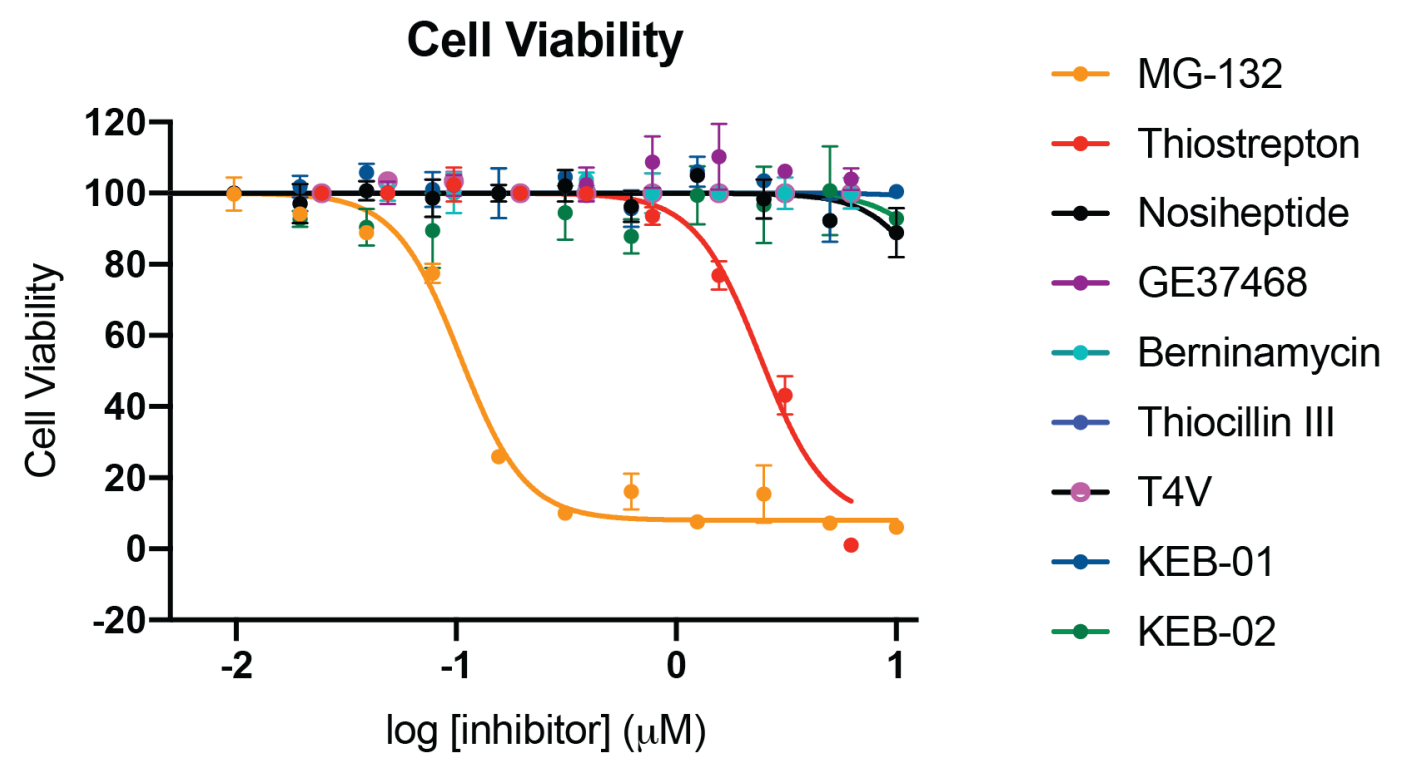


Figure S.7 In cellulo induction of autophagy representative photos. Thiopeptide induced autophagic flux was monitored by localization of RFP positive puncta in RAW Difluo ${ }^{\mathrm{TM}}$ mLC3 cells. Cells were treated with compound for $16 \mathrm{hr}$ at $5 \mu \mathrm{M}$. Following treatment, cells were fixed with 3.7\% formaldehyde and nuclei were stained with Hoescht 33342. Representative images were captured on an inverted Olympus FV1000 confocal microscope with an IX81 base. Scale bar: 40 $\mu \mathrm{m}$.

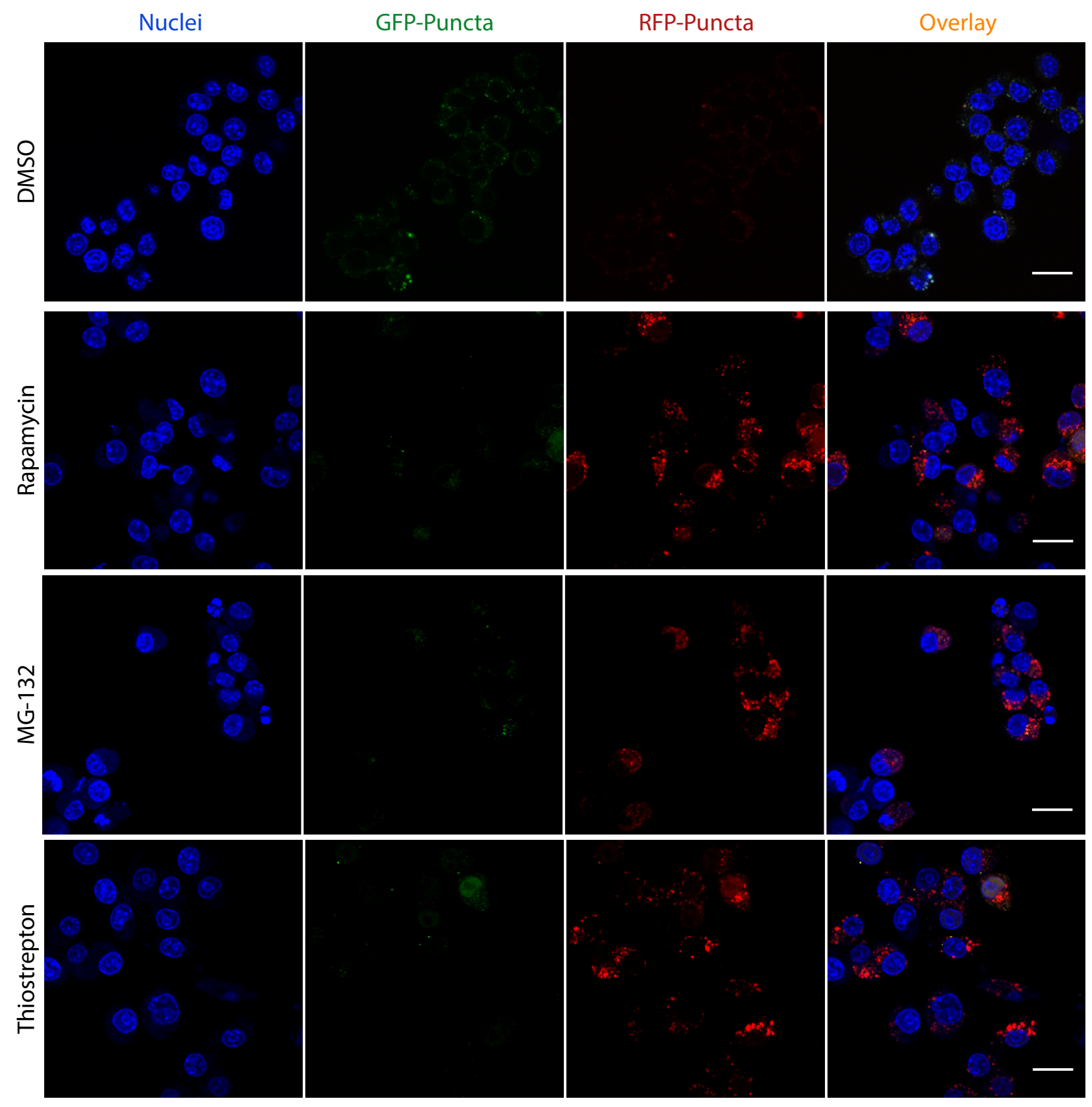




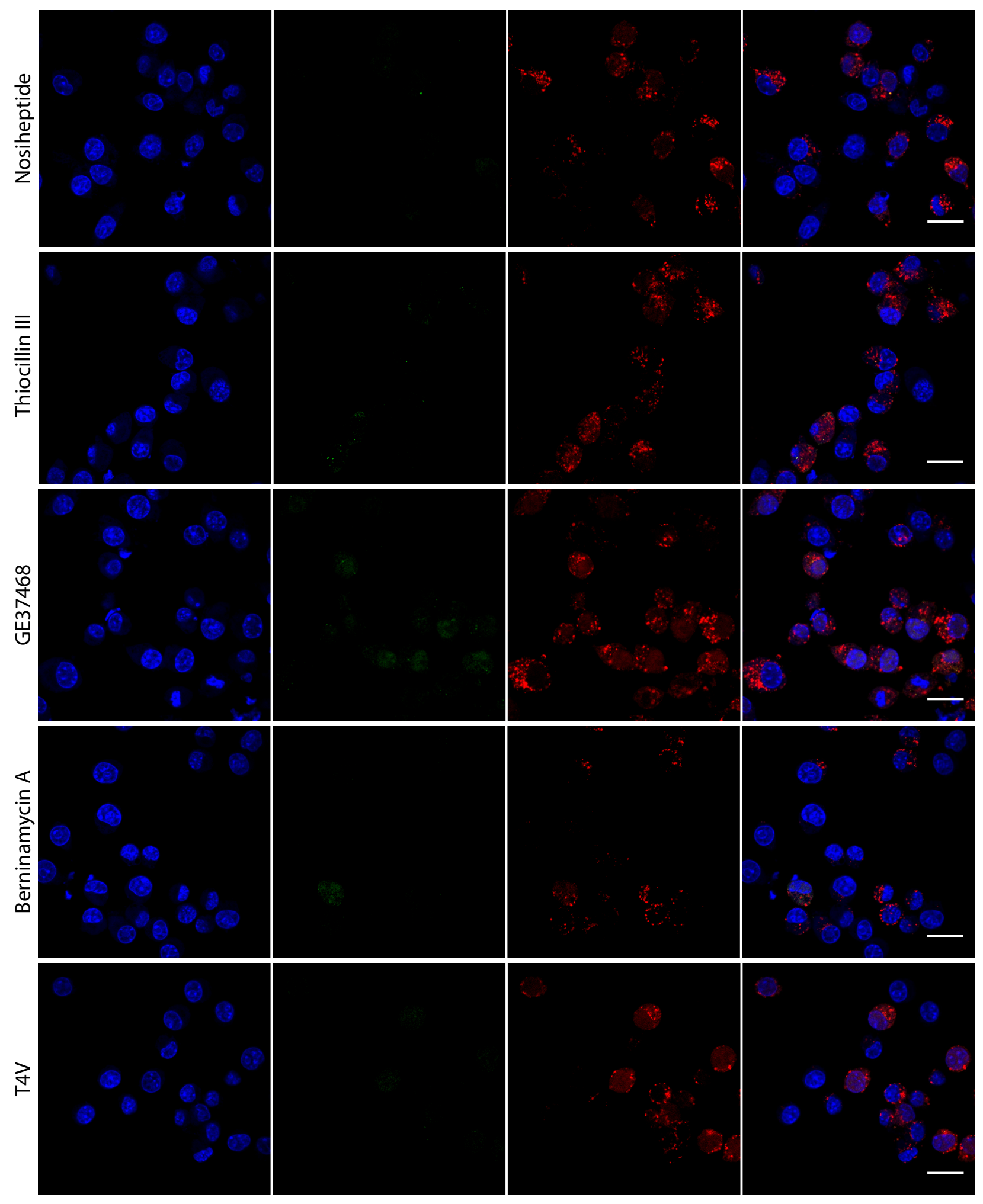




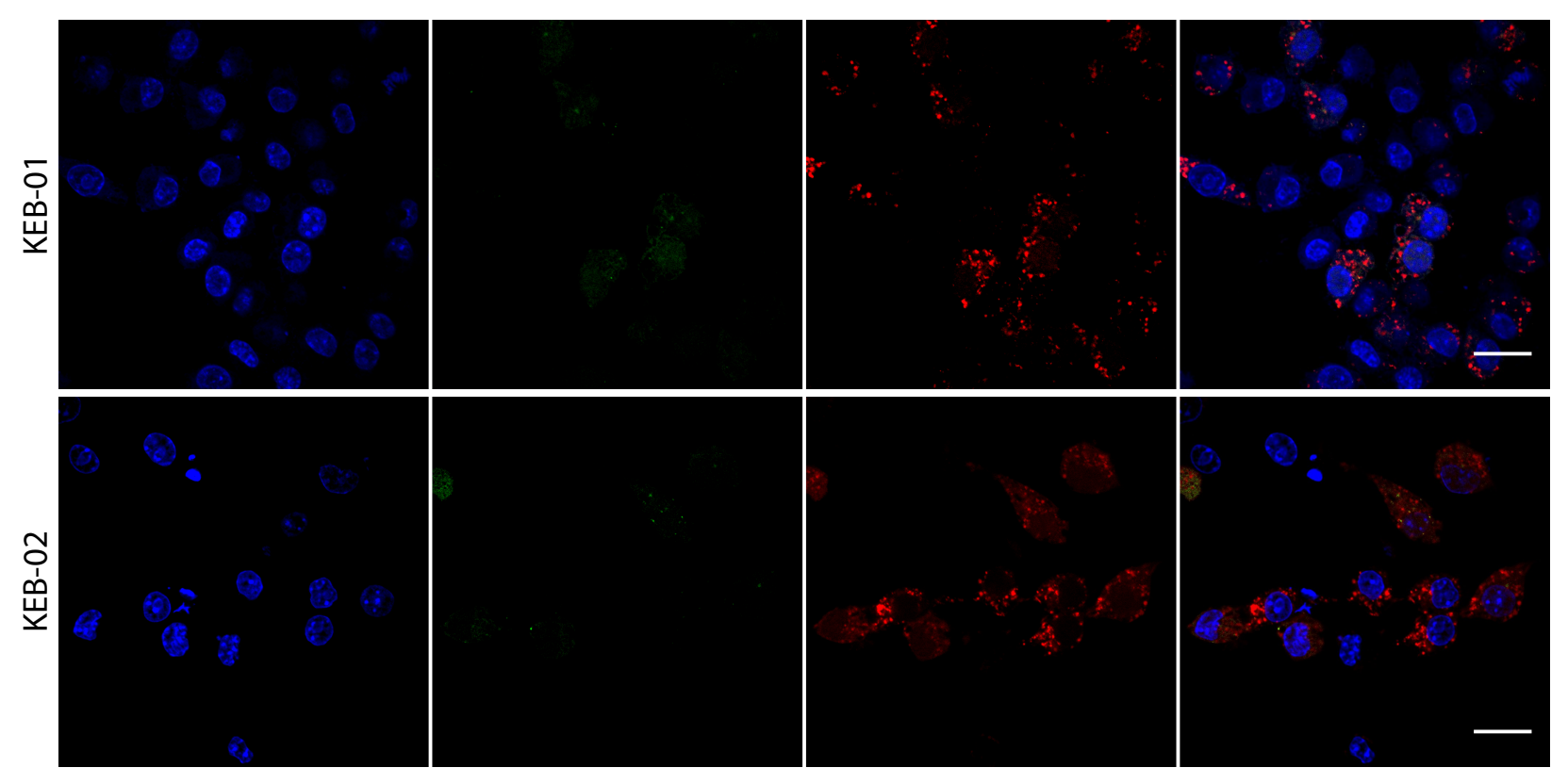


Figure S.8 In cellulo Induction of Autophagy EC50 Curves. Quantification of thiopeptide induced autophagic flux was calculated from the dose-dependent RFP positive puncta per cell using RAW Difluo $^{\mathrm{TM}} \mathrm{mLC} 3$ cells. Percent induction of autophagy was normalized to rapamycin-induced autophagic flux.
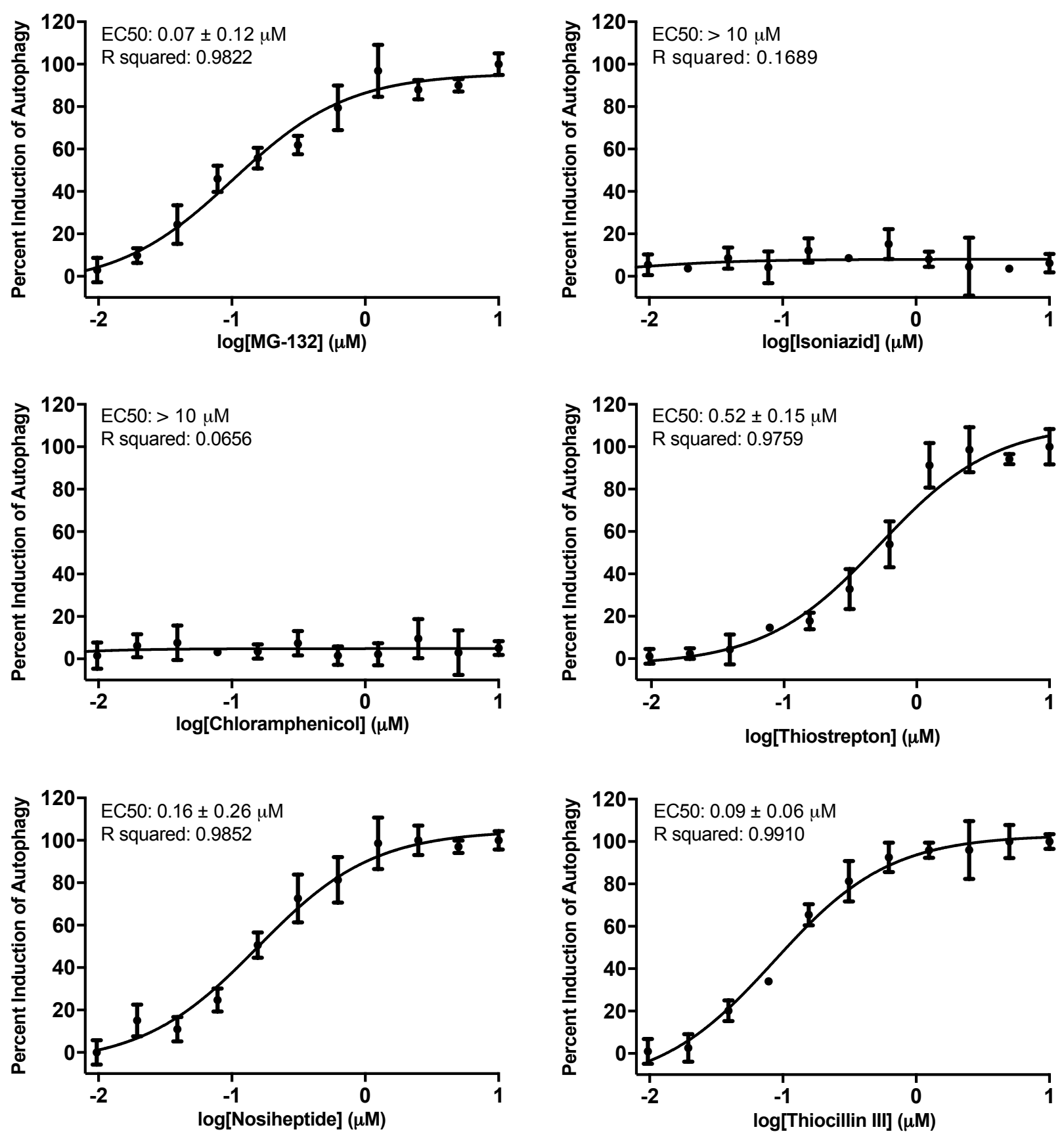

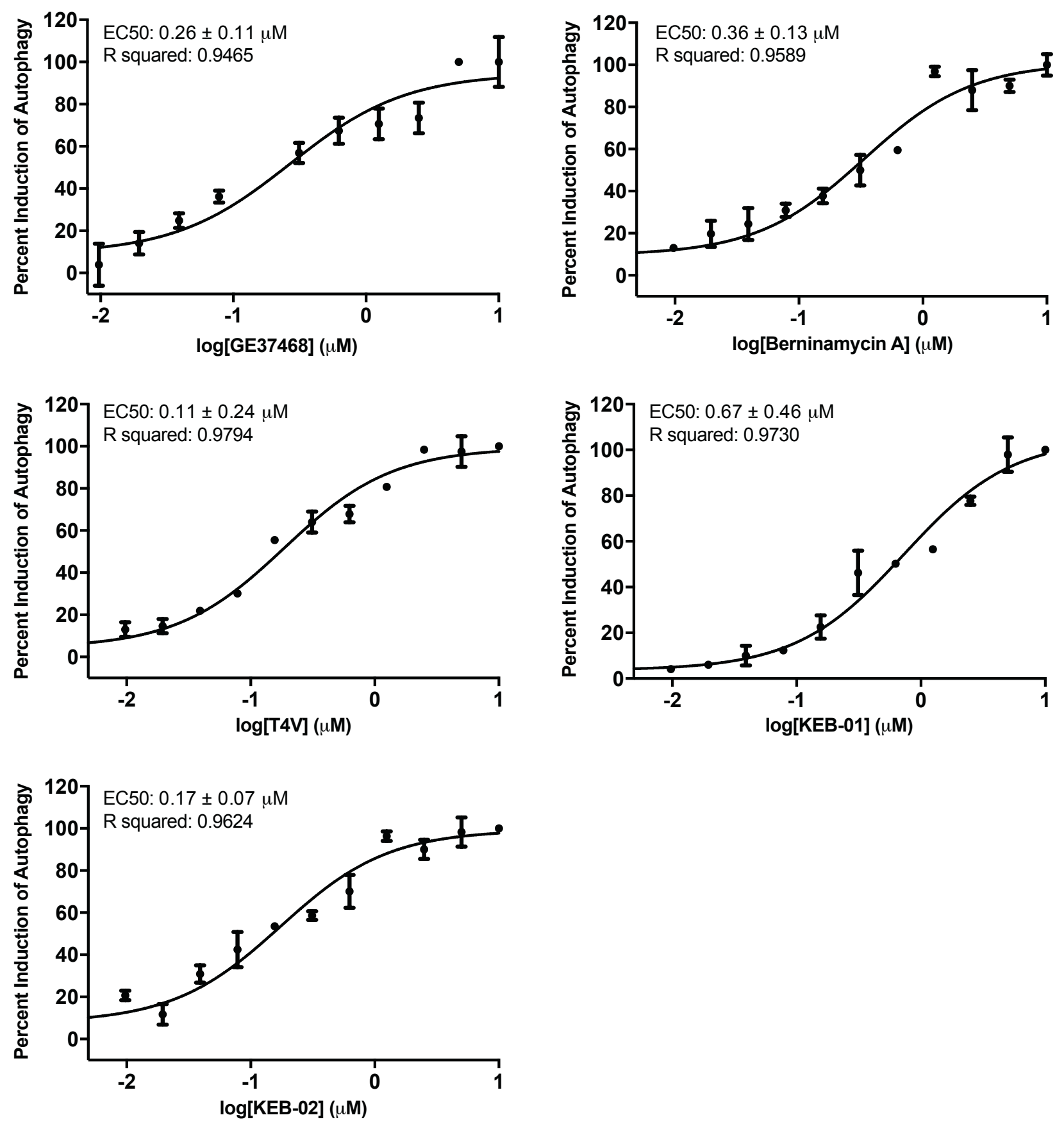
Figure S.9 Proteasome inhibition and autophagy induction proteomic marker validation. Western blot analysis of two proteomic markers validated the results of phenotypic assays used to monitor proteasome inhibition and induction of autophagy. RAW 264.7 cells were treated with compound $(5 \mu \mathrm{M})$ for $16 \mathrm{hr}$. Antibodies specific for ubiquitin and LC3B were used to monitor proteasome inhibition and autophagy induction, respectively. $\beta$-tubulin was used as a loading control.

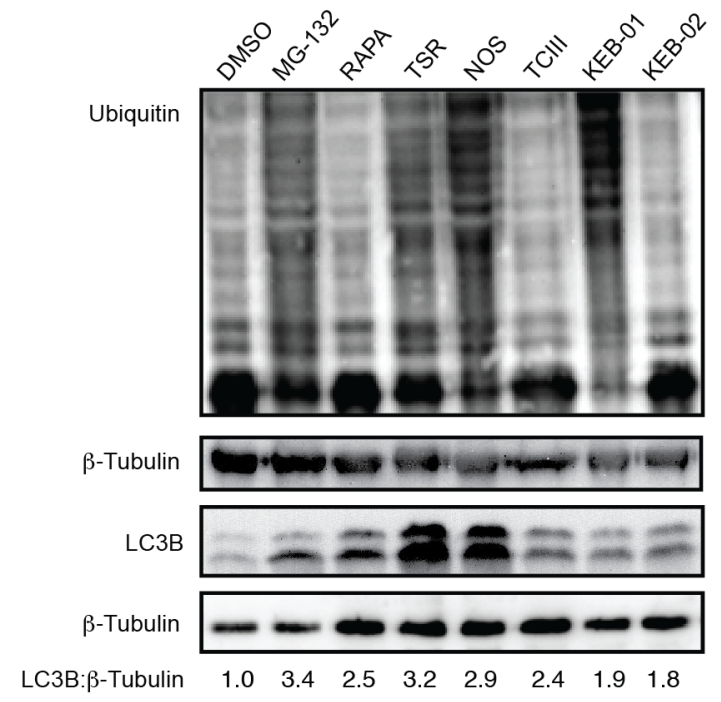


Figure S.10 Direct Inhibition of the 20S Proteasome. Direct inhibition of three 20S proteasome related activities were monitored by three luminogenic substrates provided by the ProteasomeGlo $^{\mathrm{TM}}$ Assay. Human 20S proteasome was incubated with compound for $16 \mathrm{hrs}$. Percent inhibition was reported as a function of luminescence and normalized to DMSO treatment.
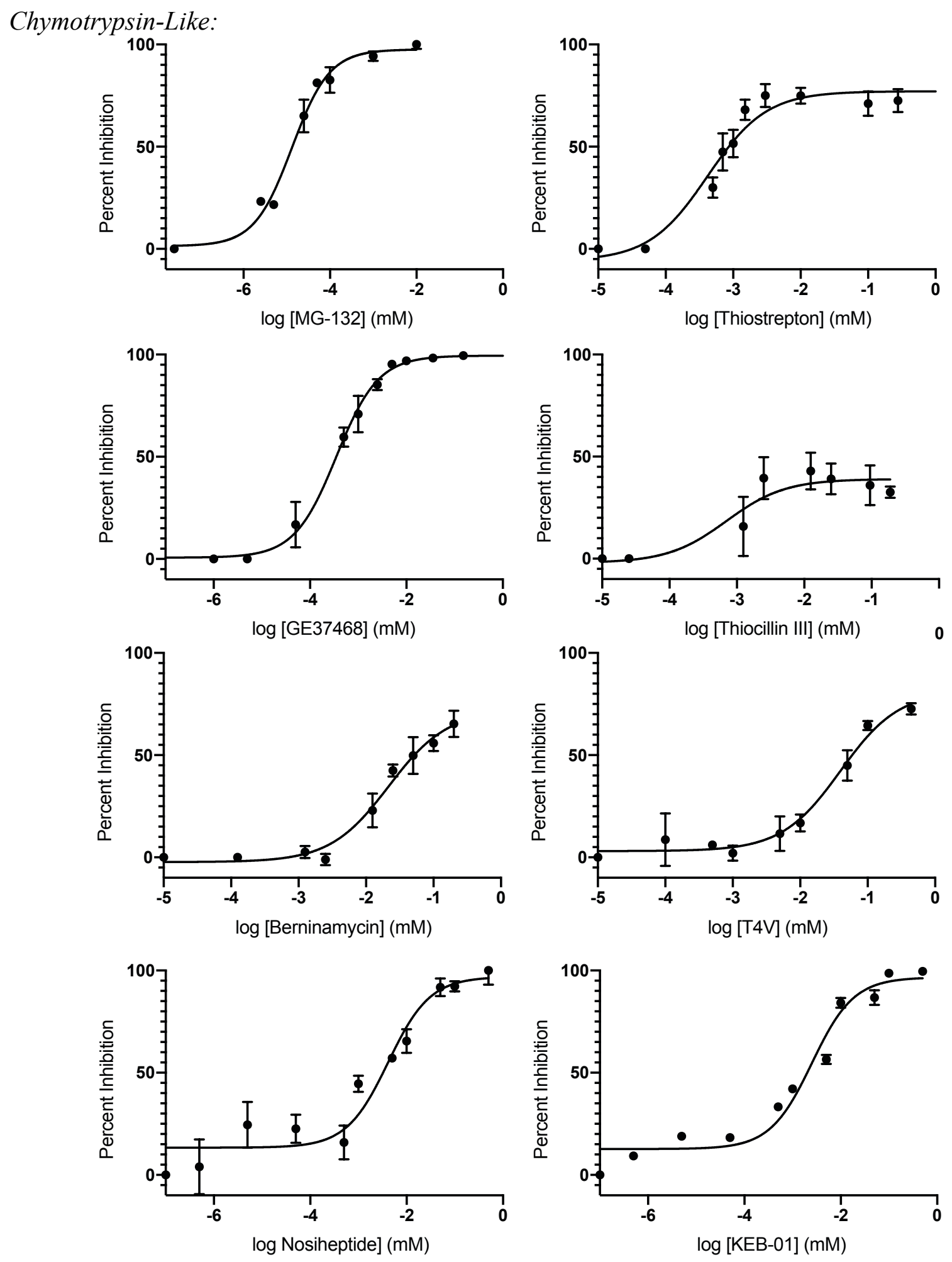


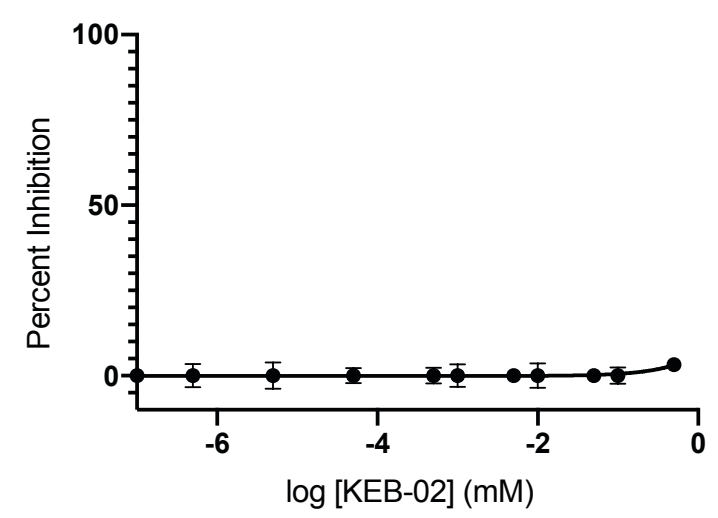

Caspase-Like:
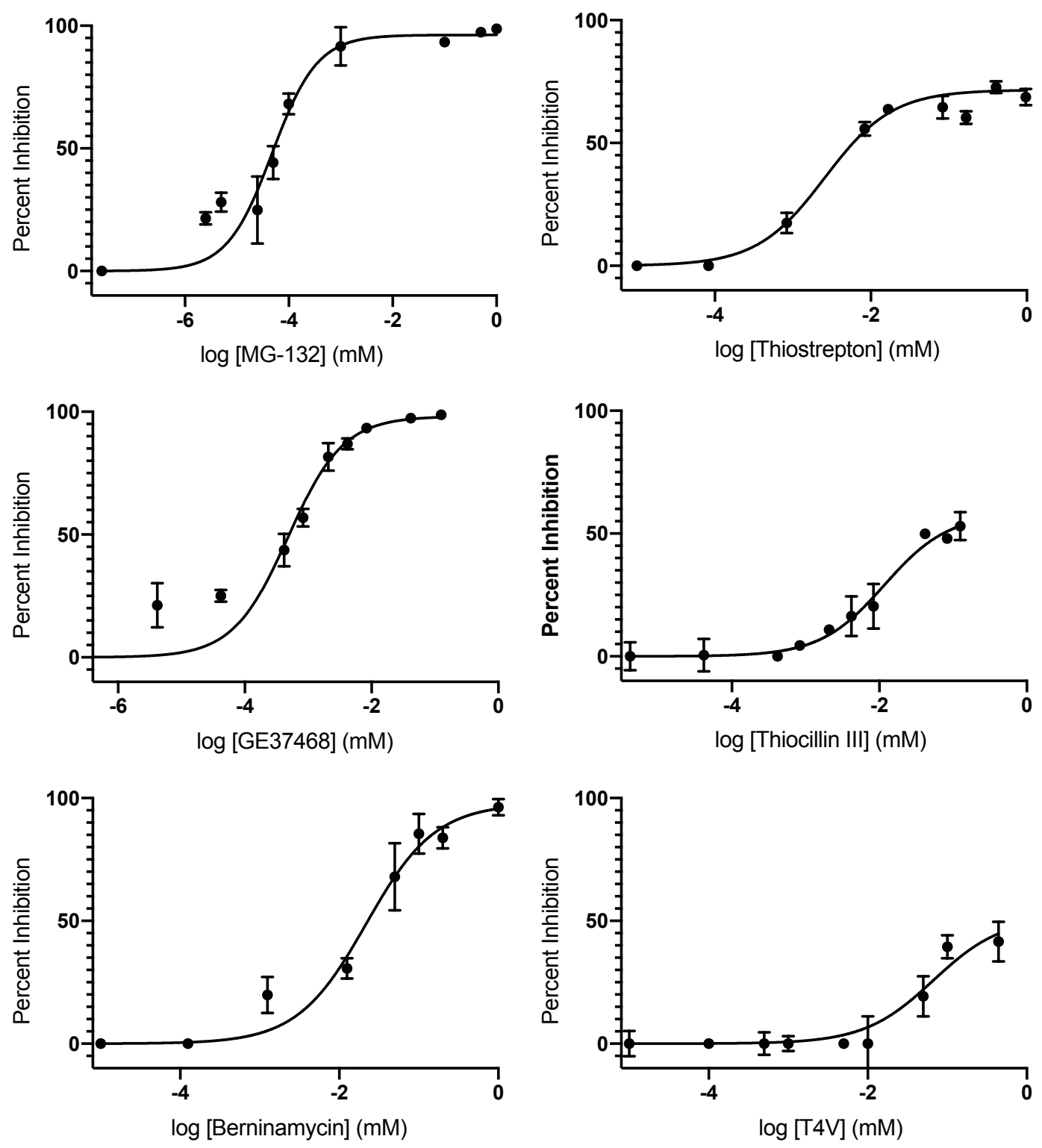

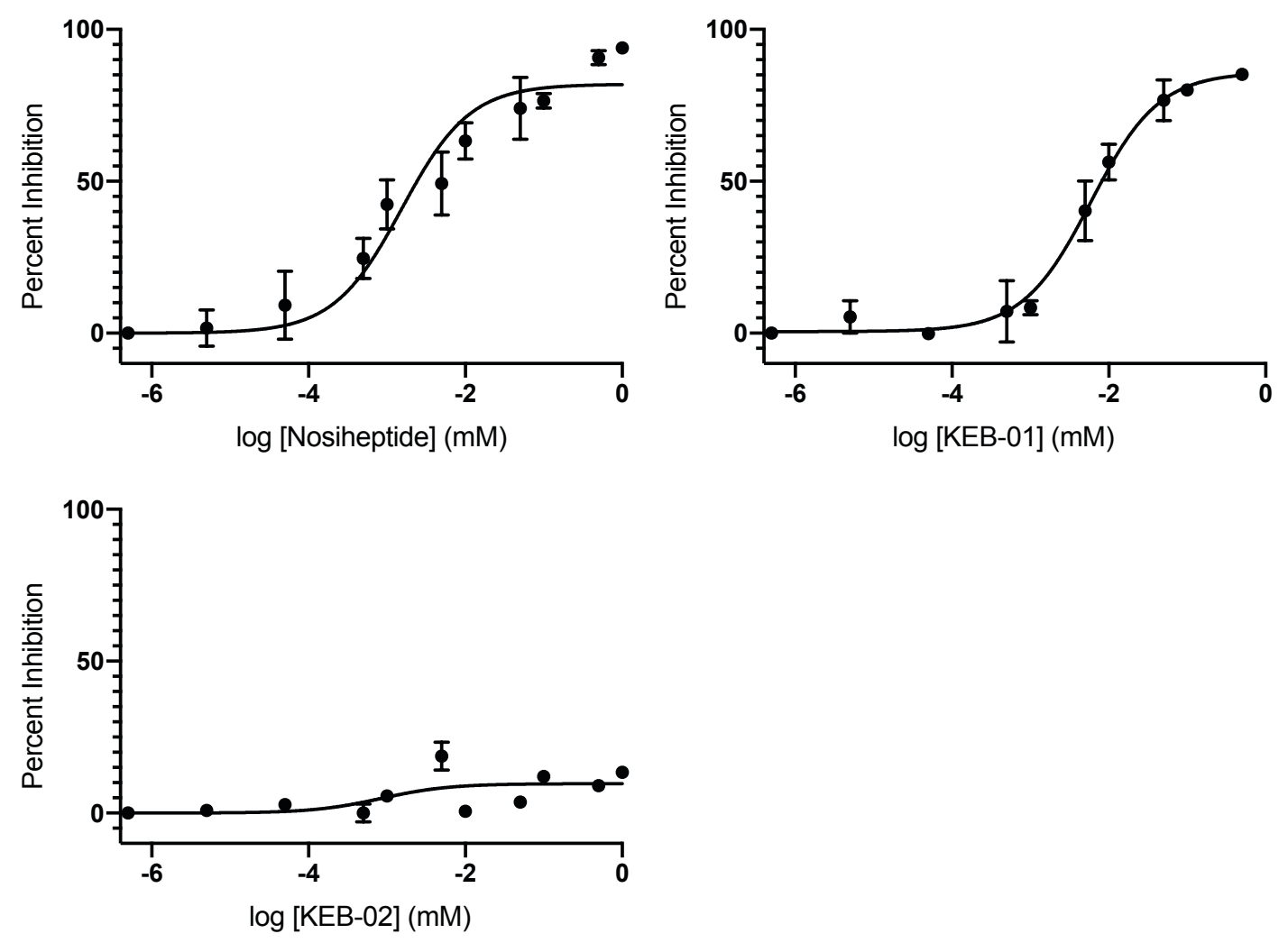

Trypsin-Like
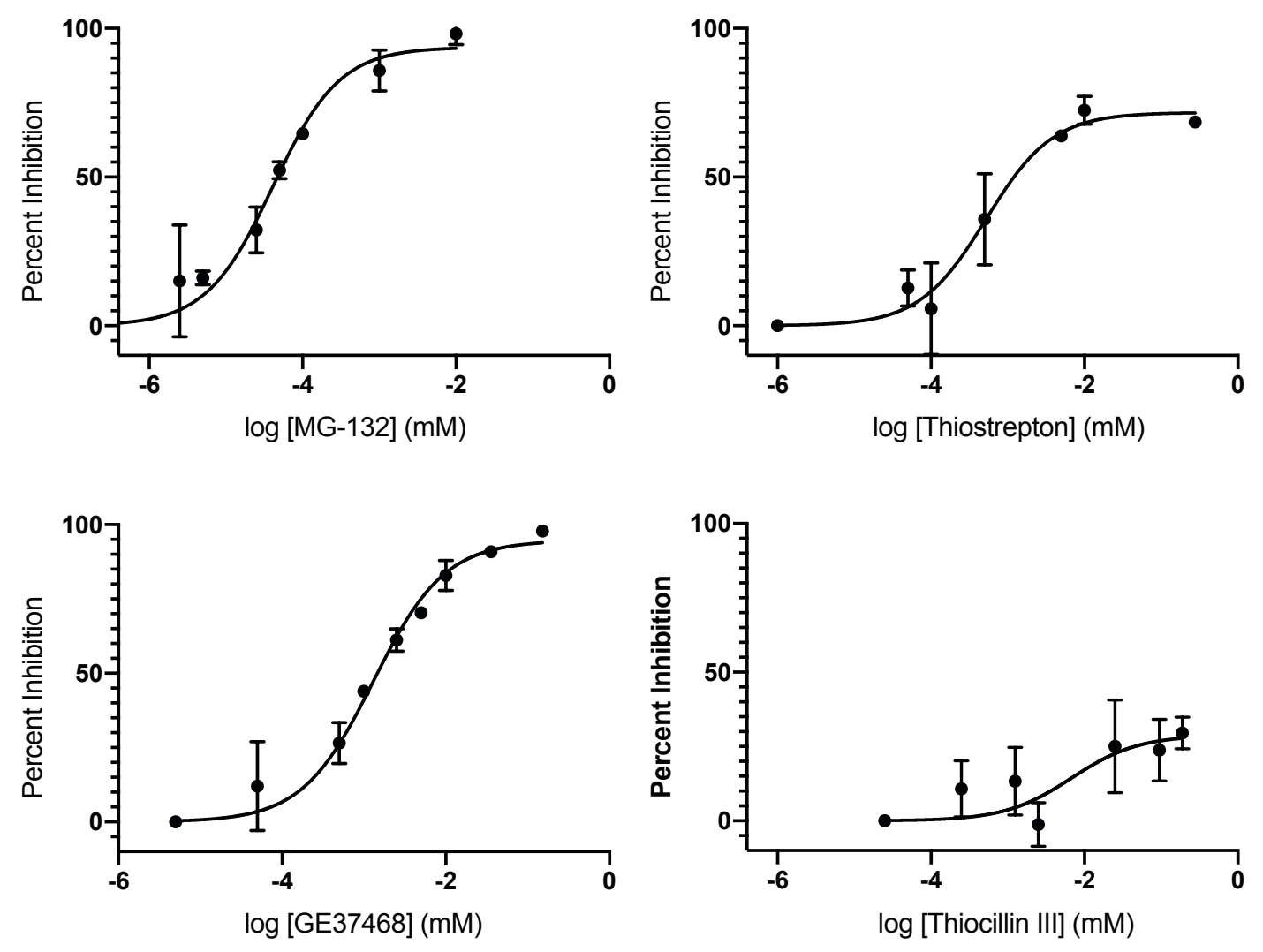

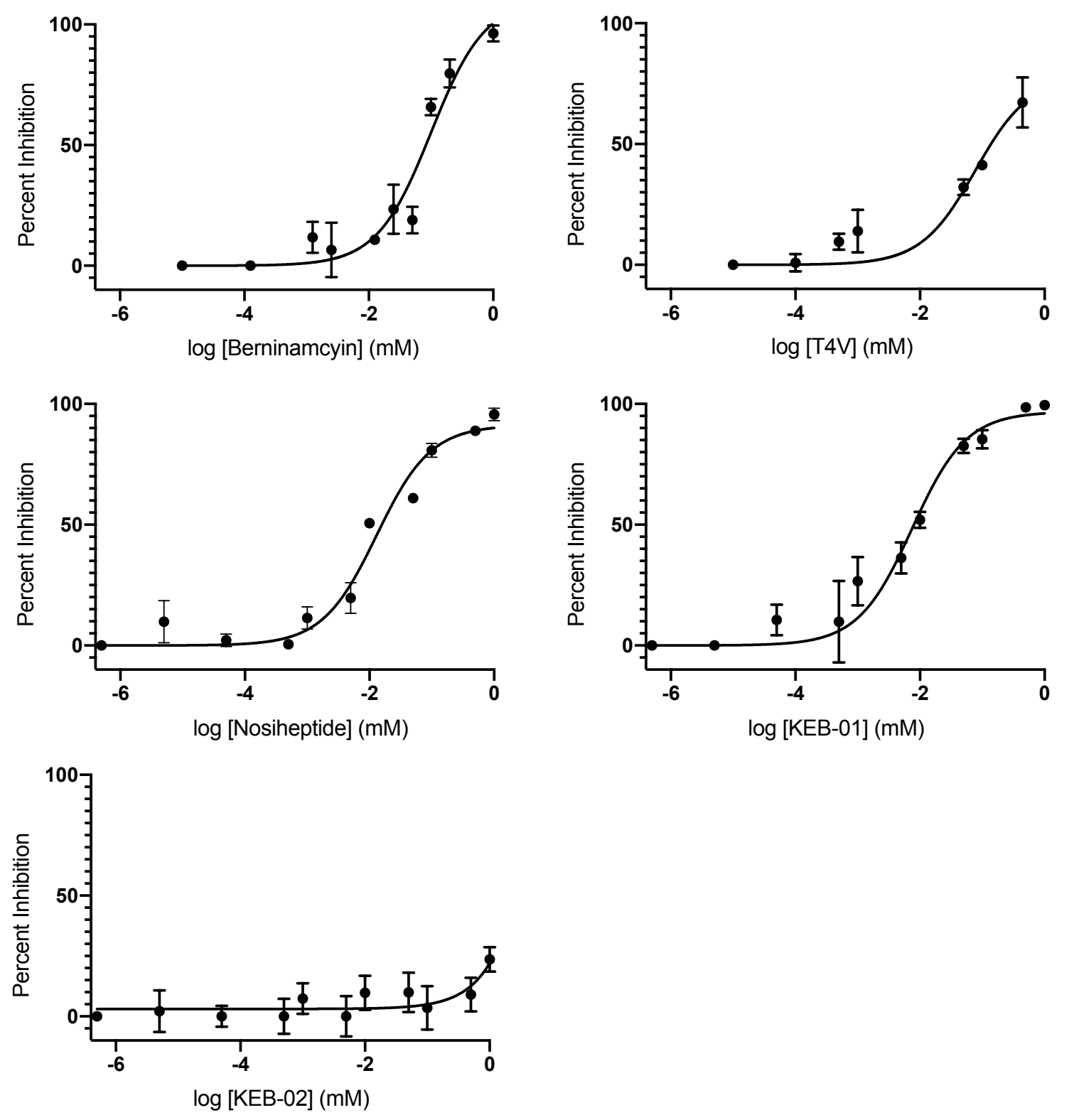
Figure S.11 Bacterial translation inhibition $\mathrm{IC}_{50}$ curves. Antibiotic activity of thiopeptides was assessed using the Promega ${ }^{\circledR}$ E. coli S30 Extract System for Circular DNA. Inhibition of translation of pBESTluc ${ }^{\mathrm{TM}}$ DNA led to decreased expression of luciferase and thus decrease in luminescence from the low levels of oxyluciferin. Bacterial translation machinery was exposed to thiopeptide concentrations ranging from $250 \mu \mathrm{M}$ to $0.0025 \mu \mathrm{M}$. Luminescence was monitored on the Perkin Elmer Envision 2103 Multilabel Plate Reader.
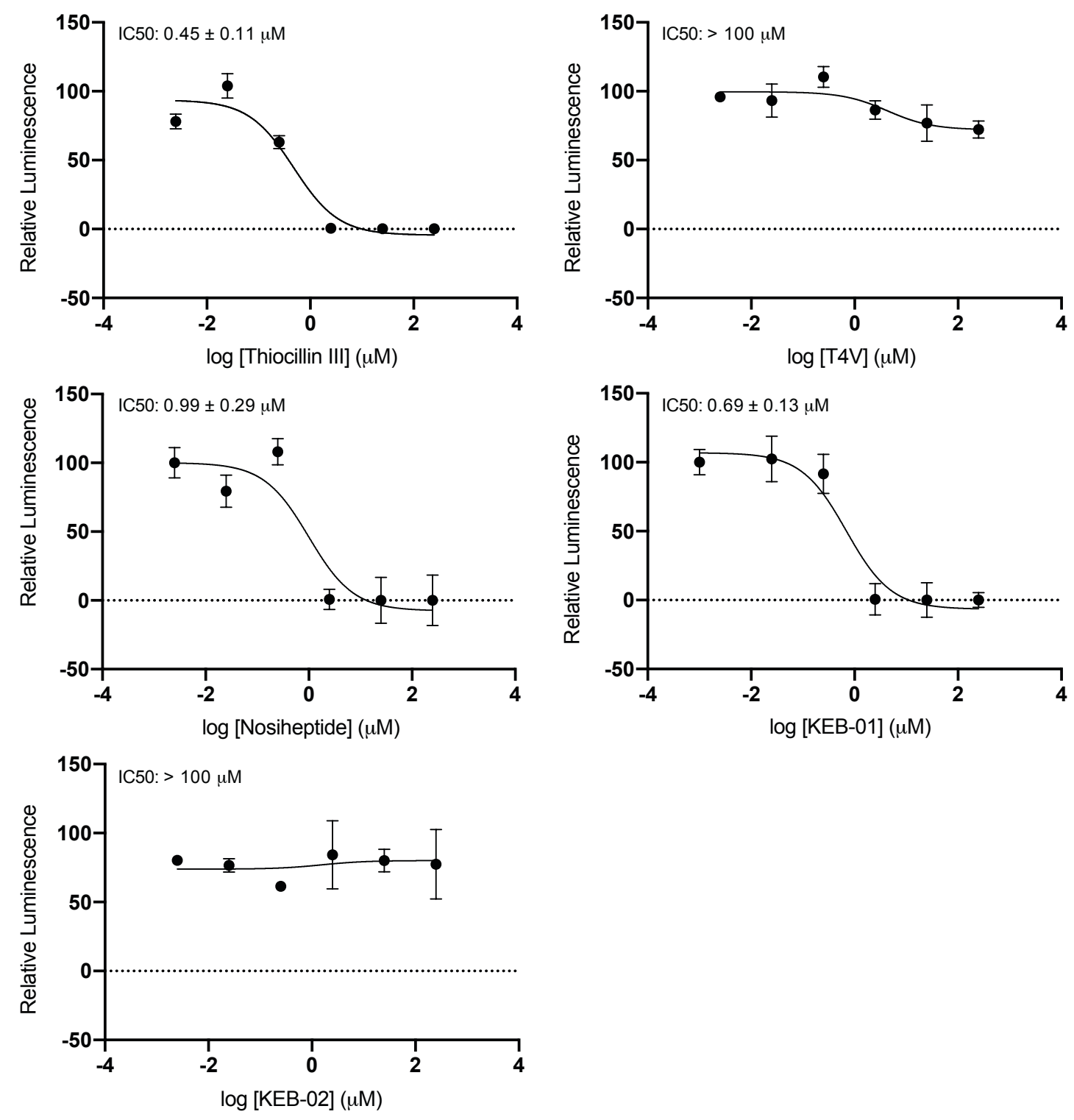
Figure S.12 In vitro $M t b$ growth inhibition representative $\mathrm{IC}_{90}$ curves. Representative curves of in vitro $M t b$ growth inhibition that were used to calculate $\mathrm{IC}_{90} \mathrm{~s}$ for each compound. Inhibition of $M t b$ growth was assessed using the resazurin microtiter assay (REMA). ${ }^{9}$ Cells were treated in a dosedependent manner. After $96 \mathrm{hrs}$, bacterial growth was indicated by an increase in fluorescence signal. Percent inhibition of $M t b$ growth was normalized to kanamycin.

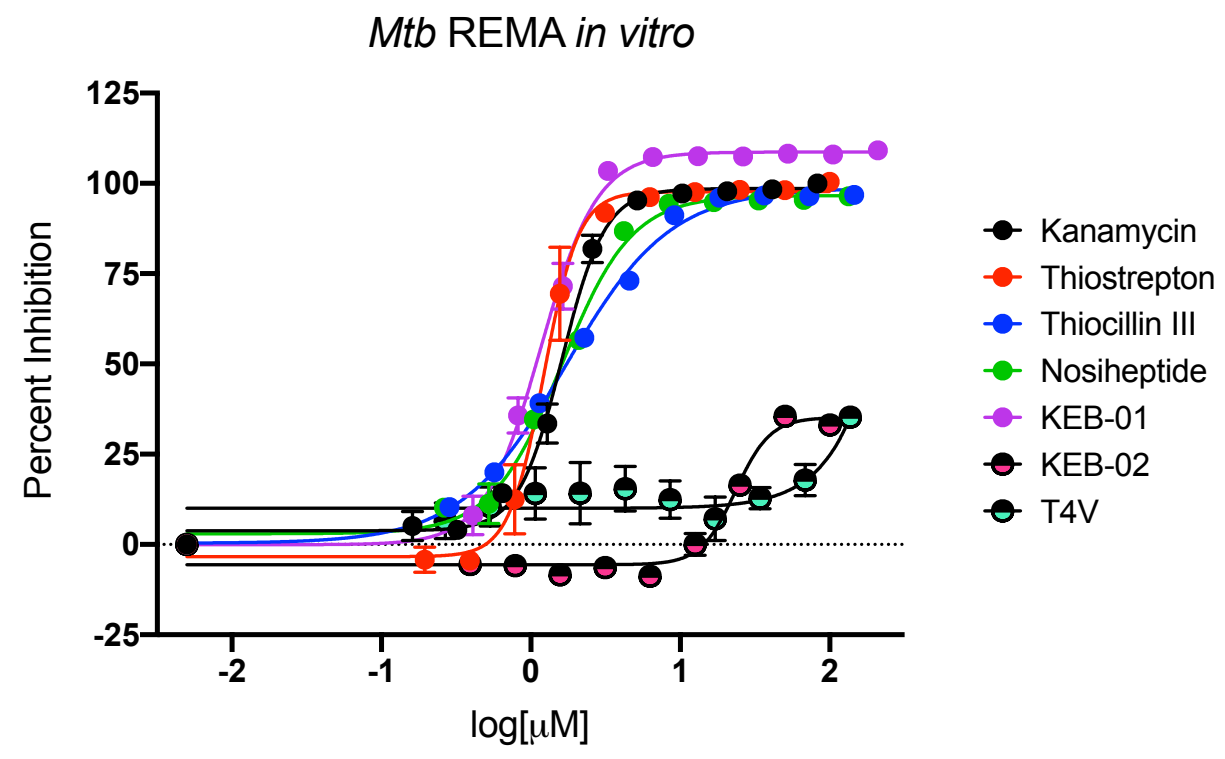


Figure S.13 Intracellular Mtb growth inhibition. Representative dose-dependent curves of intracellular $M t b$ growth inhibition resulting from thiopeptide treatment and respective $\mathrm{IC}_{50}$ and $\mathrm{IC}_{90}$ values with standard deviation (SD). Use of a bioluminescent $M t b \mathrm{H} 37 \mathrm{Rv}$ strain that expresses the luxBCADE operon permitted the quantification of Mtb growth inhibition in THP-1 cells. Initially, THP-1 cells were infected with an MOI of 1 and were treated with compounds in a dosedependent manner for 7 days.

\section{Inhibition of Intracellular Mtb Growth}

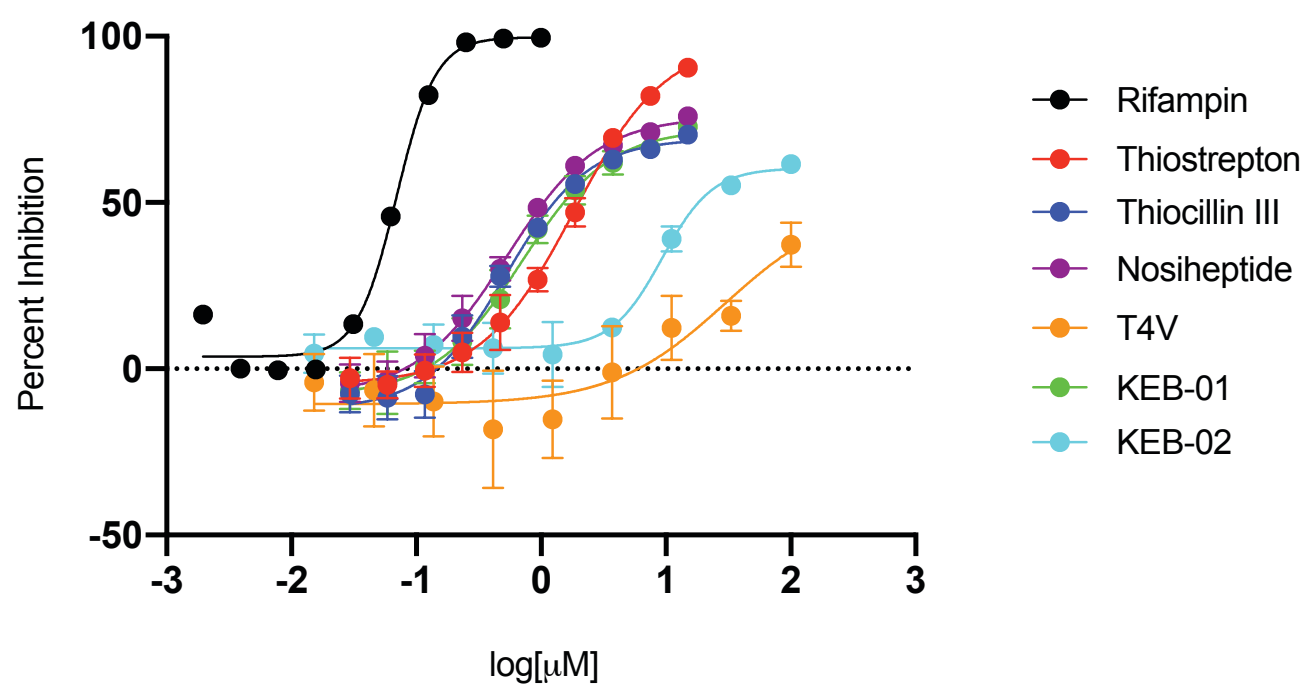

\begin{tabular}{ccc} 
Compound & $\begin{array}{c}\text { In vitro Mtb } \\
\mathrm{IC}_{50}(\mathrm{UM}) \pm \mathrm{SD}\end{array}$ & $\begin{array}{c}\text { In vitro Mtb } \\
\mathrm{IC}_{90}(\mathrm{UM}) \pm \mathrm{SD}\end{array}$ \\
\hline Kanamycin $($ In vitro $)$ & $1.38 \pm 0.36$ & $3.11 \pm 0.85$ \\
TSR & $1.44 \pm 0.31$ & $3.49 \pm 1.81$ \\
NOS & $1.08 \pm 0.37$ & $5.93 \pm 4.28$ \\
TCIII & $2.14 \pm 0.91$ & $8.06 \pm 3.15$ \\
T4V & $>10$ & $>10$ \\
KEB-01 & $0.92 \pm 0.34$ & $3.30 \pm 0.39$ \\
KEB-02 & $>10$ & $>10$
\end{tabular}


Figure S.14 Wortmannin autophagy inhibition and cytotoxicity. Validation of wortmannin as an inhibitor of thiopeptide-induced autophagy. (A) THP-1 cells were treated with wortmannin in a dose-dependent manner (50 nM - 50 $\mu \mathrm{M}$, 2-fold dilutions) for seven days and monitored for cellular cytotoxicity using CellTiter Glo. (B) Validation of thiopeptide-induced autophagy in THP1 cells expressing GFP-RFP-LC3 fluorogenic reporter and subsequent inhibition of thiopeptideinduced autophagy via wortmannin treatment. THP-1 cells were differentiated into macrophages using $20 \mathrm{nM}$ PMA for $24 \mathrm{hr}$, washed 3x and recovered for another $24 \mathrm{hr}$. THP-1 cells were then treated with thiopeptide for $16 \mathrm{hr}$ and monitored for increases in RFP-LC3 puncta as a marker of induced autophagy. Autophagy was inhibited prior to thiopeptide treatment. THP-1 cells were treated with wortmannin $(15 \mu \mathrm{M})$ for $1 \mathrm{hr}$ and thiopeptide $(10 \mu \mathrm{M})$ was added without removing wortmannin from the media. Cells were treated for $16 \mathrm{hr}$, fixed with formaldehyde $(3.7 \%)$, stained with Hoechst 33342 and visualized on the confocal microscope. Scale bar: $20 \mu \mathrm{M}$.

A.

THP-1 Cell Viability

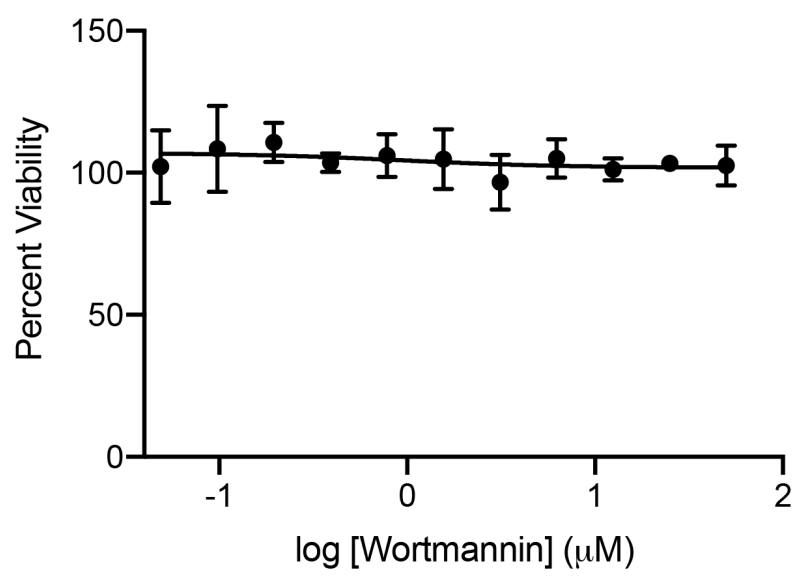

B.

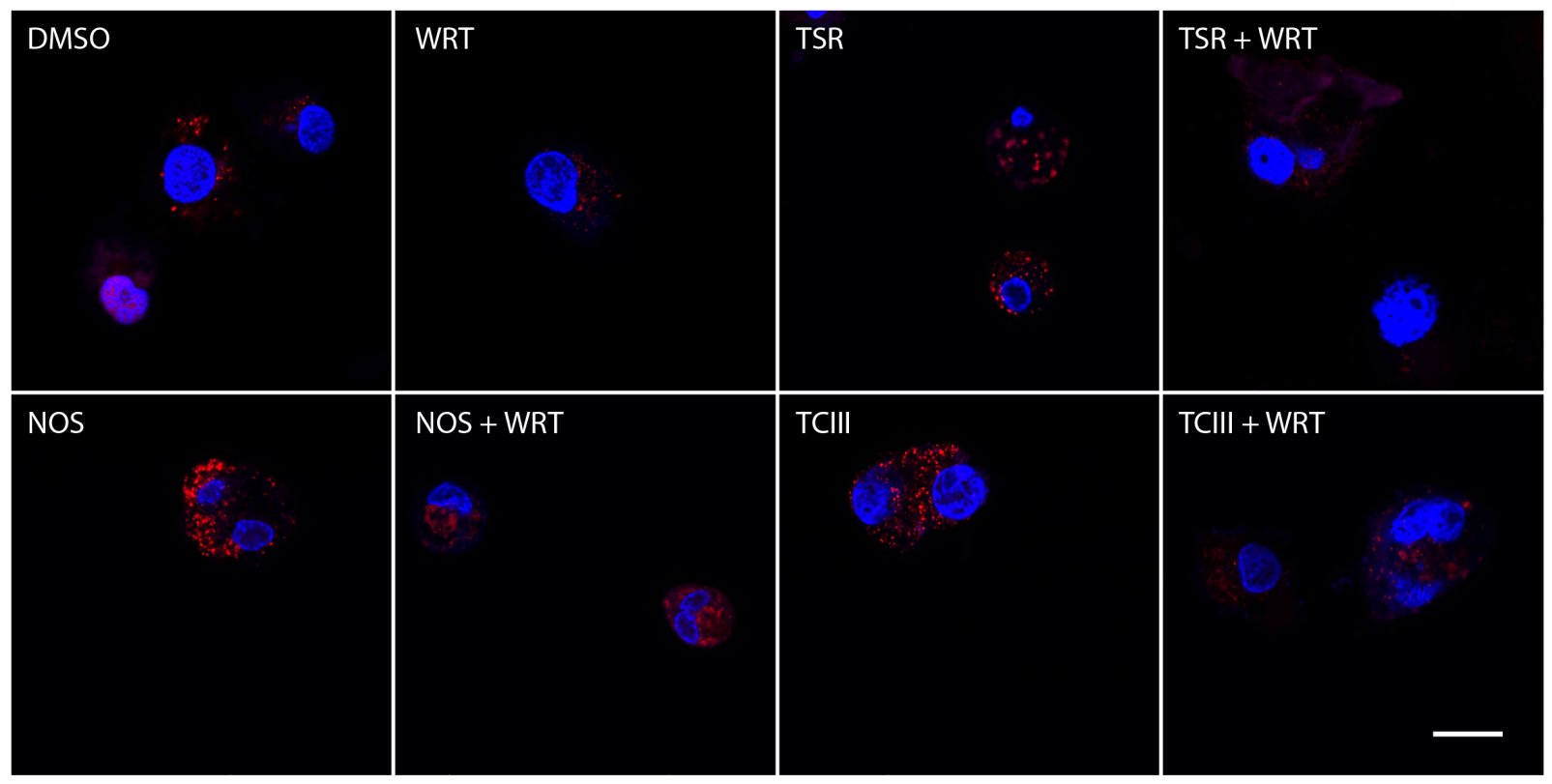


Figure S.15 Assessment of the effects of wortmannin treatment on intracellular Mtb. THP-1 cells were infected with a bioluminescent $M t b \mathrm{H} 37 \mathrm{Rv}$ strain that expresses the luxBCADE operon (MOI of 1). Mtb luminescence was quantified after 7 days of treatment with vehicle (DMSO) and wortmannin $(15 \mu \mathrm{M})$. As shown, wortmannin had no effect on $M t b$ growth validating its use as an autophagy inhibitor that has no effect on $M t b$ growth. The average of each biological replicate $(\mathrm{n}=3)$ and the standard deviation are shown below. The statistical significance was determined using one-way ANOVA.

\begin{tabular}{cccc} 
& $\begin{array}{c}\text { Average } \\
\text { Luminescence }\end{array}$ & $\begin{array}{c}\text { Standard } \\
\text { Deviation }\end{array}$ & $\begin{array}{c}\text { Statistical } \\
\text { Significance }\end{array}$ \\
\hline Vehicle & 12177.33 & 994.66 & NS \\
Wortmannin & 11707.00 & 790.51 &
\end{tabular}


Figure S.16 Visualization of autophagy in Mtb infected cells. THP-1 cells were transiently transfected with RFP-LC3 plasmid followed by GFP-Mtb infection at an MOI of $1 .{ }^{5}$ The cells were treated with vehicle or compound for $16 \mathrm{hr}$ and subsequently fixed and visualized on an inverted Olympus FV1000 confocal microscope. Scale bar: $40 \mu \mathrm{m}$.

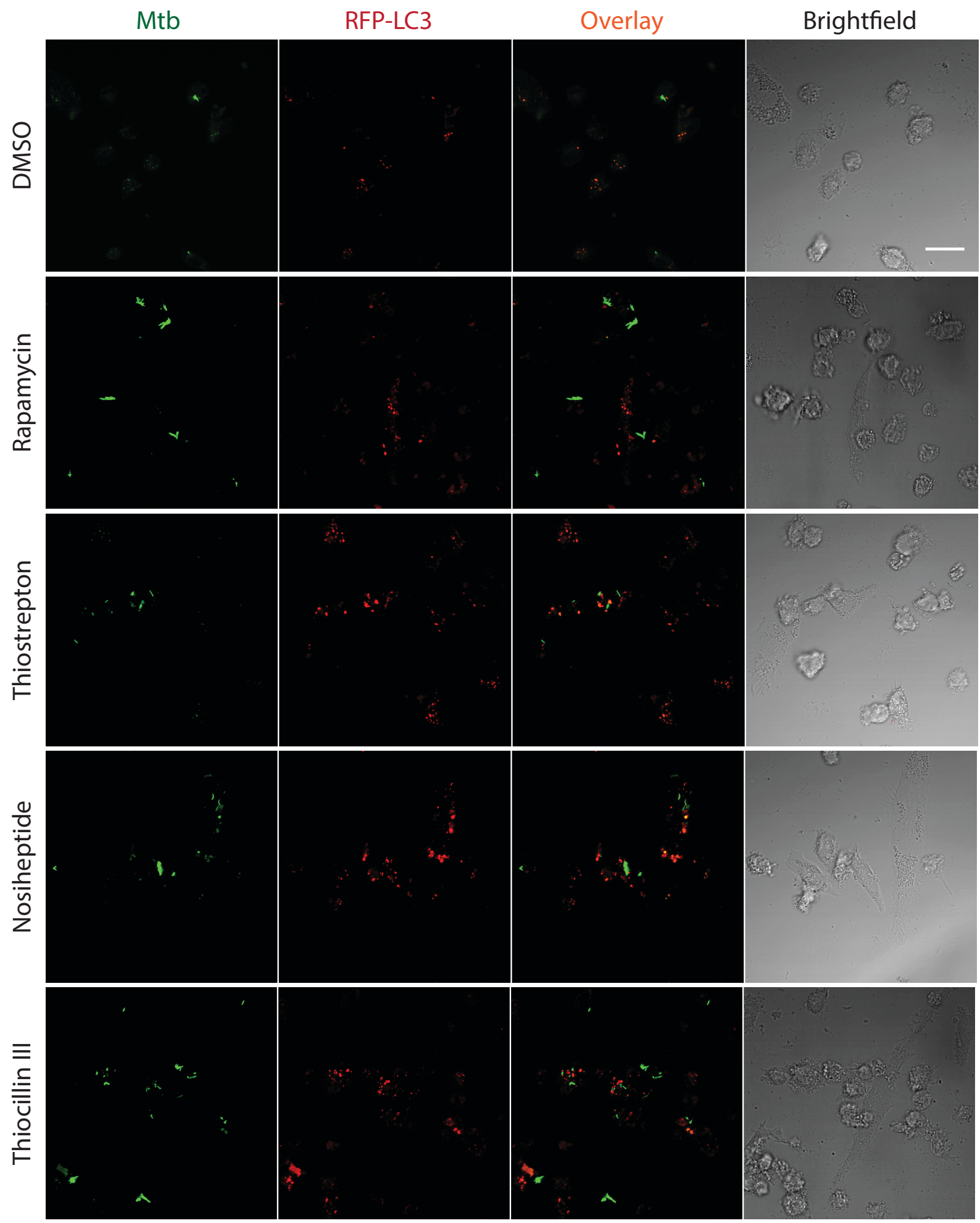




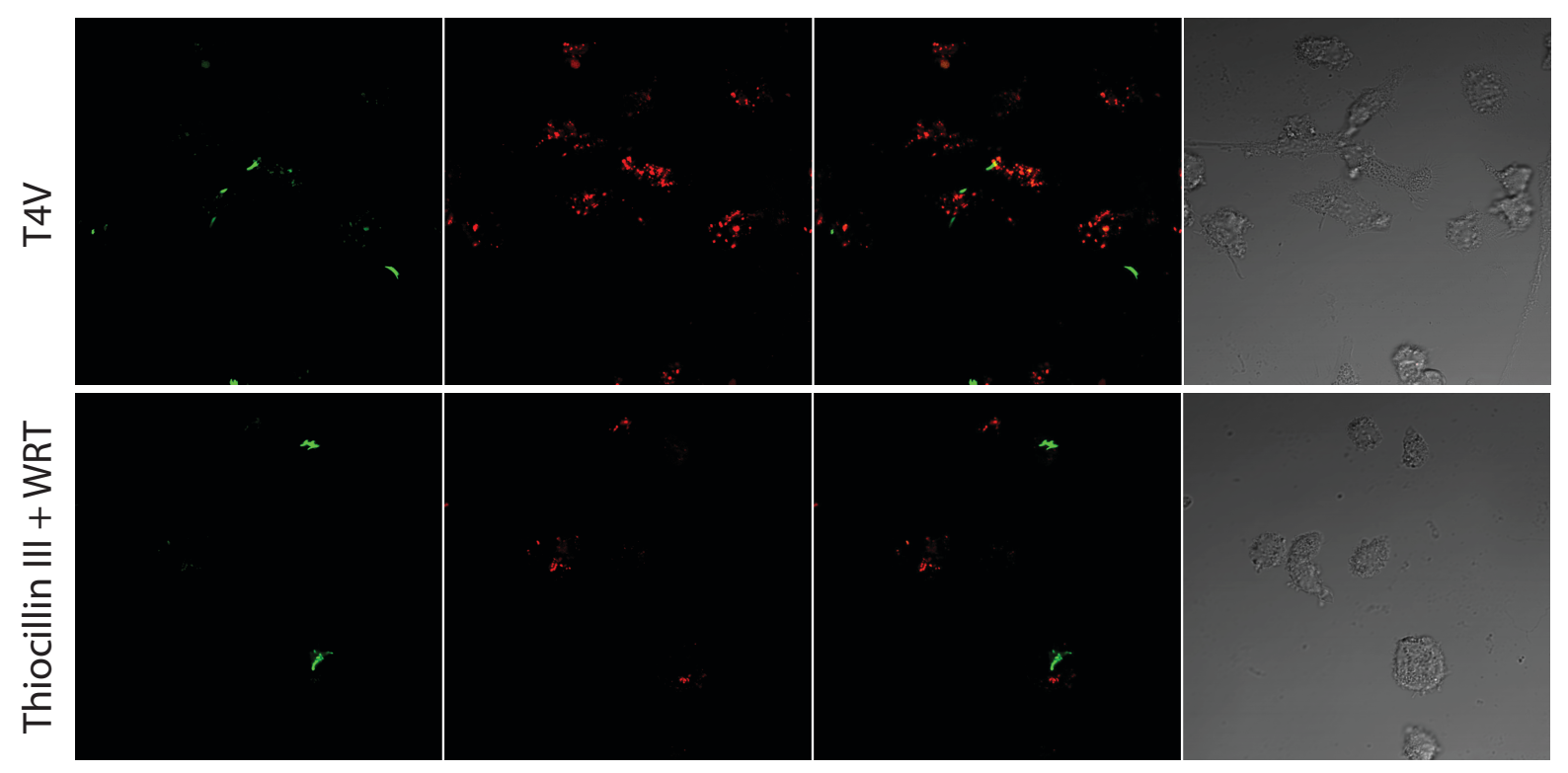


Figure S.17 Confocal imaging of mitophagy. Representative photos of compound induced mitophagic flux were captured with the use of Mtphagy Dye (Dojindo Molecular Technologies, Inc.). ${ }^{1}$ Initially cells were treated Mtphagy Dye followed by $5 \mathrm{uM}$ thiopeptide for $16 \mathrm{hr}$ following the manufacturer protocol. Following compound treatment, the cells were treated with LysoDye and Hoescht 33342 and visualized on an inverted Olympus FV1000 confocal microscope. Scale bar: $40 \mu \mathrm{m}$.

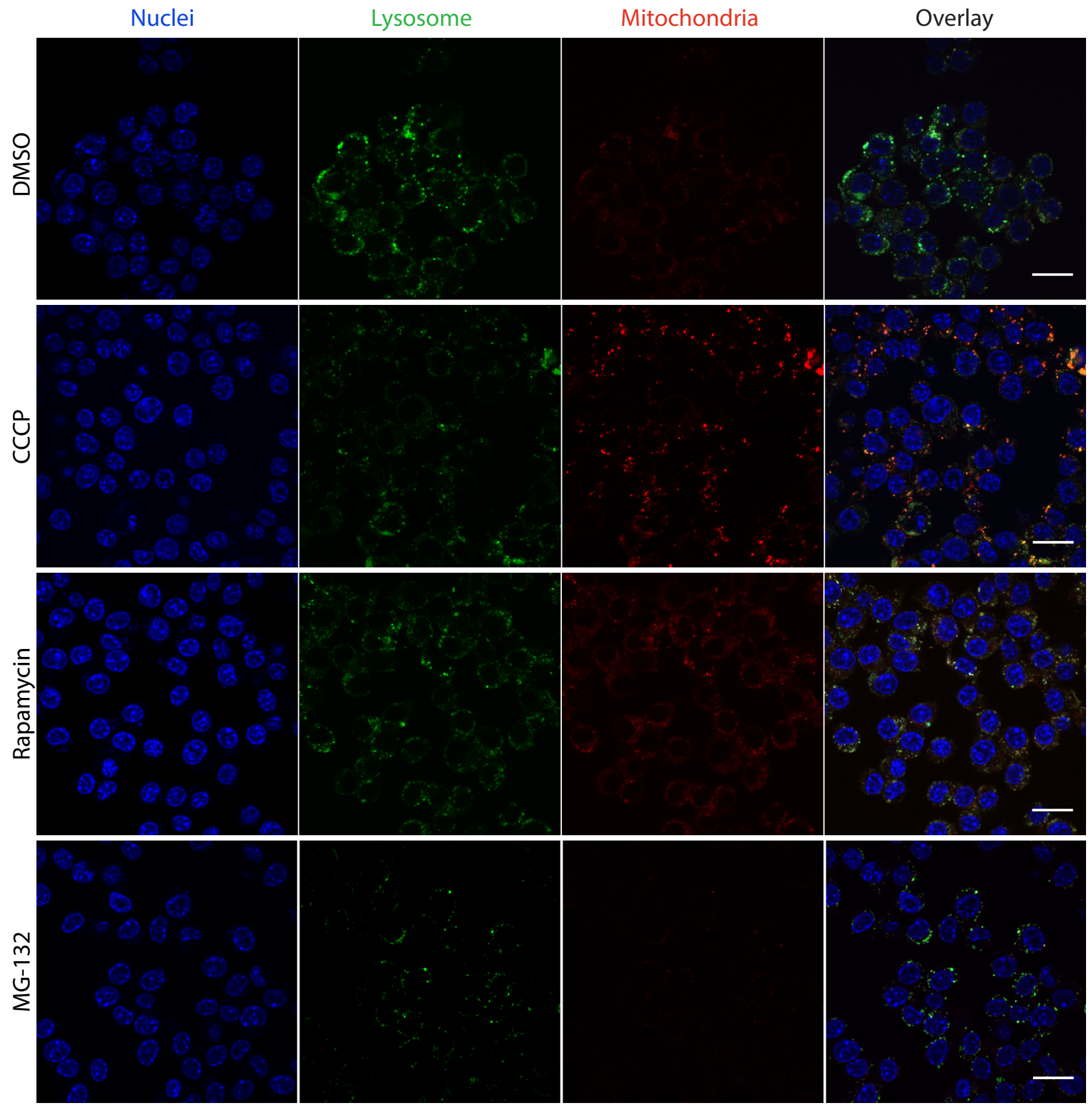




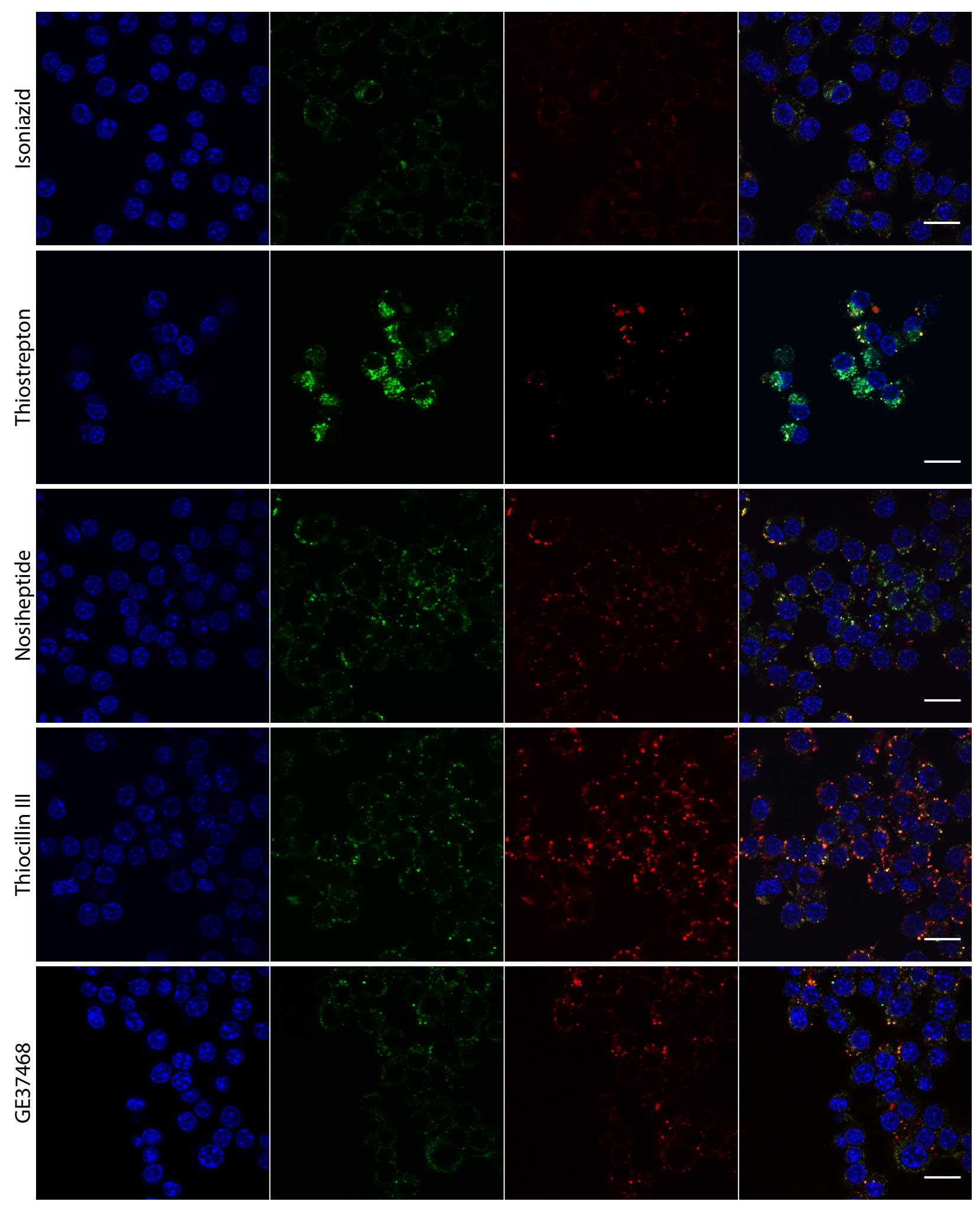




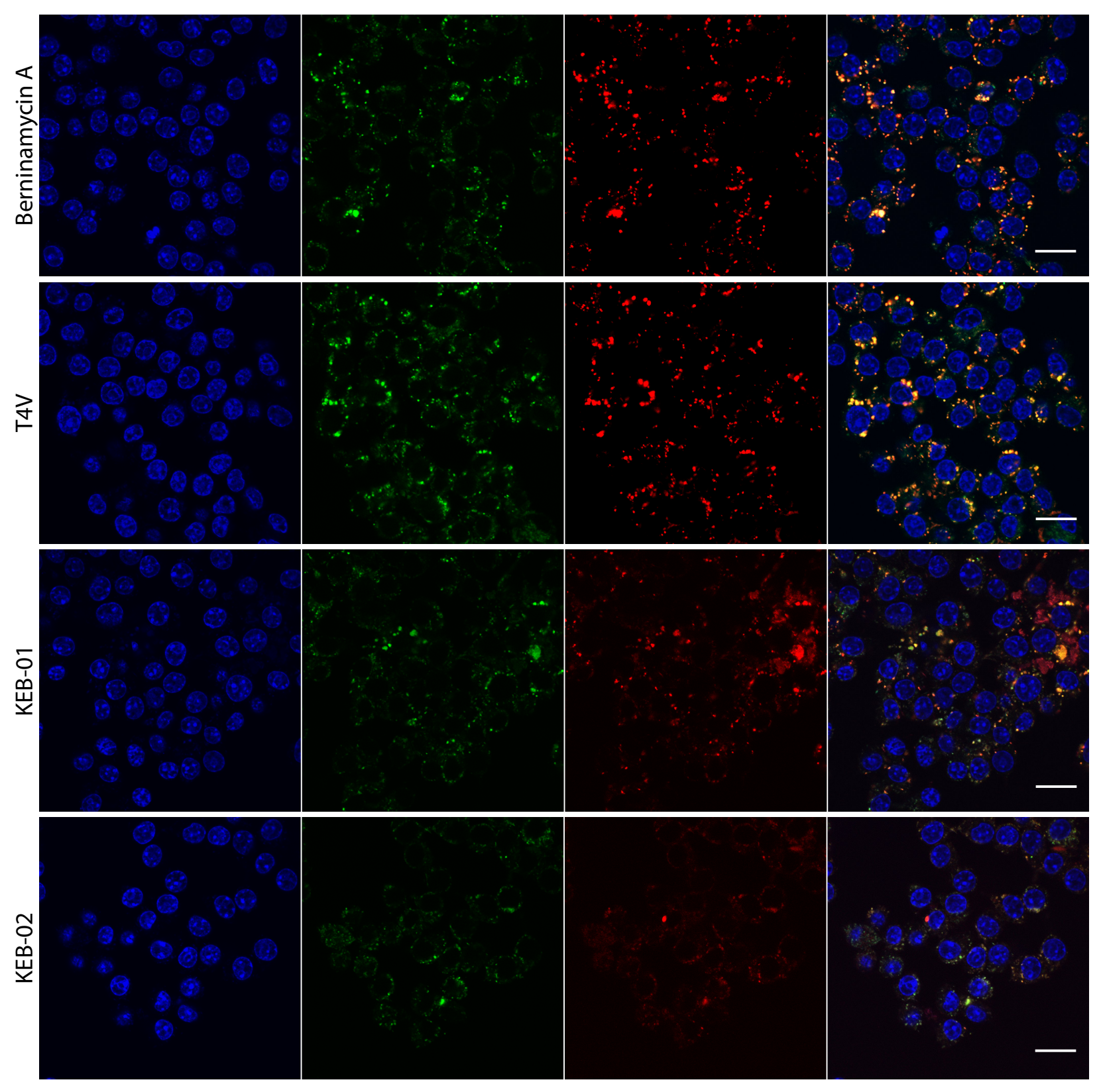




\section{References}

(1) Iwashita, H.; Torii, S.; Nagahora, N.; Ishiyama, M.; Shioji, K.; Sasamoto, K.; Shimizu, S.; Okuma, K. ACS Chem. Biol. 2017, 12 (10), 2546.

(2) Acker, M. G.; Bowers, A. A.; Walsh, C. T. J. Am. Chem. Soc. 2009, 131 (48), 17563.

(3) Penn, B. H.; Netter, Z.; Johnson, J. R.; Dollen, Von, J.; Jang, G. M.; Johnson, T.; Ohol, Y. M.; Maher, C.; Bell, S. L.; Geiger, K.; Golovkine, G.; Du, X.; Choi, A.; Parry, T.; Mohapatra, B. C.; Storck, M. D.; Band, H.; Chen, C.; Jäger, S.; Shales, M.; Portnoy, D. A.; Hernandez, R.; Coscoy, L.; Cox, J. S.; Krogan, N. J. Mol Cell 2018, 71 (4), 637.

(4) Zulauf, K. E.; Sullivan, J. T.; Braunstein, M. PLOS Pathogens 2018, 14 (4), e1007011.

(5) Kimura, S.; Noda, T.; Yoshimori, T. Autophagy 2007, 3 (5), 452.

(6) Collins, L. A.; Torrero, M. N.; Franzblau, S. G. Antimicrob. Agents Chemother. 1998, 42 (2), 344.

(7) Changsen, C.; Franzblau, S. G.; Palittapongarnpim, P. Antimicrob. Agents Chemother. 2003, 47 (12), 3682.

(8) Sullivan, J. T.; Young, E. F.; McCann, J. R.; Braunstein, M.; Flynn, J. L. Infection and Immunity 2012, 80 (3), 996.

(9) Palomino, J.-C.; Martin, A.; Camacho, M.; Guerra, H.; Swings, J.; Portaels, F. Antimicrob. Agents Chemother. 2002, 46 (8), 2720. 